PIGMENTATION AND PRACTICE: UNDERSTANDING PERCEPTIONS OF WHITE

FEMALE TEACHERS WITHIN A COLORBLIND RACIAL IDEOLOGY

FRAMEWORK

A Dissertation
presented to
the Faculty of the Graduate School
at the University of Missouri-Columbia
In Partial Fulfillment
of the Requirements for the Degree
Doctor of Education
STEPHANIE SANDERS GREEN
Dr. Sarah Diem, Dissertation Supervisor
buly 2020


(C) Copyright by Stephanie Sanders Green 2020

All Rights Reserved 
The undersigned, appointed by the dean of the Graduate School, have examined the dissertation entitled

\title{
PIGMENTATION AND PRACTICE: UNDERSTANDING PERCEPTIONS OF WHITE FEMALE TEACHERS WITHIN A COLORBLIND RACIAL IDEOLOGY FRAMEWORK
}

\author{
presented by Stephanie Sanders Green, \\ a candidate for the degree of doctor of education, \\ and hereby certify that, in their opinion, it is worthy of acceptance.
}

Dr. Sarah Diem, Dissertation Chair

Dr. Emily Crawford-Rossi, Committee Member

Dr. Ty-Ron Douglas, Committee Member

Dr. Jennifer Fellabaum-Toston, Committee Member 


\section{DEDICATION}

\section{For my daughters,}

McKenzie Ashten, the reader and writer who reflects and questions

Allyssa Caroline, the adventurer who accepts without condition and Lane Beatrice, bighearted and inquisitive

If my example teaches you nothing else, I hope it has instilled in you this: the path of least resistance is never the path for you. Some things are worth the fight. It is my prayer that you will always, always be brave enough to start a conversation that matters.

I love you so very, very much.

\section{and for you, Mom}

Here it is! You were my strength when I was weary. While I know you are so very proud of me, you cannot fathom how immensely proud I am to be your daughter. Though you could not know so long ago that setting me upon your lap for those many

hours of stories - and the example you have been to me as a reader and pursuer of goodness - would ultimately set me upon a continuous journey of inquiry throughout my life, it is you to whom I owe the greatest debt. Words cannot express the feelings in my heart. I love you so. Proverbs 23:25

\section{and for Dad}

Whatever our story, you taught me to fight (and that has made all the difference). I'd like to think that somewhere from the Great Beyond you, too, are proud of me.

I love you still.

\section{and as always}

With much affection for those teachers working diligently in the trenches each day-you attempt to figure "it" all out for the benefit of our children and the communities in which we live, and you do so expecting no thanks and very often receiving none. May our classrooms be communities that celebrate our differences, acting as catalysts for building connections and developing deeper understandings of each other. 


\section{ACKNOWLEDGMENTS}

There are no words to adequately express my indebtedness to my Committee Chairperson, Dr. Sarah Diem. Her expertise and knowledge in this area of study helped me stay the course and added immense depth to this project. I am exceedingly grateful for her insight and encouragement, steadfast support, her patience when I grew tired, and her belief in me as a doctoral student and writer. She has inspired me to reach across barriers in an attempt to tear them down, and she has my unending respect. My words of thanks can never be enough.

I have often said that I have a "rock star" doctoral committee — and it is absolutely true. Dr. Sarah Diem, Dr. Emily Crawford-Rossi, Dr. Ty-Ron Douglas, and Dr. Jennifer Fellabaum-Toston gave me confidence to dig deeper and truly see myself as a scholar. Their support and feedback added value to this project and influenced my practitioner lens for the better. I am grateful to them for introducing me to a vast array of writers on the subject of equity and the American experience of marginalized groups. My library shelves have grown and will forever stand as a reminder of my committee's investment in me as a learner. Dr. Fellabaum-Toston, thank you for your friendship and support since my early days in the ELPA program. It is much appreciated.

Thank you to Dr. Juanita Simmons for serving as my committee chairperson in the early stages of my dissertation journey. She allowed me to come into my own as a White girl determined to raise her level of consciousness regarding the role of race in the classroom. I am especially grateful for that seminal question, the one that now guides my professional decisions: "How brave do you want to be?" I hope it will serve as a catalyst for ongoing conversations on race and privilege and their impact on equity in education. 
During a summer of leadership development nearly a decade ago, Dr. Carol Maher introduced me to the Educational Leadership and Policy Analysis program at the University of Missouri at Columbia. If not for that fateful meeting, my life today would look very different today. She assured me that once I completed this program, I would be changed in ways yet unimagined. Truer words were never spoken. Never in a million years could I have divined writing a dissertation on this topic. It has been an evolutionary process begun around the table during those many hours of doctoral coursework. I thank her for her confidence and mentorship in the early days of this journey.

I have been blessed by countless people who have made a difference during my doctoral program:

- God-thank YOU.

- Mom-you give breath to the definition of a mother's love. You have been my sustenance, always, and I can never adequately express what you mean to me. You are my angel on earth and I love you. Thank you for everything.

- And to my extended family — for the encouragement and interest in my studies, and for entertaining my children so I could research and write - to all of you, I am forever indebted. Some of you saw possibilities in me long before I envisioned them for myself. I thank you for the votes of confidence. Amy, thank you for being more than a sister. I am blessed to call you my friend. 
I have a phenomenal circle of people who have inspired, encouraged, and supported me:

- To my Steel Magnolia compadres: Bowden, Audria, and Jen — the roots run deep and I cannot imagine doing life without you! The conclusion of this study means more together time. Let's celebrate!

- Thank you to Dr. Gretchen Guitard, fellow Mizzou ELPA alumna and former Assistant Superintendent within the Jefferson City Public Schools. I appreciate your advice and review of my work. Your leadership example and friendship are much appreciated and have proven to be invaluable throughout the terminal degree process.

- Thank you to Pat Sullivan, Attorney Extraordinaire, for helping me navigate the sometimes perplexing world of case law and its associated verbiage. I am extremely grateful for your support since the infancy of this work. Factum est!

- Thank you to Dr. David Wilson, also a fellow ELPA alumnus. Your insight into the art of writing is much appreciated and I am grateful for your feedback on the literature review section of this dissertation.

- I value the coworkers and friends who have been a source of support and encouragement during this terminal degree and dissertation journey—-those who have shown a genuine interest in my efforts to raise consciousness and contribute to the educational settings in which our children learn and grow. Your support and encouragement have added meaning to this work.

- And to my grade level teams both past and present, you have forever changed the way I view professional collaboration and I am profoundly humbled to call you 
my unfailing friends. When I grow up, I hope to be more like you. Thank you from the bottom of my heart.

- I value the professional connections and superb friendships I have developed among classmates within my doctoral cohort at Mizzou. It has been a pleasure to study with and learn from you on this trajectory of educational discovery and leadership. I especially treasure the connection with my Heidelberg group in Cohort 8, and have learned that camaraderie over Happy Hour appetizers has merit as educational and professional development... and that "Mintzberg" will always elicit a laugh. Dr. Eric Johnson, it is finally time for us to write that book!

- I have fallen in love with Mizzou's hidden gem - the Conley House — and am grateful for the Campus Writing Program there. The many writing retreats I attended during my dissertation years were of immeasurable benefit. I appreciate the fellow writing enthusiasts who encouraged me to "Write well, Sanders!" —especially my weekend writing group. Dr. Nicolette Yevich, you are a gem. Someday perhaps we'll manage to find Aunt Sally in the attic.

- Somewhere Johann Pachelbel is likely smiling, aware that his Canon in D (on repeat) was also vital to my productivity.

- And last but certainly not least, without the input of the practitioners who participated in this research project and provided me with data for study, this dissertation would not have come to fruition. I am grateful for your candid and invaluable contributions. In many ways your stories mirror my own. I am thankful to have had the opportunity to reflect alongside you. While your names are written invisibly here, they are etched indelibly upon my heart. Namaste. 


\section{TABLE OF CONTENTS}

ACKNOWLEDGMENTS. ..ii

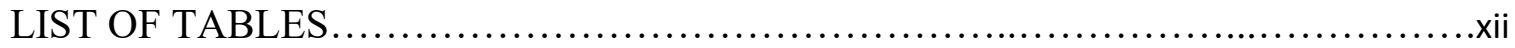

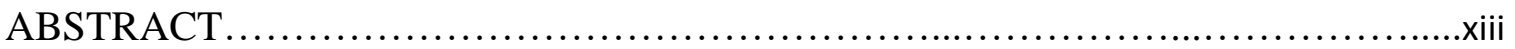

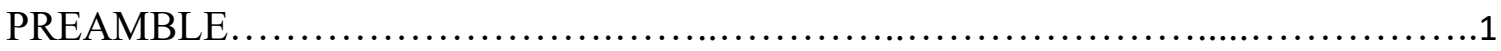

CHAPTER 1: INTRODUCTION ..............................................4

Statement of the Problem..............................................4

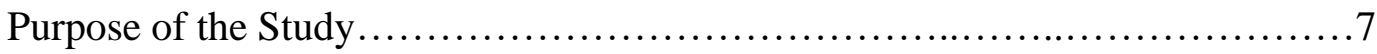

Research Question..................................................

Conceptual Framework..................................................

Research Design and Methodology......................................8

Definition of Key Terms............................................. 9

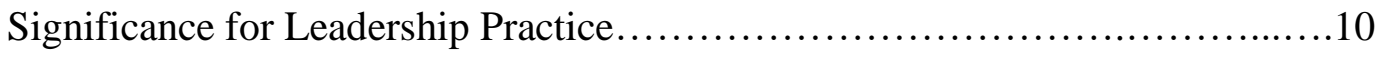

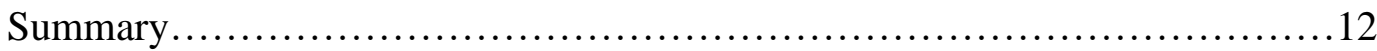

CHAPTER 2: LITERATURE REVIEW......................................... 13

Historical Separation of the Black and White Populace in America..............14

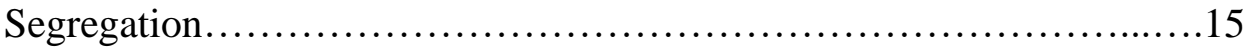

Slavery and the Denial of Rights.........................15

Laws and Court Cases......................................16

Thirteenth Amendment / End of Slavery.................17

Fourteenth Amendment / Definition of Citizenship........17

Fifteenth Amendment / African American Suffrage.......18

Civil Rights Cases.................................19

Plessy v. Ferguson and the Proliferation of Jim Crow....20 


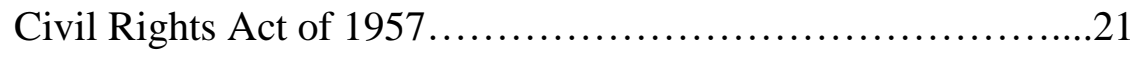

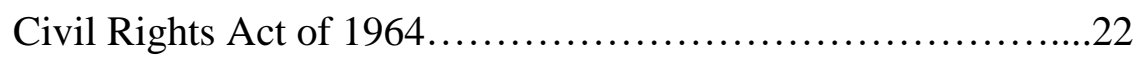

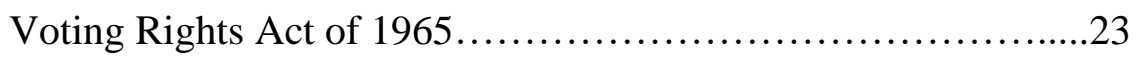

Race as a Dividing Factor in American Schools...............................23

The Evolution of School Desegregation...............................25

Separate is Not Equal............................................26

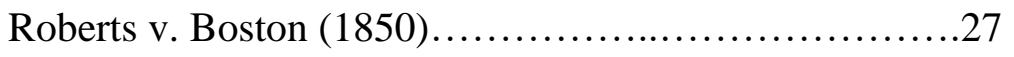

Lum v. Rice (1927) ..................................27

Mendez v. Westminster (1947).........................28

Brown v. Board (1954) ..............................28

Brown v. Board (1955)..................................30

Resistance to Integration.................................... 31

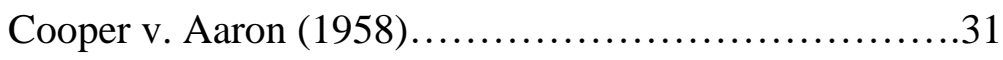

Griffin v. School Board (1964)............................32

Green v. School Board (1968)............................32

With All Deliberate Speed, Defined.............................34

Residential Considerations and School Attendance................35

Swann v. Mecklenberg (1971)............................35

Keyes v. Denver (1973).................................36

Southern Strategy and Legal Shifts..............................36

Milliken v. Bradley (1974)..................................37

Milliken v. Bradley (1977)................................37

Legal Implications of Unitary Status............................38

Riddick v. School Board (1986)............................39

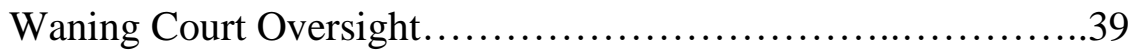


Board v. Dowell (1991) ...............................40

Freeman v. Pitts (1992)..................................40

Missouri v. Jenkins (1995)..................................41

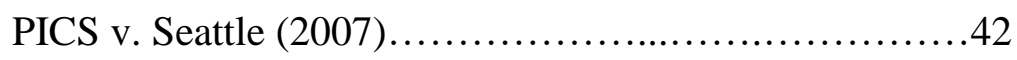

Recent Efforts of Desegregation...............................43

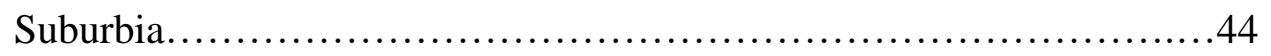

White Flight and the Emergence of Suburbs.....................44

Changing Demographics in Suburbia...........................46

Student Demographics..................................47

Midwest Percentages...........................49

Resegregation.................................50

Response to Patterns of Racial Transformation ..................51

Monoculture of the Teaching Pool....................................53

Questions of Cultural Competency.............................54

Preparation of Preservice Teachers......................55

Professional Development Addressing Race..............56

Teacher Perceptions about Race/Culture ........................57

Academic Performance of Students...................................57

Opportunity Gaps and Questions of Equity ......................58

Deficit Ideology ..............................................59

Culturally-Responsive Teaching ..............................60

Theoretical Framework....................................................61

Race Neutrality and Colorblindness in Classroom Practice...............62

Concept of Niceness........................................62

Expectations of Sameness........................................63 
Color-Evasive Mindsets

Meritocracy............................................64

Assimilation into Dominant Culture Norms.........................66

Cultural Deprivation...........................................66

Students within a Culturally Nonresponsive Classroom..........65

White Teachers.......................................65

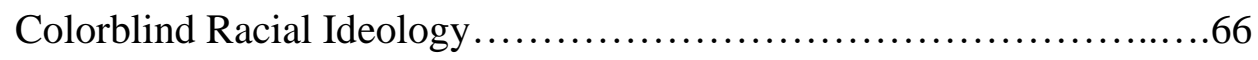

Tenet 1: Abstract Liberalism..............................67

Tenet 2: Naturalization of Race-Related Matters...............68

Tenet 3: Cultural Racism..................................68

Tenet 4: Minimization of Racism........................69

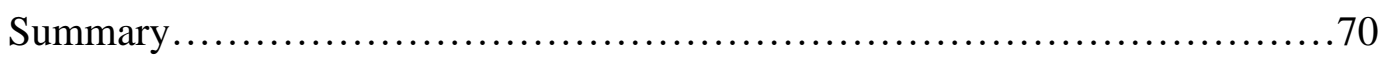

CHAPTER 3: RESEARCH DESIGN AND METHODOLOGY ......................71

Purpose of the Study............................................... 72

Research Question................................................73

Research Paradigm................................................73

Research Design....................................................... 73

Multiple Case Studies..........................................74

Research Context and Sampling Procedures........................ 75

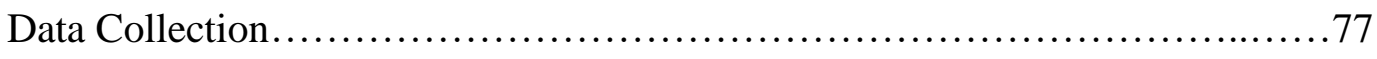

Interviews................................................ 77

Field Notes................................................ 78

Research Journal.............................................79

Human Subjects Protection.......................................79

Data Analysis......................................................... 80 
Researcher Positionality ......................................................

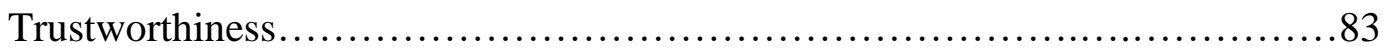

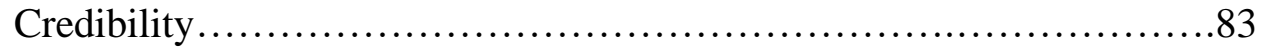

Dependability .................................................... 84

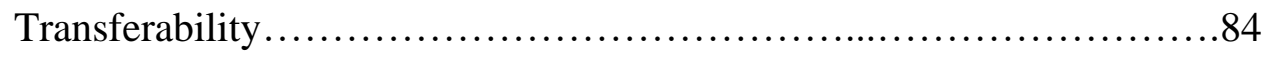

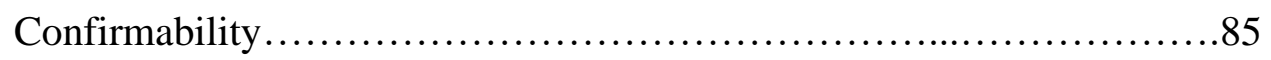

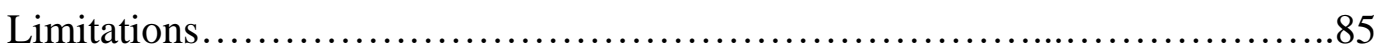

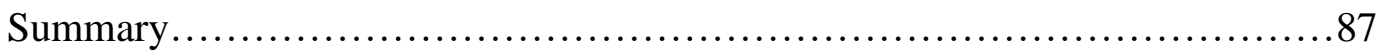

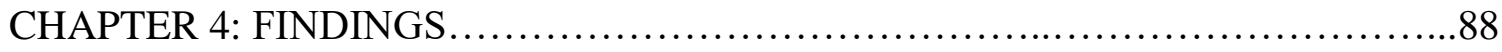

Participant Stories........................................................... 89

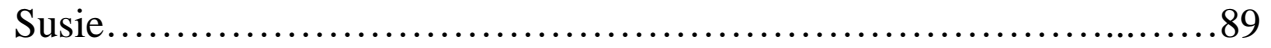

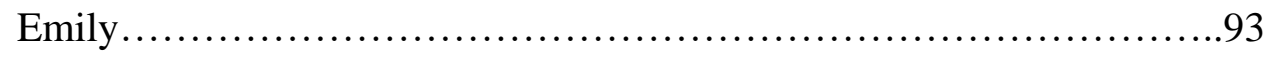

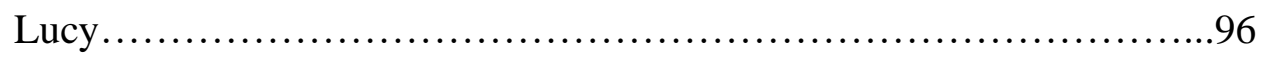

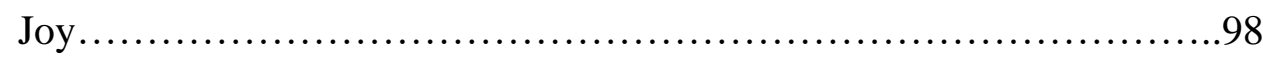

Marie ........................................................... 101

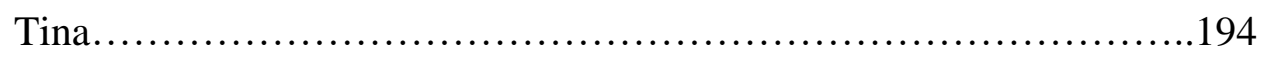

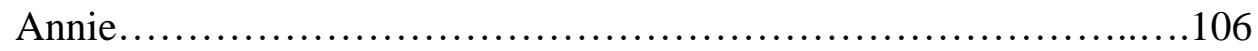

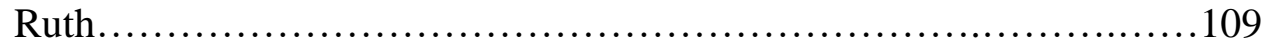

Overarching Themes.....................................................111

Tenet One: Abstract Liberalism.......................................112

Equal Opportunities for All.................................112

Correlation of Achievement and Effort........................113

Tenet Three: Cultural Racism......................................115

Legitimization of Race-Based Stereotypes.....................116

Prodigious Examples...........................................119 
Tenet Four: Minimization of Racism 120

Oversensitivity to Race. 120

Race as a Crutch. .121

Professional Development Needs: An Emerging Theme.

122

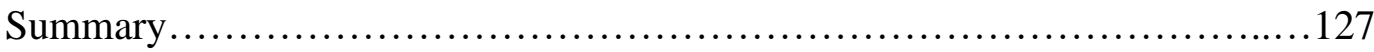

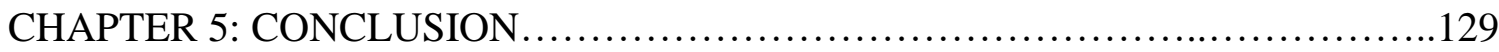

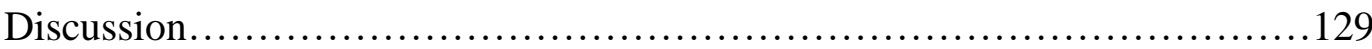

Abstract Liberalism................................................130

Cultural Racism................................................... 132

Minimization of Racism............................................ 133

Professional Development.........................................134

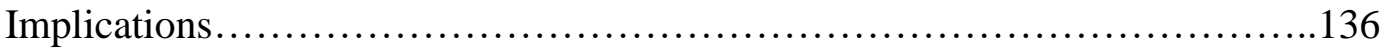

Positionality-A Final Note ...................................................

APPENDIX A: Informed Consent............................................... 142

APPENDIX B: Teacher Interview Protocol........................................146

APPENDIX C: A Dream Deferred................................................ 149

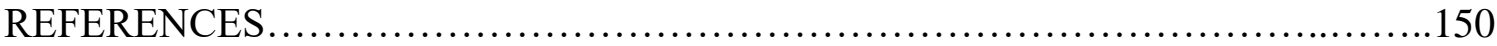

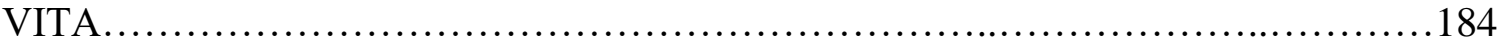




\section{LIST OF TABLES}

Table 1. Enrollment Percentages per Subgroup Nationally and in the Midwest..........49

Table 2. Praxis Summary of Governmental Approaches to the Equitable Education

Following Brown v. Board (1954) .................................52

Table 3. Teacher Participant Demographic Data.................................... 78 


\begin{abstract}
Thoreau said, "The question is not what you look at, but what you see ${ }^{1}$." In the world of education, what we don't see-or at least claim not to notice-matters just as much. For non-White children in American schools today, a failure to acknowledge their racial and cultural identity can have lasting impact on academic success. A failure to acknowledge racial and cultural identities can also impede full access to equitable educational opportunities. A well-documented educational achievement gap persists between Black students and White students despite the legally-sanctioned school desegregation of years ago. Because the teacher has great influence over classroom norms and instructional delivery — and recognizing that American teachers are predominantly White and female - this study seeks to look closely at the perceptions of those teachers with regard to race and education.

This dissertation is a qualitative inquiry of multiple case study design. Using the tenets of Colorblind Racial Ideology to construct meaning from teacher viewpoints and experiences, the goal is to facilitate candid conversations about racial diversity and promote the academic success of all students.
\end{abstract}

\footnotetext{
${ }^{1}$ Richardson, Robert. 1986. Thoreau: A Life of the Mind. Berkeley: University of California Press. 


\section{PREAMBLE}

Diversity. The meanings are as diverse as those who might attempt to define it. As a White middle class kid, I never thought much about diversity.

Looking back I see that diversity, to me, was what I viewed on Sesame Street-a collection of characters in a spectrum of colors and backgrounds who happened to share a neighborhood. It was the people on Good Times and Sanford and Son. It was George and Louise Jefferson and their honkey neighbor in my White family's television. It was Peter in my books by Ezra Jack Keats.

Diversity was my Black friend, Lisa, whose family ate pizza at my house once. Black people did not otherwise visit my home... and I did not visit theirs. Sometimes I wonder where Lisa is today.

Diversity was also the Iranian family that moved in down the street and became my neighbors shortly before the hostage crisis in the late 1970s. As children we all played together. Our parents did not speak to one another. Not ever. Eventually the family moved away. We, the children, were the ones who were sad.

There were some Black kids in my school and they were my friends. They were everyone's friends. We were all the same, or so we thought.

As a young adult I didn't give much thought to Civil Rights. It was a subject for history class. My thinking was that I didn't want any "special” treatment because I was female, and I suppose I thought along those same lines with regard to the others... and race. I believed the proverbial playing field had been made level during the years of Civil Rights legislation, and groans to the contrary elicited little more than my yawns. I 
defined myself as something beyond tolerant-I was actually intentional in my efforts to be inclusive of others.

When I became a teacher, I was proactive in my efforts to build relationships with all of the families represented in our classroom. I prided myself (and still do) in the ability to form partnerships with my students' families regardless of race or ethnicity or religion or any other defining attribute. It mattered a lot to me. It matters to me still. A lot.

I remember a day when I was reading a story about Ruby Bridges to my first graders. I love sharing the story of Ruby because she was a first grader too when she became famous. My students always make connections to her because of her age during the time of mandated school desegregation. They emotionally connect her story to the reality of our own classroom which boasts a diverse student population, a classroom filled with the many friends who are very much unlike themselves. On this particular day a substitute speech teacher stopped by to pick up one of my students for therapy. The substitute was a Black woman. (We never see Black teachers in my school other than an occasional substitute.) She asked if she could sit awhile as I shared Ruby's story. And so I read... The children gasped; they asked questions; and then one of them said, "Mrs. Green, you're White and you're nice to Black kids like me, too." The student was comparing me to Ruby's first grade teacher. Later, the substitute asked me if speaking about the subject matter and addressing the accompanying comments made me uncomfortable in her presence. It did not, and I was glad.

It was not until my doctoral coursework and a period of ongoing reflection that I encountered the concept of privilege. Not once in my four decades had I even considered 
it. That was my privilege. Even now, as a forthcoming Doctor of Education who is working to heighten my racial consciousness so that I might benefit the children I serve, I would be lying if I denied ever wrestling with some occasional defensiveness — not a sense of guilt for being White and privileged, but rather a determination that "this" isn't personally and individually my fault. I am still working on not making the subject matter personal.

"When I was a child I spoke as a child, I understood as a child, I thought as a child; but when I became a [wo]man I put away childish things."

1 Corinthians 13:11

It is my hope to be transparent in my thinking and unafraid to put my voice into a conversation that matters. 


\section{Chapter 1: Introduction}

The academic achievement of American school children is paramount to the development of an educated citizenry, and it provides an unbounded field of study for education researchers. Today there are many Americans who believe we now live in a post-racial society, one in which race is inconsequential and discriminatory practices have been relegated to a collective national memory (Frankenberg \& Orfield, 2012). As "evidence" of this supposition, we have twice elected a Black man to the presidency. In recent years, however, cities across the United States have borne witness to race-related "incidents" that have incited violence with tragic results. The riotous aftermath of one such Midwestern case has roots in the area's history of

voter suppression; limited or no access to public education; extreme enforcement of segregation, including "sundown towns"...places which blacks ${ }^{2}$ had to vacate before nightfall or else; discriminatory policing policies; and the numerous iterations of separate-but-equal practices—all these took dignity and power away from people of African descent. (Smith, 2015, p. 258)

Consequently, there has been an increase in anti-Black prejudice which suggests that race remains a significant divide in the United States (Neville, Awad, Brooks, Flores, \& Bluemel, 2013).

It is in this context that I began my research and writing. The two decades I have spent as a practitioner within a conservative suburban public school system have also deeply influenced the curiosity behind this study. In my own professional experience,

${ }^{2}$ Capitalization of Black and White is employed throughout this dissertation to ascribe value to the groups discussed within the study. Omission of capitalization is evidenced within quotations of original sources and does not reflect this author's stylistic choice. 
students who do not visually "fit" into a stereotypical Black/White binary—such as students of immigrant families — are not rendered culturally invisible in their classrooms and schools. Conversely, multiculturalism often receives, at minimum, some degree of formal acknowledgment within the school community and the represented diversity is often even celebrated. What I seldom encounter, however, are candid, purpose-driven conversations and attention directly related to race or cultural differences of Black students and White students. Instead, colorblindness appears to be a safe and politically correct manner in which to "address" the differences between these two groups - in other words, a "benign" way to envision a collective "we" in which racial cultural differences are neither acknowledged nor embraced. The focus here on Black and White subgroups stems from our unique American history and the struggles borne of slavery and the denial of rights over the course of hundreds of years - education among the most significant of these.

\section{Statement of the Problem}

In the United States there is incongruence in academic performance among subgroups of American schoolchildren, and this includes a persistent achievement gap ${ }^{3}$ between Black students and White students (NCES, 2019) ${ }^{4}$. Specific to this study is the consideration of particular phenomena which may impact the achievement gap between White and African American student subgroups in the most finite of contexts- the classroom.

\footnotetext{
${ }^{3}$ The term achievement gap is used in this study in a way that subsumes an opportunity gap. Achievement gap is terminology specifically familiar to the participants in the study. Its use here does not discount research showing that gaps in achievement result from gaps in opportunity (Carter, Welner, \& LadsonBillings, 2013).

${ }^{4}$ See Digest of Education Statistics 2017, tables 221.10; 221.12; and 222.12.
} 
Rankings and statistical comparisons abound in the field of education.

Nationally, these comparisons exist across state lines and school districts, and are delineated according to student demographics. Declining or stagnant student achievement prompts inspection of possible root causes. Questions of teacher effectiveness and concerns regarding the efficacy of teacher preparation programs have become subjects of critical debate in the media and among policymakers (Milner, 2012, 2015). The demand for highly-qualified teachers and improved student achievement outcomes accelerated by the No Child Left Behind Act (2001) within all American schools has acted as an impetus for strategic school and district-level data analysis efforts, focusing on the students themselves and their scholastic performance. When student achievement is subsequently linked to teacher effectiveness, however, classroom climate and instructional practices then also become critical factors for examination (Cochran-Smith, 2003; Milner, 2012). Individual teacher characteristics merit consideration as well. Given the preponderance of White teachers as instructional leaders and classroom authority figures, Black students will spend the bulk—if not all—of their educational careers in classrooms with teachers who bear visible and cultural differences from themselves (Howard, 2006; Jackson, 2011; Ladson-Billings, 2006a; Milner, 2012).

Regardless of educational rankings or performance comparisons, "people are the real wealth of a nation" (Malik, 2013, p. 4). In essence, teachers and students matter. The link between teacher and student is an impactful one, and a chasm of separate histories and unique experiences borne of racial differences may therefore have a significant effect on that connection and its influence on student success (Jackson, 2011; Milner, 2010). While this study addressed a problem of practice locally, examination of race as a factor 
in the analysis of academic achievement is not a recent abstraction. The emerging themes should offer practical usability in school districts nationwide.

\section{Purpose of the Study}

The purpose of this qualitative multiple case study was to elicit teachers' perceptions of the achievement gap between Black students and White students, and to do so within the American historical framework of separateness and education debt. This study engaged teachers in discourse of deficit ideologies and colorblind difference, and questioned expectations of sameness and assimilation into dominant culture norms. Given the current urgency associated with a persistent chasm of racial divide in this country (Howard, 2006; Lipman, 2015), courageous conversations in our schools that facilitate the academic success of all students - and promote healing and a changed society_-are no longer optional.

\section{Research Question}

The research question I sought to answer for this study was: What are White teachers' perceptions about race and the achievement gap between Black students and White students in a post-Civil Rights era?

\section{Conceptual Framework}

This study was guided by the tenets of Colorblind Racial Ideology (CBRI) which provided a framework for making meaning of participant perspectives regarding race and educational outcomes. The four tenets of Colorblind Racial Ideology — abstract liberalism, naturalization of race-related matters, cultural racism, and minimization of racism - impede racial progress (Bonilla-Silva, 2013). Because these beliefs are deeply 
embedded in the human psyche, those who espouse colorblind beliefs are generally unaware that they do so (Hartmann, Croll, Larson, Gerteis, \& Manning, 2017).

White teachers permeate the American teaching force and yet teach in classrooms of much racial and cultural diversity. Using the lens of Colorblind Racial Ideology, I was able to make meaning of perspectives about race and education as they were coupled with the unique participant histories within an America of longstanding racial strife and separation.

\section{Research Design and Methodology}

This study proceeded on social constructivist assumptions that "subjective meanings are negotiated socially and historically. They are not simply imprinted on individuals but are formed through interaction with others... and through historical and cultural norms that operate in individuals' lives" (Creswell, 2009, p. 8). The study is a qualitative multi-case study of White female teachers and their perceptions of race and scholastic achievement in light of America's unique and longstanding turmoil along the color line.

The multiple case study design allows for diversity of data, offering closer inspection of an array of perceptions and attitudes (Meyer, 2001). Each of the eight participants - all with at least three years of teaching experience in the elementary setting — has a unique history, experiences, and perceptions - and thus, each represent a bounded case. Research across numerous cases strengthened the findings of the study (Baxter \& Jack, 2008; Stake, 1995) by eliciting the span of ideations represented at the site. 


\section{Definitions of Key Terms}

Achievement Gap. For the purpose of this study, achievement gap refers to the chasm in performance between student subgroups. This term may reflect performance on both classroom formative and summative assessments, as well as on more formal standardized testing; also recognizing that gaps in opportunity factor into achievement outcomes. Achievement gap, as indicated in the qualitative data gathered from participants, may also reflect overall perceptions of success or performance in comparisons of White and Black subgroups generally and beyond the classroom setting.

Black. For the purpose of this study, Black refers to people commonly identified as African American. This definition does not exclude biracial students who identify as African American. It also does not exclude biracial students whose White teachers recognize "African American" as the predominant racial descriptor.

Deprivation. Deprivation is defined as "the damaging lack of material benefits considered to be basic necessities in a society" (lexico.com, 2018) and applies, at minimum, to the suppression of cross-culture sharing.

Monoculture. In this study, monoculture refers to the predominance of White female teachers in American schools while males, Black teachers, and other subgroups are significantly underrepresented by comparison.

Racism. In this study, racism is defined as racial inequality that is perpetuated through ideologies and attitudes, legitimizing difference and marginalizing non-Whites (van Dijk, 1992).

White. For the purpose of this study, White refers to a skin color classification of people. White is their predominant racial identifier and they do not segment or qualify 
this classification by identification with another group (for example, Asian or Hispanic). In this study, teachers self-identified as White. Students were recognized as White based on the racial identity attributed to them in their academic records.

White Supremacy. In this study, the term acknowledges the "genocide, enslavement, and internal colonization of indigenous populations" (Cole, para 3, 2020) by European colonists - practices that served as predecessors to African slavery in America and the discriminatory policies that continued past Emancipation. White supremacy encompasses the inequitable foundations of education and socioeconomics on which America was founded, and also includes the fallible concept of meritocracy (Cole, 2020).

Whiteness. Not a signifier of skin color in this study, but rather, whiteness is the overtone of differences as a mechanism of control or supremacy (Mazzei, 2011; Shesadri-Crooks, 2000).

\section{Significance for Leadership Practice}

This research is significant to leadership practice for several reasons. First, it sought to contribute to the existing body of literature that addresses Colorblind Racial Ideology, and did so by constructing meaning from the perceptions of practitioners within a setting in want of deep conversations connecting race and academic success. The study sought to augment the existing body of literature with additional insight from White female teachers and add this to the overall conversation of racial differences within the classroom. As the researcher and author, I am faced with my own confrontation of racial attitudes and their connection to my interactions with Black students. In The Pedagogy of Confidence, Yvette Jackson (2011) reminds education professionals that enriching 
educational opportunities for all students stimulates intellectual development, and that by doing so, teachers show confidence in the belief that all students can experience academic success. Dr. Jackson's reference to "all students" does not discriminate based on race. This study attempted to make meaning of teachers' perceptions of pedagogical practices in relation to the performance of Black students and White students, and examine their beliefs about how these views manifest themselves in the classroom. Instructional practices will be informed by themes that emerged from the data.

Finally and most specifically, this project has implications for my own professional practice. My role as teacher-leader within my organization necessitates engagement in dialogue centered on student performance, data analysis, and identification of strengths and areas for improvement—in both students and their teachers. These conversations take place with professional peers at both the school building and district levels. Analyses focused on contributory factors of overall student academic performance and success, and they inform instructional practice to facilitate equitable performance outcomes across student subgroups. It was a goal of this study to gather data which will aid in efforts to remove "stereotyping and bias," to ultimately decrease a "minority person's sense of alienation and frustration" (Delpit, 2006, p. 1160), thereby positively impacting teacher efforts to facilitate academic success for all students. Like policymakers and school administrators, teachers should be proactive in acknowledging "that our conceptions of race, even in a postmodern and/or postcolonial world are more embedded and fixed than in a previous age" (Parker, Deyhle, \& Villenas, 1999, p. 9) .... and then strive to do something about it. A focus on student performance 
deficits is not an adequate avenue toward remediation if it is devoid of considerations of classroom culture and climate that may directly impact that performance.

\section{Summary}

Education is a field ripe for critical analysis. Performance is evaluated at all levels - from districts, to schools, to classrooms, and students. The achievement gap between student subgroups begs the question, "Why?" In addition to public scrutiny of curriculum and instructional practices, characteristics impacting teacher effectiveness should also be examined in attempting to answer that question. Because the American teaching force is largely White and female and because there is a divide in academic performance data between Black students and White students, this qualitative case study explored White female teachers' perceptions about race and achievement and attempted to understand their potential to impact both personal and academic relationships with Black students. 


\section{Chapter 2: Literature Review}

There is no shortage of studies related to race in education and yet, even as a doctoral student of educational leadership, this trajectory of examination is personally neoteric. It was no small task to identify and then compartmentalize key areas necessary to provide a basic understanding of the foundational concepts on which to build this study. I approached the literature review using a perspective that is both critical and personal. The latter is relevant and as equally important as critical analysis to this project. In Dr. Yvette Jackson's book The Pedagogy of Confidence (2011), she shares this quote by W. E. B. Du Bois and I offer it as explanation:

There is a miraculousness of personal transformation that only happens when you bravely look back and feel the fragility and the insight in what you know to be your personal truth of "moral compass." When you are brave enough to move from this truth, you use a bold voice to stand up and articulate what you know to be right and just...It allows us the freedom to articulate the truth about our beliefs. It emancipates us to change our perspective, remembering, rediscovering, and reimagining our confidence in our ability to speak in a bold voice for those who have no voice... (p. 14)

This personal transformation is indeed fragile in that it is in its infancy, and I approached this chapter not only as footing for the work of this dissertation, but also as professional development for my own teaching practice.

The literature review explores several areas that provide an overview of key issues relevant to this study—racial division in America and her schools, an educational climate predominated by a White teaching force, and the academic achievement of Black 
students within that context - and it also serves as a backdrop to the conceptual framework of the study. This project specifically focused on the Black/White binary. The purpose for the narrow focus is more fully addressed in Chapter 3, where I speak to my positionality as a White teacher and connect it to personal interest and experiences that have propelled this query.

The first section focuses on the tenacious nature of racial separateness in the United States, followed by a closer look at race as a dividing factor in American schools. The review then delves into race and education in a post-Civil-Rights era, examining the implications of Whiteness on classroom practice. The final section of the chapter introduces Colorblind Racial Ideology and the associated mindsets that are evidenced in today's society and manifested in our school environments.

\section{Historical Separation of the Black and White Populace in America}

While most Americans are at least nominally familiar with the landmark Civil Rights Act of 1964, "contemporary" struggles for civil rights truly began immediately following the conclusion of the Civil War (e.g. The Civil Rights Acts of 1866 and 1875, and The Enforcement Acts). Eight years after the Civil Rights Act of 1875 upheld the rights of African Americans regarding access to public accommodations, transportation, and jury service, the Supreme Court ${ }^{5}$ invalidated this legislation by way of the Civil Rights Cases of 1883. This in turn led to pervasive discrimination of Black Americans - especially in the private sector-for decades to come (Gerber \& Friedlander, 2008). It was not until 1957 and by President Eisenhower that any further civil rights legislation was signed into

\footnotetext{
${ }^{5}$ References to the Supreme Court will be signified with an uppercase C, while references to all other courts will be indicated by use of the lowercase.
} 
law (see the Civil Rights Act of 1957). The catalog of battles over racial discrimination indicates a repetition of the earlier, inaugural civil rights movement—one that is as old as emancipation.

\section{Segregation}

The term segregation represents isolation; barriers. It is defined here as the forced separation of Black individuals from other races with regard to accessing facilities and opportunities - in housing, education, healthcare, etc.—based solely on race (Woodward, 1974). Racial segregation, specifically among Black people and White people in the United States, became rudimentary practice once agricultural workers were separated by race — a system that was ultimately promulgated by the institution of slavery in the southern United States (Ogden, Perkins, \& Donahue, 2008; Quintana, 2018). For hundreds of years, the separation of Black and White people in this country—whether legally sanctioned or otherwise—-has been a vanguard focus in American life.

Slavery and the denial of rights. Africans were first brought to the New World, to Jamestown, by the Dutch in 1619. Records indicate these captives were regarded as indentured servants, suggesting they should have been entitled to freedom after a period of servitude (Morgan, 1975). However, while there were no laws sanctioning slavery at that time, a Virginia man who attempted to abscond from servitude was condemned to slavery in 1640 (Donoghue, 2010). In 1641, Massachusetts became the first colony to legally authorize slavery (Rodriguez, 2007). As slavery spread and became institutionalized, the economic development of the South depended upon slave labor. The oft espoused ideal of a White utopia of wealth and exclusivity depended upon this 
labor force as well. Slaves were essentially the "architects of a new nation" (Berlin, Favreau, \& Miller, 1996, p. viii; Quintana, 2018).

To those benefitting from slavery, the suffering endured by Black families throughout their centuries of enslavement was of little consequence. White Americans structured their thinking in ways such that Black life and White life existed in wholly separate spheres and the concept of African American rights was negligible (Finkelman, 2012; Quintana, 2018; Van Horn, 2017). Even in his Notes on the State of Virginia, Founding Father and revered statesman, Thomas Jefferson, argued that beyond being inferior to White people, slaves seemed to have less emotions than their European counterparts, and certainly any suffering they endured was quickly forgotten (Jefferson, n.d.).

During the Civil War, President Abraham Lincoln issued the Emancipation Proclamation in 1862, freeing slaves in rebellion states that were currently in Union hands. Lincoln's personal beliefs aligned with emancipation but did not take priority over a reconciled Union, however, and he would have backpedaled if necessary to see the nation unified (Schwartz, 2015). This liberation granted by Lincoln's proclamation did not eliminate slavery in its entirety and the postwar status of slaves remained indeterminate, particularly since the Constitution did not provide for governance by way of proclamation (Donald, 1995).

Laws and court cases. Despite Lincoln's questionable loyalty to the promise of emancipation, his proclamation was the inaugural effort to free African Americans from forced servitude, and it triggered a nexus of events that facilitated integration of Black people into mainstream society (Schwartz, 2015). Still, true integration remained elusive, 
as Black "citizens" and White citizens were hardly amalgamated. Slavery was formally deinstitutionalized but the cultural habituations and conditions entrenched in a nation that accommodated longstanding racial bondage still permeated American life, creating a legacy of inequality for Black individuals (Meyer, 1994; Ruef \& Fletcher, 2003; Tilly, 1998).

Thirteenth Amendment and the end of slavery. Congress passed the Thirteenth Amendment to the United States Constitution in 1865, the first of the Reconstruction Amendments following the Civil War, formally abolishing slavery but granting former slaves no civil rights - this, nearly a century after the Declaration of Independence declared that all men are created equal (U.S. Const. amend. XIII). In response, Black Codes were passed in the South and the North, effectively stifling the liberation of former slaves. These Codes were laws intended to curtail the freedoms of African Americans and confine them to low wage occupations (Scott, 2014; Spero \& Harris, 1968). Black workers could be arrested for refusing to sign yearly employment contracts that ultimately forced them into low paying jobs and longstanding indebtedness (Wilson, 1965). The Black Codes also greatly impeded African American access to buying and leasing land and restricted their assimilation into the larger community (Wormser, 2003). Thus, while the Thirteenth Amendment made slavery illegal, White dominated legislatures made sure that full emancipation was deferred.

Fourteenth Amendment and the definition of citizenship. The Civil Rights Act of 1866 granted citizenship to African Americans and guaranteed that all citizens had equal protection under the law. The Fourteenth Amendment, the second of the Reconstruction Amendments addressing post-Civil War issues, was subsequently adopted 
in 1868 and ensured that the Supreme Court could not abrogate the rights granted by the civil rights legislation of two years earlier. It also specifically limited state and local activity that might infringe upon the rights of United States citizens without due process of law (U.S. Const. amend. XIV). The amendment nullified the Dred Scott Decision-a decision which held that African Americans whose ancestors were brought to America as slaves could never be citizens of the United States, and therefore were not entitled to the liberties of such (Dred Scott v. Sandford, 1857).

The Equal Protection Clause within this amendment has often been a cornerstone in desegregation court cases, as indicated in later sections of this literature review. What the Fourteenth Amendment left open for debate, however, is whether or not the Bill of Rights was extended to the states. The author of the amendment intended for these rights to be nationalized with this legislation, but for many years the Supreme Court did not share that stance - a position which would not shift until the $20^{\text {th }}$ century (United States Congress, 1866).

Fifteenth Amendment and African American suffrage. The third and final Reconstruction Amendment, the Fifteenth Amendment, gave Black men the right to vote in 1870. It stated the "right of citizens of the United States to vote shall not be denied or abridged by the United States or by any state on account of race, color, or previous condition of servitude" [emphasis added] (U.S. Const. amend. XV). Although the Civil War ended any question of state sovereignty (Elliott, 2001), Southern Democrats attempted to assert states' rights in determining suffrage specifics, and there were grassroots efforts by secret organizations to prevent Black individuals from exercising their voice at the polls - including lynchings and terrorist threats (Baker, 1994; Valelly, 
1993). In 1871, Congress passed the Ku Klux Klan Act (also known as the Third Enforcement Act) to prevent attacks to suffrage rights granted by the Fifteenth Amendment.

Civil Rights Cases (1883). Amid Reconstruction momentum, the Civil Rights Act of 1875 in part was designed to specifically protect the rights of American citizens' access to public accommodations and services, particularly in light of the newly added Thirteenth, Fourteenth, and Fifteenth Amendments to the United States Constitution (Civil Rights Act, 1875). The Act was overturned in 1883, but even before, its importance was undermined when a key provision - the proscription of racial discrimination in public schools—was removed (Grudridge, 1989). In the Civil Rights Cases of 1883, the Supreme Court held that while the Fourteenth Amendment mandated State action must ensure equal protection to all citizens under the law, the government did not have authority to control private interactions that might be discriminatory (Civil Rights Cases, n.d.). In his lone dissent, Justice Harlan argued against the narrow interpretation of the Reconstruction Amendments and stated that by relegating assertions of discrimination and "continuing slavery" to the jurisdiction of local powers, the Court was demonstrating "a de facto acceptance that white southerners could do as they wished with the black people in their midst" (Blackmon, 2008, p. 93).

The Civil Rights Cases had a profound impact on headway that had been made toward civil rights - progress which had resulted, in no small part, from biracial activism. The Cases undercut the democratic advancements of Reconstruction and gave credence to the White conservative notion of a proper social hierarchy (Cable, 1889; Robinson, 
2017). In 1887 and predating the Plessy decision, W.E.B. Du Bois decried the turning climate, echoing sentiment within the African American community:

It is not against particular acts that I inveigh, but against the spirt that prompts them: it is not that I care so much about riding in a smoking-car, as the fact that behind the public opinion that compels me to ride there is a denial of my manhood. Against such a sentiment, laws, or force cannot avail. It lies wholly with you [white people]. (Du Bois \& Aptheker, 1985, p. 4)

Certainly, the Civil Rights Cases instigated a new realm of activism which would persist through the years of Jim Crow segregation. Similarly, the Supreme Court would enter a new phase of "separate but equal" litigation beginning with the Plessy v. Ferguson decision (Robinson, 2017).

Plessy v. Ferguson and the proliferation of Jim Crow. Two decades after passage of the Ku Klux Klan Act, legislative power was transferred to the Democrats in the elections of 1890. By 1892, Republicans had lost control of the House of Representatives, the Senate, and the White House. A newly elected President Cleveland unequivocally opposed enforcement of fair voting laws (Valelly, 1993). Now, southern states began to vigorously implement Jim Crow laws and force segregation of Black Americans in public spaces (Baker, 1994; Woodward, 1974).

In the case of Plessy v. Ferguson, Homer Plessy was a man of mixed race (oneeighth Black) who participated in a staged challenge to Louisiana's Separate Car Act (Maglo, 2010). The Act mandated that White people and Black people travel in separate (but apparently equal) cars on the railway system. The railroad opposed this law on the basis that it was a financial burden and necessitated the purchase of additional railway 
cars to accommodate segregation requirements. As planned, Plessy was arrested when he refused to exit the Whites-only car. Legal counsel argued the arrest violated his protections under the Thirteenth and Fourteenth Amendments (Maidment, 1973).

The Supreme Court handed down the landmark decision in 1896. It held that racial segregation was permissible in public facilities if amenities were analogous (Plessy v. Ferguson, 1896) and established "legal racial inequality" as law (Hutchison, 2015, p. 426). The "separate but equal" doctrine, allowing compulsory segregation, had an instantaneous effect, including on American education. Black schools were disproportionately funded, buildings were habitually inferior to those attended by White children, and materials were lacking (Klarman, 2004).

Civil Rights Act of 1957. This was the first such legislation since the Civil Rights Act of 1875 (50th Anniversary, 2008). Signed by President Eisenhower, the purpose of the Act was to enforce voting rights of African Americans (Civil Rights Act, 1957). Opposition to the 1957 civil rights legislation elicited the longest one-person filibuster in history by segregationist Senator Strom Thurmond (Cohodas, 1993). Although limited in scope in no small part due to the actions of then Senator Lyndon B. Johnson-who was concerned about voter support of his political office and southern opposition to civil rights within the Democratic party (Caro, 2002) - the Act was ratified in September of 1957 and was instrumental in paving the way for future civil rights legislation. The Act also equipped the Justice Department with means to prosecute those who criminally stood as impediments to voting equality. This was evidenced by the creation of an Assistant Attorney General whose singular focus was civil rights, the 
creation of the Justice Department's Civil Rights Division, and the development of Civil Rights Commissions charged with data collection (50th Anniversary, 2008).

Civil Rights Act of 1964. Following the Civil Rights Act of 1957, Congress passed the Civil Rights Act of 1960 to address certain limitations in the previous legislation. Specifically, the latter sanctioned federal examination of voter polls and criminalized obstruction of voting rights (Civil Rights Act, 1960). This was a time of civil rights momentum in America, and in 1963 as Jim Crow laws persisted in the South, President Kennedy called for legislation to further increase liberties for all Americans (Kennedy, 1963). It was also a time for civil rights resistance and 1963 bore witness to the infamous death of Medgar Evers (a civil rights activist killed by a White supremacist and klansman) (Ellis \& Smith, 2011) and the bombing of the $16^{\text {th }}$ Street Baptist Church (killing four young girls; also the work of klansmen) (Anderson, 2008).

The terrorist acts of 1963, including retaliatory actions against the non-violent Birmingham Campaign which sought to highlight integration efforts of Black students (Lowery, Marszalek, \& Upchurch, 2003), actually helped garner public support for Kennedy's call to civil rights expansion. The aim of the legislation was to "ratify, effectuate, and extend what Congress and everyone else understood [emphasis added] to be the principle of Brown v. Board of Education...the prohibition of all official race discrimination" (Graglia, 2014, p. 103).

Following the assassination of President Kennedy, President Lyndon B. Johnson (Pauley, 1997), acting in concert with and as a vehicle of the movement (Carson, 2005), pressed Congress to pass the Civil Rights Act (Pauley, 1997). This landmark legislation was enacted on July 2, 1964, ubiquitously prohibiting discrimination based on race, color, 
religion, sex, or national origin (Civil Rights Act, 1964). Further, Title IV of the Act explicitly confronted school desegregation and banned discrimination by entities funded with federal monies (Civil Rights Act, 1964; Graglia, 2014; Orfield \& Eaton, 1996).

Voting Rights Act of 1965. The impetus of civil rights progress continued the following year with the Voting Rights Act of 1965. The United States Constitution initially allowed States wide berth in determining voter qualifications (U.S. Const. art. 1, $\S 2$, cl. 1). It did not, however provide universal voter protections until after the Civil War when, in 1870, the Fifteenth Amendment guaranteed Black men the right to vote (United State Department of Justice, 2017; U.S. Const. amend. XV). Despite the Reconstruction Amendments (Thirteenth, Fourteenth, and Fifteenth) and the Enforcement Acts which were designed in part to protect suffrage rights [and thus to some degree, the voices] of African American males (Enforcement Act, 1869; Second Enforcement Act, 1871; Third Enforcement Act, 1871), the Voting Rights Act was necessary to fully enfranchise the Black community. In particular, the Act eliminated literacy tests which long served as criteria for voter eligibility (Voting Rights Act, 1965). Black districts with marked increase in voter participation subsequently witnessed an increase in accessibility to state resources, not the least of which were improvements to the quality of education experienced by Black children (Cascio \& Washington, 2014). Black citizens could now exercise their voices at the ballot box rather than merely be subjected to the policies of White school boards with minimal, if any, say or representation.

\section{Race as a Dividing Factor in American Schools}

The complex process of unshackling Black Americans is inconsequential without equitable access to education. Concerning true freedom, Frederick Douglass said in 1894, 
"Education means emancipation. It means light and liberty. It means the uplifting of the soul of man into the glorious light of truth, the light by which men can only be made free" (Douglass, 2016). To the detriment of all Americans, the historical, longstanding racial divide within the United States has facilitated inequities of educational opportunities for non-privileged groups (DeCuir \& Dixson, 2004). Accordingly, scholastic incongruence has ensued between racial subgroups - a differential which, not surprisingly, continues today and is evidenced by the prevailing achievement gaps in classroom performance and on standardized assessments (Hillard, 1995; Howard, 2006; Milner 2015). Although all citizens are now guaranteed the right to an education and segregation of American schools is no longer a legally-sanctioned practice, concerns remain regarding race as a factor in our educational systems.

From the days of America's infancy, schooling was an eclectic amalgam of systems and funding sources — or the lack of either — and propagated social and educational disparity (Tyack, 2003). European immigrants to the New World had to reconceive a system of education that better reflected a new society. Schools, particularly in England, had been formal and abundant; yet in America, young White children were initially taught by their parents as taxpayers were disinclined to financially support the costs of a structured system of public education (May \& Vinovskis, 1977). It was not until 1870 that all states had free elementary schools in cities, and schooling was not compulsory in all states until 1917 (Monroe, 1911-1913).

Formal education—often devoid of any real sense of organization—naturally benefited White families and perpetuated isolation of the privileged from even the less advantaged non-Black groups, which also had limited or no access to schooling (Cohen, 
1974; May \& Vinovskis, 1977; Vinovskis, 1987). After the Civil War, the

"standardization and bureaucratization" of education was designed to advance Whites and not African Americans, encumbering any real post-war efforts at civil rights for all (Dorris, 2009, p. 4).

\section{The Evolution of School Desegregation}

The right to learn was denied to the majority of Black people in the United States for centuries as racial segregation was inherent in American education. In the early days of America, free Blacks had access to education in some areas of the North (Bridenbaugh \& Bridenbaugh, 1962). Slaves, however, were forbidden to read and write and teaching them to do so was a criminal act (Goldstein, Gee, \& Daniel, 1995). Following the Civil War, Blacks in the South gained access to schools, albeit segregated ones (Anderson, 1988; Zuczek, 2015). During Reconstruction and the years that followed, discourse concerning the education of Black Americans increased, as did pressure for their social integration into mainstream society (Tyack, 1974; Watkins, 2001). Civic-minded groups — especially missionaries — and industrialists resolute in growing a strong workforce were among the first to involve themselves in the education of a Black populace. Still, freedmen were simply more or less accommodated, and the religious orders were intent on helping them accept their station (Anderson, 1988; Watkins, 2001).

Just as the years following emancipation and Reconstruction evidenced slow progress in equitable treatment of and opportunity for Black Americans, the advancement toward equitable education was similarly lethargic. This was in no small part due to the segregated nature of American schools and the legal acceptance under Plessy that separate was equal (Plessy v. Ferguson, 1896), an acquiescence that was later determined 
to ensure disproportionate access to schools and quality educational resources for Black students (Brown v. Board of Education, 1954; Bullock, 1967; Ogbu, 1978, 1994).

Today, despite the reality of past and present court-mandated desegregation, we continue to question the impact that centuries of denied access to education-followed by decades of denied access to equal education — has had on generations of Black children in America. In Freedom to Learn, W.E.B. Du Bois (1949) states

Of all the civil rights for which the world has struggled and fought for 5000 years, the right to learn is undoubtedly the most fundamental. We must insist upon this to give our children the fairness of a start which will equip them with such an array of facts and such an attitude toward truth that they can have a real chance to judge what the world is and what its greater minds have thought it might be! (pp. 230-231)

$\mathrm{Du}$ Bois speaks of the potential that is borne of educational opportunity and he underscores that learning is a cardinal right. American history is in part a story of the dogged determination for the true and complete emancipation of all. If, as Du Bois suggests, access to a fair start at learning is critical, then the quest for educational freedom and equal opportunity is the cornerstone of school desegregation. The history of the United States is rife with arbitration focused on justice via racial integration, and the path of desegregation has been a contentious one- "circular following the swings of social eras" for more than one hundred and fifty years (Daniel, 2005, p. 57).

Separate is not equal. In the United States, history has shown that race is too often used for division; to classify and separate...that "racial categorization is... a moving 
target" (Ortiz \& Jani, 2010, p. 178). While Brown I (1954) ${ }^{6}$ is known perhaps as the foundational case against school segregation, it certainly was not the first. There were numerous legal battles that laid the foundation for Brown, of which select key ones are briefly discussed here.

Roberts v. Boston (1850). In Boston, Massachusetts, a five year-old Black child attended a Black school far from her home. Her father petitioned the courts to allow her to enroll in an all-White school nearby - and was denied. The Supreme Judicial Court of Massachusetts similarly found in favor of the city, stating there was no constitutional justification for deciding otherwise (Roberts $v$. Boston, 1850). Persistent in his pursuit of the matter, Mr. Roberts wrote to the legislature and in 1855 , more than a decade ahead of the Fourteenth Amendment, Massachusetts became the first State to ban racially segregated schools in America (Kluger, 1975). Interestingly, the Roberts decision to uphold segregated schools was cited as foundational in Plessy (Plessy v. Ferguson, 1896).

Lum v. Rice (1927). In the case of Lum, the Supreme Court unanimously upheld a Mississippi school board's decision to bar an American-born Chinese student from attending a White school. The Board determined that, being Asian, the student was not White and therefore must attend a "colored" school. The Court endorsed the definition of “separate" used in Plessy (Lum v. Rice, 1927) in keeping racially segregated schools. Further, Lum emphasized that schools funded through State taxation were thereby under

\footnotetext{
${ }^{6}$ For distinction, Brown v. Board of Education (1954) and (1955) are also referenced as Brown I and Brown II respectively.
} 
the governance of said State and not under Federal authority (Kluger, 1975) with regard to school system policy and practice.

Mendez v. Westminster (1947). The Mendez case involved five Mexican fathers who, in 1945, attempted to send their children to a local elementary school. The children were denied entry and told they must enroll at the "Mexican" schools (Mendez $v$. Westminster, 1947)—schools which were significantly inferior to those attended by White children (Strum, 2014). Other members of the families had attended school in the Westminster district, and yet the plaintiffs' children were turned away solely based on their Hispanic-sounding names and dark skin color. The families successfully sued to gain access to the integrated school (Aguirre, 2005; Santiago, 2013; Strum, 2014).

Judge McCormick and the Ninth Circuit expressed the opinion that "a paramount requisite in the American systems of public education is social equality. It must be open to all children by unified school association regardless of lineage" (Mendez v.

Westminster, 1946). The language of Westminster declared the segregation actions of the State of California to be in violation of the law, summarily laying the foundation for the Brown I decision (Strum, 2014).

Brown v. Board of Education (1954). Brown was a pivotal Supreme Court decision, facilitating ongoing legislation and policy redress toward equitable opportunities and desegregated schools (Daniel, 2005; Mickelson, 2001). Cases like Brown concentrated on the detrimental effects of segregation on the psyche, and not solely on the physical materials available to students in racially-siloed schools (Wells, Holme, Revilla, \& Atanda, 2004). 
Although not required to do so, Kansas schools were permitted to racially segregate students - and did so-from the time of Reconstruction in the South. In Topeka, Kansas, Linda Brown, a plaintiff's daughter, was forced to walk six blocks to her bus stop to then travel to her all-Black school located a mile away. The White school was just seven blocks from her home. Thirteen parents attempted but were not allowed to enroll their children in the White neighborhood school. The District Court found in favor of the school board. Despite the court's belief that segregated education was detrimental to Black students, it found that the separate schools were "equal" and thus supported by the ruling of Plessy.

The Brown v. Board decision was a combination of five cases: Brown, Briggs v. Elliott (1952), Davis v. County School Board of Prince Edward County (1954), Gebhart v. Belton (1952), and Bolling v. Sharpe (1954). The Briggs case challenged segregation in South Carolina, a state vehemently opposed to integration, arguing that both transportation and facilities were vastly disparate for White students and Black students. The school district disallowed bus service to Black families, stating their tax contribution was negligible (Briggs v. Elliott, 1952). The Davis case was a demand for integration borne of student protest in Virginia. The resolutions of the all-White school board in Prince Edward County failed to adequately fund the Black school, resulting in harshly substandard facilities for teachers and students - to the extent that a gymnasium, cafeteria, staff bathrooms, and student desks were absent, and some classes were held in shacks and dilapidated buses (Branch, 1988; Davis v. County School Board of Prince Edward County, 1954). Gebhart was originally two distinct cases (see also Bulah v. Gebhart) that were combined at trial. In Delaware, school segregation was mandated by 
the Constitution. The Gebhart case(s) argued for integration based on unequal facilities and non-existent school transportation provisions for Black students (Gebhart v. Belton, 1952). The Bolling case was the result of parents' failed entreaty to have a newly constructed junior high school in Washington D.C. opened as an integrated school. The Bolling case is singular in that segregation was found to be unconstitutional not because of the Fourteenth Amendment, which was specific only to states and therefore not applicable, but under the Due Process Clause of the Fifth Amendment (Bolling v. Sharpe, 1954).

Under the banner title of Brown v. Board of Education, the Supreme Court unanimously struck down the "separate but equal" doctrine of Plessy and held that laws mandating racially separate schools were unconstitutional (Brown v. Board of Education, 1954). It acknowledged that "equal opportunity... would not be achieved unless racially separate school systems, which perpetuated and reinforced inequality, were eliminated" (Orfield \& Eaton, 1996, p. 29).

The result was a swell of optimism within the Civil Rights movement (Orfield \& Eaton, 1996) and Justice Thurgood Marshall himself speculated that official school segregation would disappear within five years after the Court's ruling (Patterson, 2005). Brown was not decided in a political or civic vacuum, however, and certainly did not address discriminatory practices outside of the education setting. At this juncture American ambience was racial dissonance, and additional federal statutes were necessary to end government-sanctioned discrimination in all sectors of American life (Gartner \& Ferreira, 2014; Winter, 2014). 
Brown v. Board of Education (1955). The Brown ruling of 1954 upended the Court's stance of "separate but equal" as a viable means for perpetuated segregation and discrimination. It did not, however, provide direction or timelines for desegregation efforts. The implementation and enforcement component of the Court's decision, Brown II, was summarily vague. The ruling indicated desegregation should transpire "with all deliberate speed" (Brown v. Board of Education, 1955) and yet the Court failed to define "desegregation" and gave no clear mandate on compliance with delimited alacrity (Lopez \& Burciaga, 2014; Orfield \& Eaton, 1996). Ending desegregation "with all deliberate speed" failed therefore to become prevailing dogma (Orfield \& Eaton, 1996), ensuring that equitable educational opportunities for all remained elusive. What followed was decades of court cases (Fine, 2004) seeking the dream set forth in the Brown decisions.

Resistance to integration. Despite the rulings set forth in both Mendez and Brown I, the ambiguous language of Brown II helped foster defiance in the face of desegregation directives from the Supreme Court, increasing "the politics of education rather than decreas[ing] its importance in the school desegregation" (Brown, 2004, p. 191). This was evidenced in the cases of Cooper v. Aaron, Griffin v. County School Board of Prince Edward County, and Green v. County School Board of New Kent County.

Cooper v. Aaron (1958). The State of Arkansas asserted the right of interposition - entitlement to stand as a proverbial blockade between federal law and the imposition of such on the people of the State - and attempted to quash the mandated desegregation of Brown I. Despite the Little Rock Board of Education's attempts to comply with desegregation directives per the Brown I and II decisions, Governor Faubus 
ordered the National Guard to prevent African American students from entering Little Rock Central High School. It was not until President Eisenhower federalized the Arkansas National Guard that these students were given protection and permitted to attend. Because of the chaos surrounding the desegregation plan, the school board requested a two-year delay in implementation. The District Court granted the delay but the decision was reversed in the superior courts (Cooper v. Aaron, 1958), emphasizing the preeminence of the Court. Even now, Cooper stands as "one of the Court's most sweeping affirmations of its own constitutional authority within the American federal system of government" (Freyer, 2006, p. 2).

Griffin v. County School Board of Prince Edward County (1964). In similar efforts to resist desegregation orders, the case of Griffin v. County School Board of Prince Edward County (1964) showcased the results of massive resistance, a strategy also designed to resist federal law. Here, the school board refused to appropriate the necessary funds to operate the public schools in defiance of the Brown I and II decisions. The failure to grant and disseminate requisite monies forced closure of the public schools for five years, thereby halting any pretense of integration effort. As recompense for the closures, the district issued vouchers to enable students to attend private schools, but as these schools remained segregated by race, formal education was ultimately reserved for White children while being denied to Black children (Griffin v. County School Board of Prince Edward County, 1964). The Court held that the school board could not close public schools to perpetuate segregation (Daniel, 2005). When the public schools did reopen, the system had to be restructured to accommodate a nearly all-Black population that had been without any formal schooling for five years. The impact on Black students 
in Prince Edward County was keenly felt as denied access to education impacted employment opportunities and made socioeconomic ascent difficult (Waugh, 2012).

Green v. County School Board of New Kent County (1968). A prominent case of massive resistance is that of Green v. County School Board of New Kent County. Green questioned the legality of "freedom of choice" plans. This Virginia district operated a dual, segregated school system. Calvin Coolidge Green and his wife, Mary, were employed as teachers in the district. As a member of the NAACP, Mr. Green urged the district to comply with the desegregation ruling of Brown, to no avail. Black students continued to be bused to an all-Black, substandard school. With the passage of the Civil Rights Act of 1964, schools that refused to integrate students risked funding cuts. At this time the NAACP initiated new legislation named for Mr. Green's son. In retaliation, the school board did not renew Mary Green's teaching contract (Allen \& Daugherity, 2006).

Following the Brown ruling, students were given a choice in New Kent Countyto attend one school that was majority Black or another, which was majority White. The "freedom of choice" plans mollified the courts, yet unduly placed the burden of integration on Black families and let White families choose White schools. Unless parents requested a change in placement, students were automatically reenrolled in their previous schools. Given that Black students were not well received in "White" schools, integration remained problematic. It is of important note here that White people did not choose to attend Black schools during the time of these free choice plans. Certainly the reasons are voluminous_-but White families did not want their children attending schools with Black children. And as with de facto school segregation today, many families were 
not open to the uneasiness that accompanies experiences which are not representative of those of the majority (Crocker, Major, \& Steele, 1998; Trawalter \& Richeson, 2008; Vorauer, Hunter, Main, \& Roy, 2000).

The Court found freedom of choice plans to be ineffective in advancing desegregation and ordered that segregated dual systems must be dismantled "root and branch." Furthermore, the Court delineated specific areas for desegregation compliance-facilities, staff, faculty, students, extracurricular activities, and transportation. These became commonly known as the "Green Factors" (Green v. County School Board of New Kent County, 1968) and are used in judging acceptability of desegregation plans.

With all deliberate speed, defined. While Brown II lacked clarity concerning a specific desegregation timeframe, Alexander v. Holmes (1969) mandated an immediate end to dual systems. Fifteen years of delays since the initial Brown v. Board decision had ensured that southern schools were not desegregating with much, if any, momentum. The Alexander case involved postponement of desegregation plans in Mississippi at the request of federal agencies. Courts granted the delay and no date was stipulated for plan implementation. Further, the courts allowed the Holmes County district to continue utilizing "freedom of choice" plans. The Supreme Court, however, determined the vague timeline for desegregation set forth in Brown II was not acceptable. Schools were to achieve unitary status immediately and by eliminating any semblance of segregation set forth in the six "Green Factors" as determined in the 1968 case by that name (Alexander v. Holmes County Board of Education, 1969). Alexander necessarily ended "dilatory tactics" used by school districts to avoid adherence to the Brown decisions and forced 
them to honor Black students' constitutional rights to integrated educational settings (Doherty, 1970, p. 514).

Residential considerations and school attendance. Efforts at desegregation since the Brown I decision had been lethargic, if not apathetic. Nonchalance toward integration despite the 1954 mandate appeared to tire the Court and its decisions began to reflect as much.

Swann v. Mecklenburg Board of Education (1971). In contrast to the desegregation resistance evidenced earlier in the courts, the landmark Swann $v$. Charlotte-Mecklenburg decision called for a vigorous approach to integrating school districts. Here, the Court found that "racially neutral" schools should be achieved at the “greatest possible extent" (Orfield \& Eaton, 1996, p. xxii) regardless of residential proximity to neighborhood schools (Fiss, 1971). Although the Mecklenburg School Board had no overt policies to racially segregate its schools, the Court held that maintaining certain residential school assignments precipitated de facto segregation. President Nixon directed the Justice Department to prepare a Constitutional amendment which would effectively invalidate the Swann decision (Kluger, 1975; Motley, 1998).

Rebuffing Nixon's attempts to the contrary, busing was progressively appropriated as remedy to non-contiguous districts as a channel to maximize school integration - becoming the first district to mandate such a reassignment plan (Orfield \& Eaton, 1996; Swann v. Charlotte-Mecklenburg Board of Education, 1971). The Charlotte-Mecklenburg School District's successful implementation of a peaceful busing solution resulted in a model desegregation plan, a plan in which racial percentages 
mirrored those of the larger community and high quality, equitable education was provided for all (Godwin, Leland, Baxter, \& Southworth, 2006; Mickelson, 2001, p. 217).

Keyes v. Denver School District No. 1 (1973). Keyes is also a seminal case germane to residential considerations. Far beyond the boundaries of the South and the first such case in this geographical area of the United States, the Court found that the Denver district had, through policies and practices, intentionally created racial segregation involving both Black and Hispanic students. Schools were strategically built in racially insulated areas, and attendance zones had been gerrymandered to ensure that Black and White students remained segregated - both of which were in violation of the Equal Protection Clause of the Fourteenth Amendment. An important outcome of this decision is that now when explicit segregation is discovered in one aspect of district operations, the courts may assume the entirety of the system is similarly flawed and the district is burdened with proving otherwise (Keyes v. School District No. 1, 1973).

Southern Strategy and legal shifts. The victories in favor of racial integration have been achieved before a backdrop of antipathy, and diversity continues to be a spirited issue in our nation, in our communities, and in our schools. Viewed through the historical lens of western culture, we can see the enactment of racial dominance throughout the quest for equity (Singleton \& Linton, 2006). This was evidenced post Brown by President Nixon's Supreme Court appointments-justices who would set to change the course of desegregation with their decisions. His appointees (and even nonselected nominees) favored segregation, urged "strict scrutiny" of affirmative action programs and argued against court-ordered desegregation (Zelizer, 2012). 
The "Southern Strategy" is a political tactic that has become synonymous with the school choice and voucher movement and was initially connected to the politics of President Nixon (Airstrup, 1996). The South generally did not support busing as a means of desegregating schools, and Nixon wanted Southern endorsement during his political campaigns (Brown, 2004; Sanders, 2002). In that vein, Nixon plotted replacement of the Fourteenth Amendment, instructed governmental agencies against enforcing the Brown decisions, and involved the Justice Department in proactively thwarting legal action brought against school districts that were not in compliance with the Civil Rights Act of 1964 (Brown, 2004).

Milliken v. Bradley (1974). In the case of Milliken v. Bradley ${ }^{7}$, the NAACP filed a suit arguing in part that school segregation was the result of practices such as redlining, a method of excluding or limiting minority access to certain housing. The lower court affirmed and as remedy, a desegregation plan involving interdistrict busing across 53 districts was to be enacted. The Supreme Court overturned the lower courts, finding that segregation was allowable unless it was proven that racial isolation was due to intent, or that segregation directly stemmed from policies and practices enacted by the school board. The view of the Court here was in stark contrast to the liberal approach found in the 1971 Swann case, which was to facilitate integration to the fullest extent (Milliken $v$. Bradley, 1974). Milliken allowed districts to redistribute White students to neighborhood schools, which championed White Flight to suburbs in kind (Sedler, 1987).

\footnotetext{
${ }^{7}$ For distinction, Milliken v. Bradley (1974) and (1977) are also referenced as Milliken I and Milliken II respectively.
} 
Milliken v. Bradley II (1977). The Milliken I decision proved to be major impediment to integration efforts in districts with sizable minority student populations and ensured that true desegregation was not feasible in the Detroit public schools (Milner, Delale-O'Connor, Murray, \& Farinde, 2016). Persistent effort by the school board and district court to secure quality education for minority students resulted in Milliken II. The argument was that long-term educational isolation had fostered a unique culture for segregated students - a culture that did not necessarily align with that of the larger environment in which students would need to "function and compete" (Milliken v. Bradley, 1977). Restructuring a system of pupil placement was therefore insufficient to counter the detrimental effects of educational isolation. As partial reparation for the harm caused from purposeful school segregation, the Court found that special compensatory education programs could now be included in desegregation plans and the State could be ordered to pay for them. Unfortunately, the Court set no measurement protocol (as with the "Green Factors" in Green v. County School Board of New Kent County) to ascertain effectiveness of such programs, and in the years following the Milliken II decision these programs showed no real evidence of remediation. Twelve years later the court relinquished control of the desegregation measures with no substantiation that the programs had been successful, and no assurance that any of the Milliken II programs would be maintained as school boards were not legally obligated to keep them in place (Orfield \& Eaton, 1996).

Legal implications of unitary status. In the mid-1980s, mere decades after the Mendez and Brown decisions, the Supreme Court allowed school districts to dismantle their desegregation plans in certain circumstances. If the court found a school district to 
have achieved unitary status, it assumed the district had "repair[ed] the damage caused by generations of segregation and overt discrimination" (Orfield \& Eaton, 1996, p. 3). With unitary status, the court also assumes that compliance with the Green Factors (see Green v. County School Board of New Kent County, 1968), even for a short amount of time, can negate the detrimental effects of forced school segregation (Orfield \& Eaton, 1996).

Riddick v. School Board of the City of Norfolk, Virginia (1986). In Norfolk, Virginia busing was employed as a means to integrate schools. Riddick was a case brought in the guise of legal defense of neighborhood schools. The school district argued that White Flight had resulted from forced busing, and accordingly, schools were now more segregated than ever. The district sought relief from the busing mandate, arguing successfully that should White Flight continue, any hope of an integrated school system was for naught. The Court held that once a district has achieved unitary status, its desegregation plans may be released from federal control (Riddick v. School Board of the City of Norfolk, 1986).

Once a district was granted unitary status, any past discriminatory behavior was essentially obliterated and the school board could then set attendance assignments at its own discretion—even when the assignments resulted in segregated neighborhood schools - and the districts could do so with ease. Conversely, civil rights lawyers now faced significant difficulties in their efforts at redress. School boards had only to show that neighborhood school assignments, even ones that facilitated segregation, were necessary to prevent White Fight. Civil Rights counsel had the heavier burden to demonstrate intentional racial discrimination (Orfield \& Eaton, 1996). 
Waning court oversight. A series of cases in the 1990s made it easier for school districts to be released from federal oversight. Desegregation orders were rescinded with increasing frequency as the Court found that decrees were not intended to be everlasting and also that there were pragmatic limits of the federal government regarding desegregation of American schools.

Board of Education of Oklahoma v. Dowell (1991). Similarly, in the Oklahoma City case of Board v. Dowell, busing mandates successfully created an integrated school system, leading the district to unitary status. Because of White Flight and major demographic changes within the school district over time, however, busing became more an issue of increased travel time for Black students when White students were increasingly absent. Five years after the implementation of busing, the court withdrew its enforcement of the plan based on the district's unitary status. The Board's proven compliance with the desegregation plan had allowed it to achieve unitary status and thus fulfill the plan's purpose of achieving an integrated district. As in Riddick, the court found the school district to be in compliance with the Green Factors and desegregation mandates, and therefore released it from federal oversight (Board of Education of Oklahoma City Public Schools v. Dowell, 1991) despite resegregation that would result from a return to neighborhood school assignments.

Freeman v. Pitts (1992). Unitary status accompanies an assumption-correctly or not—of a school district's implicit reformation, as evidenced in the Court's findings in both the Riddick and Dowell decisions. In 1992, however, the Court held that district courts could be released from oversight of desegregation plans even if these plans had only partially been satisfied. In the case of Freeman v. Pitts, the DeKalb County School 
District in Georgia sought relief from federal supervision of their desegregation plan. Despite having met only four of the six Green Factors, the trial court found that oversight of the district could be relinquished incrementally. The stance of the Court here, as in Riddick and Dowell, indicated a view that desegregation mandates are temporary punitive measures for discriminatory conduct rather than a means to see schools fully progress toward racial integration, easing the return of school districts to local control (Freeman $v$. Pitts, 1992).

Freeman v. Pitts underscored the Court's shift from desegregation, to facilitating resegregation. The school district was granted unitary status based on fulfillment of four Green Factors and oversight in these areas was returned to the state and DeKalb County. Federal oversight continued in the two areas in need of remediation. Ultimately the Court's stance was that districts were simply legally precluded from discrimination-a sharp turn from the years immediately following the Brown decisions when desegregation was paramount—leaving race-based programs in jeopardy (Amsterdam, 2017).

Missouri v. Jenkins (1995). The Kansas City, Missouri School District established a plan to integrate schools while attracting suburban White students through improved educational programs, including an expansive system of magnet schools. The desegregation remedies also encompassed salary augmentation derived from court ordered tax increases, rates of which exceeded the state standard. The State opposed the Kansas City plan, arguing that it was too costly. The district courts found the Kansas City plan was necessary to assuage the damage caused by perpetual segregation in the years post Brown and ordered its implementation. In Missouri v. Jenkins, the State 
sought relief and a finding of partial unitary status as was evidenced in the Pitts decision. The Court determined that such remedies under Milliken II should not continue indefinitely and that the goal was to return desegregation plans to local control as soon as possible. After nearly two decades of court battles, federal oversight of the education remedies was withdrawn despite little evidence of eradicating achievement disparities between subgroups. Of note is that the district's voluntary plan to integrate its city schools was struck down, and yet the success of court imposed educational remedies could not be substantiated (Missouri v. Jenkins, 1995).

Parents Involved in Community Schools v. Seattle School District No. 1 (2007). More recently in Parents Involved in Community Schools v. Seattle School District No. 1 (hereafter PICS), the Court found voluntary desegregation plans in Seattle and Louisville, Kentucky to be in violation of the Equal Protection Clause of the Fourteenth Amendment. Here, both school districts attempted to achieve and maintain a standard of integration through an assignment system that involved predetermined demographic ratios. In the Jefferson County (Louisville) case, a federal judge found that race-based assignment could not be used for acceptance into magnet schools, but allowed for such assignments in the public schools. In Seattle's School District No. 1, students were permitted a choice of schools, but if said populations subsequently resulted in a deviation from the prescribed ratios, racial classification could then be considered as a criterion for admission. In essence, district officials could admit or deny students according to race in order to achieve the stipulated proportion of diversity. The question of whether or not these practices violated the Equal Protection Clause was jostled in the courts. Ultimately the Supreme Court found that the districts' applications of racial criterion were indeed a 
violation. The Court found that the districts' procedures in this regard were designed to meet certain demographic goals and did not address any particular educational benefit. Chief Justice Roberts notably stated that "the way to stop discrimination on the basis of race is to stop discriminating on the basis of race" (Parents Involved in Community Schools v. Seattle School District No. 1, 2007). While the Court acknowledged that the districts' intent was compelling, it also noted that the plan was not sufficiently "narrowly tailored." This ruling successfully obstructed many routes that districts had long put into place voluntarily to achieve diversity, such as plans that balanced racial diversity with family choice (Frankenberg \& Orfield, 2012).

Recent efforts at desegregation. During his presidency, Obama supported the objectives of such voluntary desegregation programs but gave little assistance toward facilitating them (Frankenberg \& Orfield, 2012). Some argue that during his tenure, Obama expanded privatization. Economic stress provided ripe opportunities for "neoliberal expansion" (Lipman, 2015) such as charter schools, and the demise of urban schools in African American communities (Davies, 2010; Peck, Theodore, \& Brenner, 2012), which "contributed to [the] disinvestment and destabilization of low-income communities of color" (Lipman, 2015, p. 60).

The Obama Administration did, however, provide strong guidelines for promoting diversity in education through joint efforts of the Departments of Justice and Education, and attempted to provide funding for diversity programs in the "Stronger Together" budget initiative (McDermott, Frankenberg \& DeBray, 2016). Informed by Supreme Court decisions, criteria were established to allow education programs from elementary to the university level to regard race as a condition of admission and participation in 
support programs . As of July 2018, the Trump Administration has removed all such diversity guidelines for education set forth by Obama, indicating a return to the raceneutral policies of the past (Anderson \& Balingit, 2018). Further, Obama-era grants to assist districts in facilitating diversity were axed by Trump's Secretary of Education DeVos, arguing that the grants were not a wise use of tax monies (Brown, 2017). Raceneutral policies repudiate opportunity gaps and perpetuate discrimination and will be discussed in later sections of this study.

\section{Suburbia}

Legislation and policies are not sole factors of influence in student achievement. The communities in which children live and attend school provide predictability and insight into academic success as well. The terms "suburb" and "suburbia" lack unilateral definitions, and yet for decades Americans have conceptually understood them to mean the geographical areas beyond urban centers; the substantial residential areas along the periphery of an urban hub (Dictionary.com, 2012). Suburbs are typically accepted as more affluent than urban centers. Still, both the overall poverty rates and number of impoverished students have significantly increased in the United States over the last two decades, and more abruptly in suburbs versus city schools. Many once predominantly White suburbs are now home to African Americans and Hispanic Americans, immigrants, and lower income households (Frey, 2011; Holme, Diem, \& Welton, 2014). The changing demographics of both race and class further obscure idiosyncrasies of residential definitions (Logan, Zhang, \& Oakley, 2017; Frankenberg \& Orfield, 2012) and yet racial integration in urban and suburban areas remains an effective gauge of overall societal amalgamation (Kye, 2018; Swaroop \& Krysan, 2011). 
White Flight and the Emergence of Suburbs. White Flight is the exodus of White residents from "urban neighborhoods or schools [that are] increasingly or predominantly populated by minorities" (Merriam-Webster, 2019). Opponents of courtmandated school desegregation successfully argued that White Flight from areas with busing orders actually perpetuated segregation (see the cases of Milliken, Riddick, and Dowell). Once desegregation remedies ceased, challengers believed the exodus would end; yet cities with neighborhood schools did not necessarily have stable White populations at the onset—e.g. the Riddick and Freeman cases involved both declines in White populations without busing, and housing changes in the communities (Frankenberg \& Orfield, 2012).

Housing was specifically omitted from the Civil Rights Act of 1964 and Congress disregarded President Johnson's appeal for fair housing legislation in 1966 (Bonastia, 2015). In 1968 and during the turbulence following the assassination of Dr. Martin Luther King, Jr., Congress did pass the Fair Housing Act which safeguarded consumers from discrimination based on protected class status (Civil Rights Act, 1968; Massey, 2015). George W. Romney, Secretary of Housing and Urban Development (HUD) under President Nixon, pressed to expand fair and affordable housing and disallowed improvement projects in municipalities with overt segregation policies (Frankenberg \& Orfield, 2012). Romney reasoned it was "becoming increasingly apparent that the lower, middle income and the poor, white, black and brown family, cannot continue to be isolated in the deteriorating core cities" (Romney, 1970). Nixon did not support Romney's initiatives and fellow Cabinet members complained about the Secretary's persistent efforts (Bonastia, 2015). Nixon instead underscored federal limitations to 
authority over housing integration (Nixon, 1971). Residents viewed the Fair Housing

Act as an impingement on suburbs and subsidized housing was an unwelcome encroachment. Even Nixon's Cabinet members recognized that HUD funding with "strings attached" (Bonastia, 2015, p. 564) could "provoke a far greater social crisis than the school busing one" (Lilley, 1971, p. 2348).

Amid a backdrop of fair housing concerns, the argument over equitable educational opportunities in urban/suburban schools prompted Nixon to advance a compromise in an effort at placation. Nixon offered the concession in 1972-keeping neighborhood schools intact while providing additional monies and resources to schools with elevated concentrations of impoverished students (Bonastia, 2015). This compromise influences school finance policy, equitable education opportunities, and assessment even today and its sentiment was prominent in the language of No Child Left Behind (Ryan, 2010). Despite its replacement by the Every Child Succeeds Act (2015), NCLB was inaugural in mandating that schools track progress and emphasized quality teaching and highly qualified teachers in the classroom. Appraisal of school desegregation and White Flight scenarios, though, is compounded by the intersection of a multitude of demographic factors, including socioeconomic status, all of which impact populace changes (Reber, 2005).

Research has shown that despite a few outliers, this Nixon-styled approach has had limited success. Additional funding alone - absent fair housing and equitable opportunities - is insufficient to make the gains sought through desegregation plans. In fact, predominantly White, middle class schools have substantial advantage over 
predominantly minority, impoverished schools when it comes to high performance. They are 83 times more likely to realize exemplary achievement (Wells et al., 2004).

Changing demographics in suburbia. Demographic changes have been occurring in American cities and suburbs in the decades since Brown v. Board, and areas that were traditionally heavily populated with White residents have seen an influx of Black, Hispanic, and immigrant families (Diem \& Frankenberg, 2013; Holme et al., 2014; \& Turner, 2015). Black suburbanization increased largely after the Civil Rights movement of the Sixties, yet both Nixon and Reagan failed to offer any noteworthy response to ongoing segregation in the housing market (Lamb, 2005). Similarly, there were no such initiatives during the Carter and Clinton presidencies despite HUD advocacy for urban policy, and none in the G.W. or George Bush administrations either. Even the Obama administration saw no substantial developments on this front (Frankenberg \& Orfield, 2012). On June 25, 2015, the Supreme Court ruled that housing policies can be considered discriminatory in practice even if not in intent (Texas Dept. of Housing and Community Affairs v. Inclusive Communities Project, Inc., 576 U.S. 2015). Julian Castro, HUD Secretary under President Obama, used the ruling to influence affirmative housing integration policies (Mathis-Lilley, 2015).

As microcosms of the greater society, public schools echo statistical demographic shifts. In their influential work concerning race and economics in the context of suburban schools and their communities, Frankenberg and Orfield (2012) predicted the United States would soon have schools with no racial majority, a projection that has become reality in the ensuing years (NCES, 2018). The pressing question, then, is whether or not public schools are prepared to address their changing student populations. 
Student demographics. According to The Condition of Education Report (2016), published annually by the National Center for Education Statistics, currently nearly 50\% of public school students are White. The remaining half is largely made up of Black students (nearly 16\%) and Hispanic students (nearly 25\%), with 3\% of the total public school population identifying as two or more races. The overall percentage of traditional public schools with at least 50\% White enrollment has decreased. This is also true of schools with at least 50\% Black enrollment. Conversely, the percentage of traditional public schools with at least 50\% Hispanic enrollment has increased (NCES, 2018).

Between 2000 and 2015, overall public school enrollment has increased 7\% to 50.4 million, with projections reaching 52.1 million students by 2027 (NCES, 2017). Again, while public school populations are increasing, there has been a decrease in the percentages of White students (from 59 to 50\%) and Black students (from 17 to 16\%) in these schools with a corresponding increase in Hispanic enrollment (from 19 to 25\%), and projections for the next decade mirror this trend (NCES, 2018).

Considering public school data from 2000 to the present and including enrollment projections through 2027, we can clearly see the statistical racial and ethnic changes in school populations. Demographic variations are not uniform across the United States, however, and the effects of these changes — racial and ethnic indicators and economic impact — are exclusive to each individual community (Frankenberg \& Orfield, 2012; Holme et al., 2014). This is noteworthy because while state and federal policies should have universal applicability even as population shifts occur, there are also singular policy and professional development needs which are unique at the school district level. 
Midwest percentages. Changes in racial and ethnic distribution of public school enrollment varied by region. Table 1 below shows national enrollment percentages and projections of three major subgroups within the student population-White, Black, and Hispanic — and includes statistics specific to the Midwest. This geographic region is applicable to this dissertation study and is therefore highlighted here.

\section{Table 1}

Enrollment Percentages per Subgroup Nationally and in the Midwest

\begin{tabular}{|c|c|c|c|c|c|}
\hline & \multicolumn{2}{|c|}{$\underline{2003}$} & \multicolumn{2}{|c|}{$\underline{2013}$} & \multirow{2}{*}{$\frac{2025}{\text { U.S. }}$} \\
\hline & U.S. & Midwest & U.S. & Midwest & \\
\hline White & 59 & 47 & 50 & 67 & 46 \\
\hline Black & 17 & 15 & 16 & 14 & 15 \\
\hline Hispanic & 19 & 7 & 25 & 11 & 29 \\
\hline
\end{tabular}

NCES Status and Trends in the Education of Racial and Ethnic Groups (2018).

Using data and projections between 2003 and 2025, national enrollment percentages per subgroup predict a decline in White student populations by 13 percent, a decline in Black student populations by 2 percent, and an increase in Hispanic student populations by 10 percent. Prior to 2008, data was not collected that identified students of two or more races. Midwest enrollment percentages between 2003 and 2013 indicate a 20 percent increase in White student populations, a one percent decrease in Black student populations, and a 4 percent increase in Hispanic student populations. Relative to this dissertation study, note that in 2003, Midwest Black student populations were slightly less than a third the size of White student populations in the same geographical area. By 
2013, Midwest White student populations were nearly five times that of Black student populations.

Resegregation. The tenets of Brown v. Board that sanctioned segregation as discriminatory and an assault on the Constitution are hardly argued contemporarily (Billings, Deming, \& Rockoff, 2014; Orfield \& Eaton, 1996). Notwithstanding legal mandates of school desegregation and some concerted efforts toward racial integration, however, fluctuations in the composition of community populations have resulted in progressively segregated schools - a resegregation (Dudley-Marling, 2007; Fiel, 2013). Too, in the years since Brown, attacks on desegregation within the courts have tempered public opinion and made a shift to resegregated schools plausible. The Supreme Court ruled in 1991 that school desegregation plans were ephemeral (Board of Education of Oklahoma City v. Dowell, 1991) and many districts were released from superintendence even with partial compliance (Reardon, Grewal, Kalogrides, \& Greenberg, 2012). Further, both the United States Justice Department's Civil Rights Division and Education Department's Office of Civil Rights have not effectively settled issues left unclarified in the courts. They have provided no real specifications for appraising desegregation plan compliance which would have strengthened the decisions of the Supreme Court (Fiel, 2013; Orfield \& Eaton, 1996).

Demographic shifts and cessation of desegregation plans are factors in resegregation, but this does not mean a return to the de jure segregation of prior to the cases of Brown, Green, and Swann. Rather, results are consistent with neighborhood assignment policies to be expected following the release from desegregation plans and are fastest growing in the elementary school sector (Reardon et al., 2012). Districts must 
consider what a return to the segregation of our American past means for our students and our schools. Is the promise of desegregation once again a dream deferred ${ }^{8}$ ? Operating in a vacuum bereft of relative policy is sure to mean a regression of equitable educational opportunities for all students (Frankenberg \& Orfield, 2012).

\section{Response to patterns of racial transformation in suburban school districts.}

There exists a scarce amount of research and ostensible policy that addresses school district response to demographic and racial transformation (Holme et al., 2014). In fact, "the United States today is a suburban nation that thinks of race as an urban issue, and often assumes that it has been largely solved" (Frankenberg \& Orfield, 2012, p. 2).

Because Americans largely think of race as an issue that has been settled - that the United States today is indeed a post racial society - it is not surprising that politicians and educators circumvent meaningful discourse on the subject. Race is undeniably a sensitive topic, and with limited understanding of the subtleties and undercurrents entwined in centuries of history and injustice, leaders often lack the ability to engage in coherent and relevant dialogue with any aptitude to bridge misunderstandings and difference and produce dynamic results (Frankenberg \& Orfield, 2012). Even now, in 2020, America is experiencing widespread uprisings as protestors urge society to value Black people's lives. School districts, though, tend to reflect a community's overall demographics, and schools are thereby among the first to be confronted and tasked with understanding shifts in regional diversity and any associated political and economic division (Anderson, 2005; Holme et al., 2014). Thus, our students are disadvantaged

\footnotetext{
${ }^{8}$ This phrase is a reference to Langton Hughes's poem of the same name, "A Dream Deferred," which is included as an Appendix.
} 
when we fail to adequately address race, proceeding as though it is no longer a significant factor in the consideration of equitable education (Giroux, 2010).

In the decades since Brown, less and less priority has been placed on desegregation and racial integration efforts to ensure equitable education for all students (note Table 2).

\section{Table 1}

Praxis Summary of Governmental Approaches to Equitable Education Following Brown $(1954)^{1}$

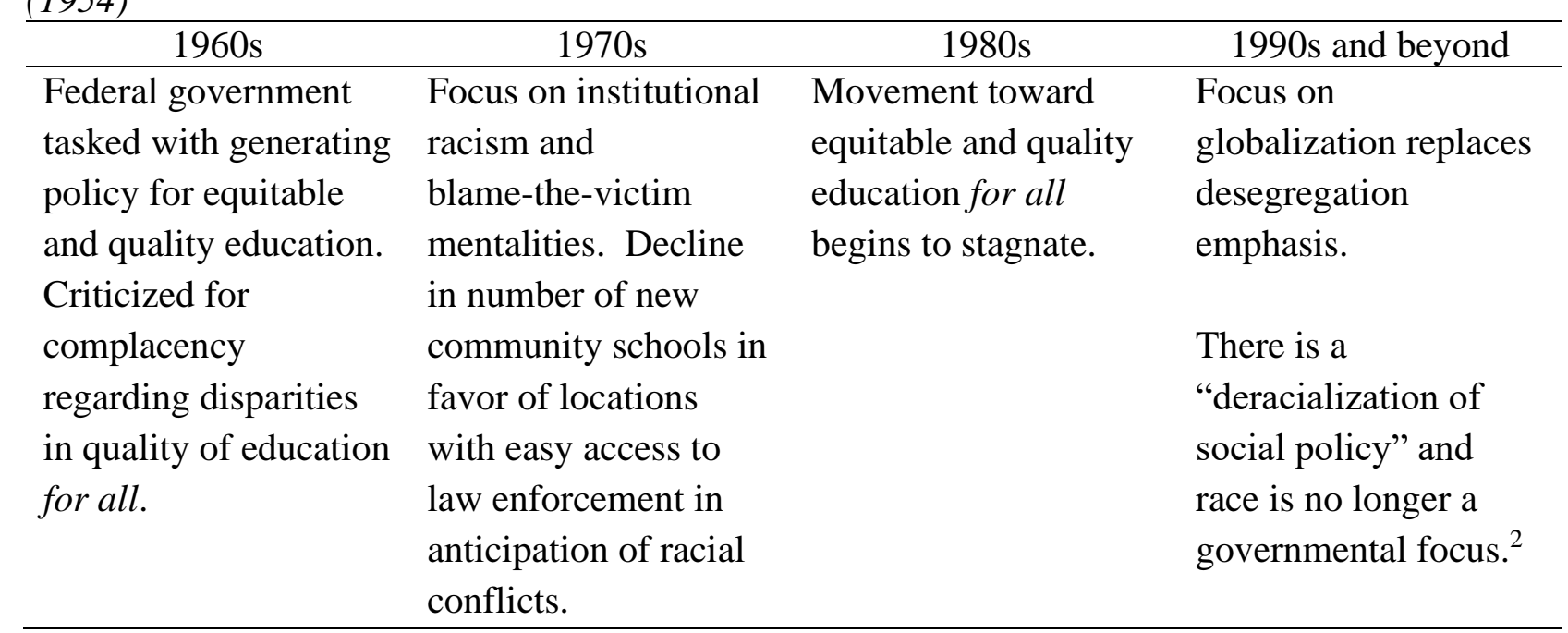

${ }^{1}$ (Dorris, 2009) Table citation except where otherwise noted

${ }^{2}$ (Gillborn, 1995, p. 18)

The data shows that demographic changes are occurring in America today, and yet the questions school districts now face concerning population shifts are nothing new. In the years during and following the Second World War there was a significant increase in movement of American people. Even in the early 1950s, a Critical Issues in Education article indicated that a lack of focused study prevented school districts from answering critical questions about population specifics, despite the reality that these demographic changes were often problematic for schools (Whinnery, 1952). 
District responses (or lack thereof) to racial and ethnic changes become manifested in policies and procedures which unfortunately often echo a lack of support. Architypes from the mid twentieth century that once attempted to address suburbanization are not sufficient for helping today's school districts ask and answer important and necessary questions about race, education, and opportunity in the ongoing transformation of today's America. This leaves districts "unable to form a coherent response to the...demographic changes" (Frankenberg \& Orfield, 2012, p. 1). In his closing remarks to Congress in 1862, Abraham Lincoln said,

The dogmas of the quiet past are inadequate to the stormy present. The occasion is piled high with difficulty and we must rise with the occasion. As our case is new, we must think anew and act anew. We must disenthrall ourselves, and then we shall save our country.

\section{Monoculture of the Teaching Pool}

Despite demographic shifts in student populations, there remains a predominance of White teachers in American PK-12 education (Boser, 2014). Despite the United States Department of Education's avowed priority to expand diversity within the teaching cadre, this trend of a White teaching force is on cue to continue even as student populations become more diverse (Kozol, 2005; Orfield \& Lee, 2004). White teachers frequently come from a background of White communities and are often trained in colleges of education that are also primarily White (Nieto, 1994). This matters because the dominant group - here, White teachers - is able to set power differentials and norms (Johnson, 2006) even for diverse student groups. This cultural divide may be a stressor for schooldependent children in that the cultures and values of their teachers are often unfamiliar to 
them, making it an arduous task to conform to the ethos of the school (Comer, 1993;

Lave \& Wenger, 1990). Individual student cultures also influence norms and values and affect habituations (Wilson, 1978), and these may conflict with those of the teacher. Too, the dominant teacher culture impacts curricular decisions and instructional strategies, and also decreases the number of mentors of color available to students within the educational environment (Jackson, 2011; Ortiz \& Jani, 2010; Parker \& Villalpando, 2007).

Questions of cultural competency. Competency implies proficiency. For the purpose of this study, cultural competency indicates an ability to effectively interact and form relationships with those of other cultural backgrounds specifically connected to race. Teachers with monocultural personal histories or limited encounters with diversity may experience discomfort or face challenges connecting with all students equitably in the classroom. Absent these critical connections in the learning environment, students may develop affective filters which may increase stress and nurture self-deprecating ideations, both of which inhibit learning (Jackson, 2011). In his argument that we cannot teach what we do not know, Gary Howard succinctly reasons that White teachers are regularly placed in professional settings that beg of them to be culturally competent educators, yet these teachers have often not been taught or learned how to become competent in this regard (Hayes \& Juarez, 2012; Howard, 2006; Ladson-Billings, 2006b). He defines cultural competence in the context of choice more so than skill, however, insisting that it is the "will and the ability to form authentic and effective relationships across difference" (Howard, 2006, p. 130). Teachers' apprehensiveness about cultural competency and their ability to positively impact nonWhite students aligns with concerns about the achievement gap between White students 
and Black students (Jackson, 2011). Further, White teachers who espouse colorblind racial ideologies may be instructionally ineffective in that their own experiences and understandings of race perhaps limit their ability to successfully influence and interact with Black and otherwise marginalized students (Johnson, 2002; Lewis, 2001; Milner, 2012).

Preparation of the preservice teacher. Asa Hilliard said, The knowledge to educate all children already exists. Because we have lived in a historically oppressive society, educational issues tend to be framed as technical issues, which denies their political original and meaning... There are no pedagogical barriers to teaching and learning when willing people are prepared and made available to children. (1995)

There may be no "pedagogical barriers to teaching and learning," but the peculiarities of race relations in American history entreat teachers to critically examine themselves to foster efficacy in multiracial schools (Howard, 2006; Hussar \& Bailey, 2013). According to the National Commission on Teaching and America's Future, "the single most important strategy for achieving America's educational goals [is] a blueprint for recruiting, preparing, and supporting excellent teachers in all of America's schools", (National Commission on Teaching and America's Future, 1996). Those responsible for instructing preservice teachers are as diverse as the collegians in their classrooms and should therefore scrutinize their own beliefs and practices so they might better understand and prepare their students (Cochran-Smith, 2003).

Preparing teachers for the PK-12 setting is particularly challenging (Milner, 2010). Education students enter teaching programs with a vast array of backgrounds, 
experiences, and needs, and their responses to curricula are influenced accordingly (Cochran-Smith, 1995). A toolbox of universal teaching strategies pales against "continual and systemic inquiry" (Cochran-Smith, 2003, p. 21) that involves teacher educators and preservice teachers in collaborative exploration of race and its connections to their work. To help them better embrace the "promising possibilities" that teachers will encounter in the school setting, preparation programs should consider increasing a focus on diversity. This includes hiring diverse faculty, addressing instructional needs of all students to encompass non-White and male students, and by emphasizing opportunity in the context of race (Milner, 2015). Further, teacher education programs that claim to focus on diversity are now commonplace, but these programs and their teacher educators should consider whether or not a social justice mission is truly being enacted and providing students with a foundation on which to grow as teaching professionals of diverse learners (Zeichner, 2006).

Professional development addressing race in the PK-12 setting. Professional Development is key to helping teachers gain confidence in adequately addressing the specific needs of their students. Instructional strategies should take into account the interplay of culture with "language and cognitions" to maximize student motivation and engagement (Jackson, 2011). Because the education labor force is largely White, the teacher who does not participate in sustained professional development which focuses on diversity in the classroom risks becoming a detriment to his or her students (Howard, 2006). For many teachers, studies in diversity involve unlearning our preconceived notions of race and culture through a process of inquiry (Cochran-Smith, 2003). This inquiry - even self-reflection as a means of questioning our practice and the educational 
structures in which we teach-is critical not only for teacher professional development, but also for avoiding placing blame on students who struggle to realize the academic success of non-marginalized students (Milner, 2015).

Teachers' perceptions about race/culture. In America, discussions about race are often politically charged and polarized around either a "liberal" or "conservative" view. This standpoint limits productive discourse and neglects to recognize that "Black people are neither additions to nor deflections from American life” (West, 2001, p. 2). Further, individuals who are not overtly racist in their behavior may have disassociated themselves from the issues of race (Singleton \& Linton, 2006). This is problematic in the school setting because educators may not know how to discuss race or tackle the associated achievement gaps. Ignoring these truths does not amend the outcome (Johnson, 2006).

Teachers who claim not to "see" race enact colorblind instructional practices which deny specific and key aspects of a student's being (Lewis, 2001; Milner, 2015). Rather than accepting racial aspects of a child's existence, the teacher, perhaps unknowingly, approaches instruction and learning activities with these students as though they are somehow lacking (Johnson, 2002). Colorblindness, then, is essentially a deficit ideology.

\section{Academic Performance of Students}

Race is a social construct (Frankenberg, 1993) and yet wide discrepancies exist on achievement measures between Black students and White students. Student achievement is perhaps most notably measured by performance on standardized tests. Disaggregated data specifies group performance based on various criteria, including race. 
The achievement gap between Black and White students lessened following court-mandated desegregation, and while some argue that related guidelines were responsible (Cook \& Evans, 2000; Grissmer, Flanagan, \& Williamson, 1998), others looked at school and community factors for reasoning (Chay, Guryan, \& Mazumder, 2009). Regardless, evidence shows that integrated learning environments provide a more comprehensive education for all students (Frankenberg \& Orfield, 2012; Mickelson \& Nkomo, 2012).

Racially consolidated schools have had limited impact on equitable educational opportunities and outcomes. Technical fixes have not rendered much success in removing or even diminishing the persistent achievement gap between racial subgroups. Schools blame cultural deficits, poverty, family deprivation, and poor neighborhoodswhich places the fault for poor performance outside of the education sector (Singleton \& Linton, 2006), and education is the only public sector in which professional development or other training not does not habitually accompany government mandates (Jackson, 2011; Noguera, 2003).

Opportunity gaps and questions of equity. Educational researcher Gloria Ladson-Billings (2006a) references an "education debt" concerning the historical and longstanding plight of African American students in this country. This debt encompasses many factors, or gaps, including economics and housing, healthcare and childcare, and teacher and curriculum quality (Irvine, 2010). The debt also takes into account the systems that influence education outcomes and does not solely fixate on the outcomes themselves. While Americans are "philosophically and ideologically" born into the "same opportunities for success," Black students have a collective history and individual 
experiences incongruent with those of their White counterparts, which ill affords them an equitable chance for academic success (Milner, 2012, p.704). This is clearly evidenced in the legal battles for equitable education throughout the course of American history. If teachers are to create meaningful, transformative learning experiences for their African American students, they must understand the interconnectedness of opportunity and economics, as well as the ways in which social context influences that opportunity (Milner, 2012).

Deficit ideology. A "worldview that explains and justifies outcome inequalities" while focusing on difference as a liability is a deficit ideology (Gorski, 2010, p. 3). Assumptions about student deficiencies may originate from personal experiences with particular groups, internalized prejudice, or by analyzing student achievement data absent considerations of the greater context (Milner, 2015). Students enveloped in the deficit ideologies of their teachers are believed to have less aptitude than non-marginalized classmates or, at minimum, are unsuccessful in school due to "poor homes, cultural handicaps, linguistic deficiencies, and deprived homes" (Arciniega, 1977, p. 12), but not through any fault of the school system. Left unexamined, these beliefs negatively impact instruction and facilitate systems of racial inequity (Howard, 2006; Singleton \& Linton, 2006).

Deficit mindsets about student aptitude and achievement espouse a meritocratic philosophy system and presume that effort and persistence are the necessary contributors to success. This ideology does not consider existing or historical opportunity gaps and may cause teachers to dilute instruction and lower expectations of marginalized students (Gay, 2010; Gorski, 2010; Milner 2012). When the focus is on the reality of difference 
and not the root causes of the socioeconomic and sociopolitical contexts associated with those differences, then deficit ideology facilitates systems that encourage the present state of affairs in education (Gorski, 2010; Ladson-Billings, 2006a)—one in which a chasm exists between the academic realities of White and Black students.

Schools are microcosms of the communities they serve (Brantlinger, 2003).

Failure to acknowledge the comprehensive backdrop impacting Black students in America has serious repercussions (Brandon, 2003; Valencia, 1997) and limits teachers' ability to effectively foster achievement:

So we cannot engage low-income and working class families equitably if we do not at least understand that these families are coming to us, in part, through the repression of this sociopolitical context. Nor can we identify and institutionalize effective strategies for dealing with the symptoms of these inequities which are in the purview of schools and their practitioners-low expectations, disproportionality, formulations of family involvement in ways that are not accessible to many low-income families - if we do not understand the ideologies and conditions that bare these symptoms. (Gorski, 2010, p. 9)

\section{Culturally-responsive teaching as an influence on achievement.}

Colorblindness is a stance of the privileged. In the classroom, avoiding race or culture may be a way to "justify inaction and perpetuat[e]...the status quo" (Banks, 2001, p. 12). Conversely, culturally responsive teaching is transformative. It addresses student identity in genuine ways and with increased rigor using cross-cultural strategies, and develops authentic relationships so that everyone, including the teacher, achieves to a higher degree (Howard, 2006). Fundamental to culturally-responsive teaching is acknowledging 
and accessing the "funds of knowledge" that exist within a diverse classroom (Moll \& Gonzalez, 2004; Ortiz \& Jani, 2010), and deeply engaging with students to really understand them in the construction of knowledge (Jackson, 2011; Ladson-Billings, 1999). These processes are relevant so as not to extrapolate biases onto students of color (Freire \& Freire, 2004) and to diminish ignorance and isolation of White teachers (Howard, 2006).

Culturally-responsive teaching positively impacts student achievement. It connects to the neural patterns that have been formed by culture, and culture influences our thinking and cognition (Ben-Hur \& Feuerstein, 2011; Wilson, 1978). Culture's leverage over cognition creates a "frame of reference through which we perceive the word" (Jackson, 2011, p. 90) and is important to student motivation and learning outcomes (Levine, Cooper, \& Hilliard, 2000).

\section{Theoretical Framework}

The roots of Whiteness run deep in American history. In 1790 the Naturalization Act defined citizenship, in part, as White capital, resolutely separating Black people"others"-from White Americans. In Sociology, Whiteness is described as "a set of characteristics and experiences that are attached to the white race and white skin" (Cole, 2018) and impels a perception of "otherness" to non-White racial groups (Cole, 2018; Fylkesnes, 2017). Whiteness, then, possesses a "property of meaning making" (Fylkesnes, 2017, p. 28) in education systems dominated by White teaching professionals, White administrators, and predominantly-White Boards of Education. (Johnson, 2006). Because the American teaching field is predominately White, it is logical for White teachers to suppose that "the culture and practice of schooling" that was 
effective for us will similarly benefit our students (Howard, 2006, p. 119) and to employ deficit ideologies when they do not.

Colorblindness as a racial ideology will be discussed later, but on a fundamental level, it invalidates racial identity and experiences by proclaiming an "I don't see race" stance or assuming "we are all the same." In this regard, Whiteness parallels those sentiments in that it assumes a "neutral" or even "invisible" identity and becomes normalized (Bissionnette, 2016; Fylkesnes, 2017).

\section{Race Neutrality and Colorblindness in Classroom Practice}

In his book about research techniques, Howard S. Becker suggests that "an excellent...way to enlarge the reach of a concept is to forget the name entirely and concentrate on the kind of collective activity that is taking place" (Becker, 1998, p. 144). Terms such as race neutrality and racial colorblindness may be unfamiliar to White teachers, especially those who have not questioned their beliefs about race, and I address this further in my positionality statement and later chapters. The "collective activity" and specific actions within these frameworks, however, may be familiar paths of least resistance (Johnson, 2006) to those same teachers. These include niceness, expectations of sameness, color-evasive mindsets, and meritocracy.

Concept of niceness. The quality of being nice is held in particularly high esteem in American culture (Bissionnette, 2016; Boorstin, 1982). For the purposes of this study, niceness stands apart from the usual connotations attached to being nice. Concerning race in the classroom, niceness allows educators to circumvent potentially tense, even confrontational topics such as race. While some teachers believe that niceness maintains a sense of peace both in the classroom and within themselves and 
therefore elevates the learning experiences in the classroom (Baptiste, 2008; Bissionnette, 2016), they are actually avoiding deep engagement (Glazier, 2003; Haviland, 2008) and furthering hegemonic ideals (Baptiste, 2008). Niceness, then, is a "superficial farce" (Asher, 2007, p. 65) which, intentional or not, allows teachers to falsely maintain a neutral learning environment.

Expectations of sameness. In education systems rife with standardization, expectations of sameness may become the norm. Teachers may espouse beliefs that children are all generally alike without considering or validating the unique backgrounds and experiences the students embody and bring to the learning environment (Causey, Thomas, \& Armento, 2000; Milner, 2012). This colorblind approach assumes that because all children are alike, well-written curricula with valid instruction and strong engagement should similarly benefit all students (Bonilla-Silva, 2013).

Color-evasive mindsets. Studies have shown that White teachers do not necessarily see the significance of race in the classroom especially when those classrooms are largely White (Lewis, 2001). Milner highlights three color-evasive mindsets that can disparage the social context in which students live and learn, all with serious repercussions to academic success. First, teachers may fear that if they overtly acknowledge race or ethnicity, they will be considered racist. Second, if teachers admit that race is globally important to a person's experiences, their stance might be deemed politically incorrect. And third, as in the concept of sameness, teachers may feel that racial considerations in instructional design are irrelevant in the classroom (Milner, 2015). 
Meritocracy. Meritocracy is the "myth" that through hard work and effort, anyone can achieve the American Dream (Milner, 2012; Randolph-McCree \& Pristoop, 2005) and overcome oppression and opportunity gaps (Causey et al., 2000). Meritocracy denies the existence of opportunity gaps and suggests that Americans are all born with the same potential for success. This philosophy is unwavering in that specific belief, and accepts no excuses for lack of achievement outside of negligible aptitude (Milner, 2010).

\section{Assimilation into Dominant Culture Norms}

The dominant culture has "meaning making" power (Fylkesnes, 2017) and sets norms. In most school districts, then, the power to influence norms resides with White teachers in the classroom. This can create antagonism when teacher and student mores do not align (Milner, 2010). Howard (2006) cautions,

One of the dilemmas of White dominance is that we are often blind to the negative impact that our imagined goodness and narrow sense of normalcy have on others who do not share the demographic advantages that have favored our group. (p. 120).

Dominant culture norms promote sameness by failing to validate the full context of our students' lives. This neglect allows teachers to "[project] onto them our own imagined assumptions and biases" (Freire \& Freire, 2004; Hale, 2004; Howard, 2006, p. 127) and has implications for student success.

\section{Cultural Deprivation}

Deprivation takes on many definitions in social science research. Lipton (1962) describes it this way: 
By our use of the word deprivation we are in a sense, manifesting a sense of superiority, a feeling of "why can't we help them become as well off as we," and other patterns of non-accepting attitudes which can't help but reflect in rejecting behavior patterns. (p. 18)

In schools across America, it is not only students who may be culturally deprived. White teachers who do not know their students and cling to colorblind and race-neutral approaches in the classroom, likewise, are culturally deprived — denied the rich tapestry offered by the diversity within the learning environment. Both groups have "something to share and something to put aside...something to learn and something to unlearn" (Austin, 1965, p. 68).

Students within a culturally nonresponsive classroom. Dr. Yvette Jackson (2011) writes about marginalized students who are not "steeped" in the Eurocentric culture and are therefore labeled as culturally "deprived" in schools where White educators determine the norms. Kozulin, Feuerstein, \& Feuerstein (2006) describe sociocultural deprivations as missing direct connections to one's own culture. Cultural deprivation here, then, reflects two parts. From the perspective of the dominant group, culturally deprived students lack the requisite "tools" to successfully understand and navigate the dominant culture (Lipton, 1962). When Black students are "disconnected" from their own cultures in a majority White learning environment, however, there is an interruption in the systems, rooted in culture, that increase motivation and encourage intellectual development (Noguera, 2003).

White teachers. Connected to the author's positionality and impetus for this particular study is the personal belief that when teachers operate with colorblind or race- 
neutral mindsets, we diminish the contributions in our classrooms and stifle maximum learning opportunities for all. Believing that in every classroom We are all students; We are all teachers, the referenced mindsets cause us to deny ourselves access to crosscultural learning experiences. Howard argues that "we may occupy the same physical space, but at the level of the heart we have been traveling in separate boats" (Howard, 2006, p. 79). Sharing of cross-cultural experiences and ways of knowing must transcend surface level fixes (Kerl, 2002; Solorzano \& Yosso, 2002) and allow us to truly "see" one another (Delpit, 2006).

\section{Colorblind Racial Ideology}

The tenets of Colorblind Racial Ideology provide the conceptual framework for this study and offer a context for understanding the responses of its participants. Racial ideology is defined as 'the broad racial frameworks, or 'grids,' that racial groups use to make sense of the world, to decide what is right or wrong, true or false, important or unimportant" (Bonilla-Silva, Lewis, \& Embrick, 2004, p. 556). Further, colorblindness is "a set of deeply held but unrecognized [racial] ideological tenets" (Hartmann et al., 2017, p. 866) regarding race. Sociologist Eduardo Bonilla-Silva (2013) describes colorblind racism [as] "the dominant racial ideology in post-Civil Rights America, and unlike its predecessor (Jim Crow racism), it is subtle, apparently nonracial, and avoids traditional racist discourse." A predominance of Americans today aligns with the principles of this ideology and often claim not to "see" race (Hartmann et al., 2017). As a result, social scientists have increasingly acknowledged the exigence of research in the area of colorblind racism (Burke, 2017). 
The disquietude linked to race in America causes race-related apprehension to remain masked (Farkas \& Johnson, 1999). This can be just as detrimental to marginal groups as the overt racism of the Jim Crow era (Dovidio 2001; Zou \& Dickter, 2013). Contemporary racial ideologies tend to be more subtle and deeply embedded in institutional practices; they avoid race-centered conversation; and are often imperceptible by those who espouse them (Bonilla-Silva, 1997; Dovidio, 2001). In this study Colorblind Racial Ideology frames beliefs about experiences within the school setting. It allows White teachers to consider potential impact of various ideals and the ways in which context matters (Hartmann et al., 2017). The four tenets of Colorblind Racial Ideology are abstract liberalism, naturalization of race-related matters, cultural racism, and minimization of racism, and each has specific characteristics and tendencies. The ideas represented in these tenets create hurdles to racial progress, often unbeknownst to those who embrace the ideologies (Hartmann et al., 2017).

Tenet One: Abstract Liberalism. Contemporary racism is often less overt than that evidenced during America's contentious racial past. Although influenced by history, politics, and economics, it is more sympathetic to social norms concerning explanations of racial matters and tends to manifest itself in ancillary ways (Dovidio 2001). Abstract Liberalism is the foundational precept of CBRI. Its views present as reasonable, even moral, while simultaneously challenging pragmatic strategies for addressing de facto discrimination (Bonilla-Silva, 2013). It is the first tenet of CBRI — an "explanatory well" used to rationalize the ongoing separateness of Black and White Americans in terms of opportunity and performance. Abstract Liberalism subscribes to a meritocratic mentality, resting on a foundation of equal opportunity for all —which, according to this mindset, 
should therefore preclude the need for such initiatives as affirmative action (BonillaSilva, 2013; Burke, 2017; Hartmann et al., 2017; Hughey, Embrick, \& Doane, 2015). In fact, within this ideal, such programs are believed to further divide America along racial lines (Bonilla-Silva et al., 2004). Additionally, abstract liberalists do not believe that effective change can be compelled through the courts; rather, that change is a gradual shift requiring time (Bonilla-Silva, 2013).

Tenet Two: Naturalization of Race-Related Matters. Once popularly believed to be rooted in biology, racial predilections and discriminatory practices such as segregation are instead social processes. Naturalization is a hegemonic concept in that it rationalizes the racial hierarchy. Those who embrace this ideal reason that people are drawn to those most like themselves (Bonilla-Silva, 2013). It becomes easy, then, to argue that America's continued reality of racial separateness is not borne of discriminatory systems but, rather, is in keeping with the natural order of things (BonillaSilva, 1997).

Tenet Three: Cultural Racism. This tenet refers to stereotyping especially common during the days of slavery and Jim Crow racism. It specifically focuses on cultural behaviors or practices linked to a given marginalized group and places the blame on its members for their social and economic circumstances. A European study by Pierre Andre Taguieff established that while biological characteristics did not themselves necessarily cause ostracism, certain cultural behaviors did (Taguieff, 2001). BonillaSilva describes a "racialization framework" and explains how stereotypes emerge and are legitimized. They may be rooted in a group's current societal realities or conditions, are perhaps borne of "genuine ignorance" about the faction, or emerge from stringent and 
skewed assumptions about race. When these stereotypes align with the group's position in society, the framework serves its ideological purpose (Bonilla-Silva, 1997). In the post-Civil Rights era, members of historically disenfranchised groups who are successful in spite of their stereotypes may be viewed as prodigious representations of their lot. Specific to this study, there are "exceptional" Black people who are successful despite historical discrimination against African Americans (Howard, 2006). Per this specific CBRI tenet, then, the problems experienced by "less exceptional" members of the group must be of their own doing and not the result of racism (Bonilla-Silva et al., 2004), and inequitable treatment of non-White groups no longer exists with any real significance in the United States as Civil Rights laws have effectively eradicated racial discrimination.

Tenet Four: Minimization of Racism. Minimization further encompasses the opinion that Black Americans are overly sensitive and perpetuate racial disconnect by playing the "race card" (Bonilla-Silva, 2013). This framework holds that racial discrimination is virtually non-existent (Ioanide, 2015) and is thus not a factor in the social positioning of Black people. According to the minimization viewpoint, minority groups should therefore not use America's history of segregation and discrimination as a crutch or an excuse for the current socioeconomic standing of Black people in this country (Bonilla-Silva, et al., 2004). They should instead take advantage of the opportunities available to everyone for mobility and success - a meritocratic ideal (Ioanide, 2015). Unlike the cultural racism of Tenet Three, minimization does not offer an explanation for the plight of Black Americans in comparison to the collective standing of their non-Black counterparts (Bonilla-Silva, 2013). Additionally, minimizers argue that "race should not and does not matter" (Neville, Lilly, Duran, Lee, \& Browne, 2000, 
p. 60) and assert there is no real correlation between a minority groups' experiences and their race (Neville, Spanierman, \& Doan, 2006).

\section{Summary}

America has a longstanding "issue" with race. Our tumultuous past has created an historical divide between Black people and White people in this country. Centuries of struggle to address equitable treatment and opportunity for all have borne progress in that regard - and yet racism and discrimination persist. The era of focused racial Civil Rights legislation has passed and yet equity remains elusive. Our education system continues to bear witness to the chasm in performance between Black students and White students.

In the next chapter I delineate methods for this qualitative inquiry. I used the tenets of Colorblind Racial Ideology_abstract liberalism, naturalization, cultural racism, and minimization - to inform my study and explore teachers' perceptions that might impact student achievement in the classroom. 


\section{Chapter 3: Research Design and Methodology}

Data show a seemingly imperturbable chasm in the academic performance of Black students and White students in American schools (Toldson, 2018). These gaps persist despite national mandates designed to ensure elevated achievement of all students - specifically, No Child Left Behind and its replacement, the Every Student Succeeds Act of 2015. Over the course of two decades in public school education, I have engaged in extensive professional development which, in part, has focused on increasing subgroup performance in the classroom and, most prominently, on statewide standardized tests. While training has consisted of instructional strategies and test item analysis, it has avoided the subject of race other than underscoring the iteration of performance gaps. Additionally, my experience has been that teachers are reluctant to discuss race beyond a context of benevolence or surface level fixes within instruction and assessment.

More recently, I have encountered classroom environments that promote equality versus equity, terms which are not identical in meaning or application. "Equality" suggests sameness while "equity" implies fairness relevant to individual circumstances (Corson, 2001). Because the pervasive achievement gap highlights notable performance deficits of a particular subgroup - in this study, African American students-it is important to examine the source of the inequality (Secada, 1989) and identify the needs and strengths of these students. This achievement discrepancy is a problem of practice that has not been adequately addressed by professional development. In the literature review, I attempted to provide historical context of racial segregation and discrimination, including inequity in educational opportunities, which has impacted generations of Black 
families in the United States. For this reason, I question how racial colorblindness within teachers impacts the learning environment and educational success of all students.

As I sought to understand teachers' perceptions concerning race and education, I used this study to explore a problem of practice — examining how teacher mindsets might impact pedagogy and achievement. This chapter outlines the research methodology for the study. I discuss the research paradigm and design which shaped this qualitative inquiry, providing background information on the research site and participants, sampling methods, and data collection instruments. I address ethical considerations pertinent to the research and detail the means of data analysis. Additionally, I highlight my own positionality and its influence on the study while detailing the ways in which I have ensured trustworthiness within the project.

\section{Purpose of the Study}

The intent of this qualitative inquiry was to explore teachers' perceptions about student achievement in classrooms with racially diverse populations-specifically the academic performance of Black students and White students and how race might be perceived as a factor in that performance. The study utilized the perspectives of White female teachers, a microcosm of the teaching monoculture in American schools. While the impact of the White teacher/Black student scenario cannot be fully ascertained and was not the focus here, the study sought to understand the role that a teacher's experiences and perspectives might have on pedagogy and instructional practices, which perhaps impact the teacher-student relationship and might ultimately affect student achievement outcomes. 


\section{Research Question}

The research question I sought to answer for this study was: What are White teachers' perceptions about race and the achievement gap between Black students and White students in a post-Civil Rights Era?

\section{Research Paradigm}

Qualitative research is positioned according to researcher beliefs about the nature of reality and knowledge (Hatch, 2002; Merriam, 2015). This study proceeded according to the constructivist view that "individuals construct reality in interaction with their social worlds" (Merriam, 2015, p. 24) and "experience the world from their own vantage points" (Hatch, 2002, p. 15). Additionally, the researcher's interpretation of teacher perspectives concerning the convergence of race and education was also a construction (Charmaz, 2006). While I am hopeful that the findings of this study will result in action steps to facilitate teacher reflection and to improve educational experiences and outcomes for all students — a goal indicative of the critical paradigm — perceptions must first be identified and meaning constructed before that can occur.

\section{Research Design}

Creswell (2009) describes qualitative study as a way of "understanding meaning ascribed to a social problem" (p. 4). This qualitative inquiry seeks to deeply understand a phenomenon relating to student achievement in American schools. The purpose of qualitative research is to explore perceptions of human behavior (Bogdan \& Biklen, 1992; Lincoln \& Guba, 1985) and understand ways in which those perceptions then influence action (Hatch, 2002). 


\section{Multiple Case Studies}

Merriam (1998) defines a case study as "an intensive, holistic description and analysis of a bounded phenomenon such as a program, an institution, a person, a process, or a social unit" (p. xiii). Case study research is a "qualitative approach in which the investigator explores a bounded system (a case) or multiple bounded systems (cases) (Creswell, 2013, p. 97). When the research transcends a single case, it safeguards against researcher bias by providing a diversity of experiences and viewpoints across a variety of cases (Meyer, 2001). The multiple case study design also helps further the understanding of a single-case finding (Miles \& Huberman, 1994). While there is no such single-case finding here from any existing study to be solidified by multiple case examination, the study did assume the presence of colorblind perspectives at the site based on existing researcher knowledge. Using that existing knowledge as an impetus for this project, multiple cases provided deeper insight into an array of perspectives which align with the tenets of Colorblind Racial Ideology.

Multiple case studies allow the researcher to provide numerous rich case descriptions and to analyze both within and across cases based on emerging themes (Merriam, 2015; Yin, 2009), strengthening the findings of the study (Baxter \& Jack, 2008). Because each individual brings her own experiences and perspectives to her professional practice, I chose to define a "case" as a single participant. Each participant has a unique story and perspective which contributes to, but does not solely define, the overarching vision of the school. Stake (1995) refers to multiple case studies as collective case studies, a descriptor which resonates with the communal aspect of teachers within schools. Each participant served a specific purpose in the purview of the 
inquiry (Yin, 1994), which aligns with the emphasis of qualitative research-discovery, meaning, and interpretation (Denzin \& Lincoln, 1994).

\section{Research Context and Sampling Procedures}

The research site was chosen as a matter of convenience. Branch Elementary $\operatorname{School}^{9}$ is a midwestern school serving approximately 400 students in Kindergarten through Grade Five. The school is one of eleven elementary schools situated in a small city with strong ties to government and tourism. The population is approximately $78 \%$ White and 17\% Black (U.S. Census Bureau, 2011), and the city’s public school student population of nearly 9,000 students mirrors these statistics. My reason for choosing this site for the study was twofold. First, I have direct experience with the teachers there and know that aspects of CBRI are present within the school. Second, I serve on my own district's professional development committee and have ongoing opportunities to contribute to decision-making processes that generate continuing education events for teachers within various school districts. Those events can be tailored to site-specific needs, providing flexibility for professional development across schools.

Qualitative inquiry seeks understanding of a social situation or behavior (Creswell, 2009) and therefore sampling procedures must be purposeful in order to ensure information richness (Meyer, 2001). Within this multiple case study design, I utilized two-tier sampling common in case study research. Two-tier sampling allows the researcher to refine the process for identifying participants using more than one layer for selection. It necessitates first generally identifying the case type (here, individual teacher

\footnotetext{
${ }^{9}$ The research site and all case study participants are identified here using pseudonyms for confidentiality purposes.
} 
participants) and then further sampling within the case (Merriam, 2015) or case typeselecting participants based on specific characteristics. I used an initial criterion-based selection in which the key participant attributes were identified and potential participants were selected (LeCompte \& Schensul, 2010). Initial eligibility required that participants be White and female. These characteristics were critical to the study because of racial classification, and also as they represent the predominant demographics of teachers in the United States.

There have been numerous staff changes at the research site and so additional purposeful sampling was used to further narrow the selection of participants. Purposeful sampling was critical to establish that participants were those from which the most insight could be gained (Merriam, 2015). Teachers were further "sifted" and chosen according to their teaching assignments. Participants were to be first through fifth grade regular education classroom teachers with a minimum of three years of teaching experience. These "traditional" classrooms necessitate that teachers spend the majority of each instructional day with the same group of students. With at least three years of teaching experience, the teachers in those classrooms have practical experience across several years to accompany their perceptions through a professional lens. Kindergarten teachers were not included in this study. Their students are new to the public school setting and have not yet acclimated to formal, structured classroom instruction, and so the kindergarten setting offers its own unique challenges. I opted to exclude special education teachers from participation in this study to rule out other biases associated with unique cognitive or physical needs. Similarly, I excluded art, music, and physical education teachers because of the atypical or varied modes of instruction and assessment 
in those classrooms. The sampling methods described in this study elicited robust data and in-depth understanding of the cases (Patton, 2002) and adequately addressed the research question. The number of individual cases studied at this site based on the aforementioned criteria was eight.

\section{Data Collection}

Data collection should be purposeful and strategic (Dey, 2003). I employed several procedures to ensure richness of detail and context from the data. Data collection sources included recorded and transcribed interview sessions, field notes from those same sessions, researcher journal and logs, and documents that provided demographic data specific to the research context.

\section{Interviews}

First, I conducted semi-structured interviews with participants, with each participant representing a bounded case. Semi-structured interviews include a mix of structured and open-ended questioning that is used with flexibility (Merriam, 2015) and allow the researcher to interact with participants on a purposeful conversational level pertinent to the study (deMarrais \& Lappan, 2003). Interviews as data collection tools are particularly valuable. They gather information about that which cannot be directly observed - thoughts and feelings, and the ways in which people perceive their world (Merriam, 2015). Table 3 highlights teacher demographics of those who were interviewed during this study. 


\section{Table 3}

Teacher Participant Demographic Data

\begin{tabular}{ccc}
\hline Participant & $\begin{array}{c}\text { Teaching Experience } \\
\text { in Years }\end{array}$ & Teaching Placement \\
\hline Susie & 6 & Grade 2 \\
Emily & 6 & Grade 2 \\
Lucy & 3 & Grade 4 \\
Joy & 5.5 & Grade 4 \\
Marie & 6 & Grade 5 \\
Tina & 10 & Grade 5 \\
Annie & 7 & Grade 3 \\
Ruth & 7 & Grade 4 \\
\hline
\end{tabular}

During interviews, participants shared attitudes, experiences, and perceptions about race in America and its connections to pedagogy and achievement outcomes, which were then analyzed using a framework of Colorblind Racial Ideology. While there is no prescribed number of participants to interview within the multiple case study design, Lincoln and Guba (1985) suggest sampling should be based on information considerations. Per the criteria set forth in the sampling discussion, the number of cases within this multiple case study was eight participants. Follow-up interviews were conducted as necessary to ask clarifying questions and gain additional insight into participant perspectives.

\section{Field Notes}

Comprehensive field notes are accepted as a key component of rigorous qualitative inquiry (Phillippi \& Lauderdale, 2018) and provide rich context for data analysis (Creswell, 2013; Patton, 2002). Field notes provided comprehensive details about participant behaviors and other observations during interviews (Merriam, 2015). These notes were critical to the data collection process in this study as they necessitated 
careful observation of the interview setting and interactions, and encouraged researcher reflection and identification of bias (Elo \& Kyngas, 2008; Emerson, Fretz, \& Shaw, 2011).

\section{Research Journal}

Throughout the project I maintained a research journal. Creswell (2009) notes that in so doing, "data analysis is conducted concurrently with gathering data, making interpretations, and writing reports" (p. 184). A journal further allows the researcher to bracket personal response or bias during data collection (Lincoln \& Guba, 1995).

Because I fit the criteria of a research participant for this study and acknowledging I have my own perceptions, experiences, and journey that led to an interest in studying racial colorblindness, it was important to set aside my own story or at least offer transparency concerning any personal connections during data collection and analysis.

\section{Human Subjects Protection}

There are three areas where ethical issues can arise: procedures outlined by Institutional Review Boards, situational concerns that emerge within the research setting, and relational factors associated with the researcher's role and influence in the relationship with participants (Tracy, 2013). To address these concerns I first obtained permission to research from the University of Missouri's Institutional Review Board and abided by its guidelines for ethical research to minimize any risk to participants. I then gained written permission from the Chief Learning Officer, a representative of the Superintendent's office within the school district, to conduct research at the elementary school. I outlined potential harm and the rights of participants on Informed Consent documents that were provided to participants for signature. Recognizing the researcher is 
a visitor in "private spaces" (Stake, 1995) and that in this study, those private spaces exist in the hearts and minds of the participating teachers, pseudonyms were used for the research site and all participants to ensure confidentiality.

\section{Data Analysis}

Creswell (2009) indicates that "case study involve[s] a detailed description of the setting or individual, followed by analysis of the data for themes or issues" (p. 184). I used several methods of data analysis during the course of this study. Given the multiple case study design, I conducted both within-case and across-case analyses and offered interpretations (Creswell, 2009). Each case within the study was first individually examined to reveal participant perspectives and their understanding of how experiences have influenced their views (Merriam, 2015), and these meanings were disclosed in case narratives, or analytical redescriptions. Coffey and Atkinson (1996) suggests "there are no formulae or recipes for the 'best' way to analyze the stories we elicit and collect" (p.80), and they count this as a strength.

Stories and narratives have a long history of being an instinctive way of making sense of the world around us (Jonassen \& Hernandez-Serrano, 2002). During interviews, detailed descriptions of teacher beliefs about race in education emerged. Within the constructivist paradigm, researchers work with interviewees to ensure understanding of the data, and through member checking, coconstruct understandings (Hatch, 2002). Descriptive case studies tell elaborate stories (Creswell, 2013; McLeod, 2015) and by using a narrative approach, the researcher "emphasizes contextualized knowledge and human intention....and takes into account the biological and environmental influences" (Rossiter, 1999, p. 35). Positioning myself as a storyteller versus an expert-and closely 
collaborating with the participants as they shared their perceptions-increased my understanding of the data (McLeod, 2015). Case descriptions thus involved a "restorying" process to delineate the views and experiences of participants (Ollenrenshaw \& Creswell, 2002) through analytic redescription (Mishler, 1995).

During the data analysis process, I applied aspects of the Constant Comparative Analysis Method championed by Glaser and Strauss (1967) in their work on developing grounded theory. The use of this method has since expanded beyond grounded theory and into other genres of qualitative study (Fram, 2013), and it supports the strong, reliable, and robust nature of multiple case study design (Baxter \& Jack, 2008). I first implemented single case coding and followed by cross-case coding to ascertain similarities and differences in data. By using constant comparative analysis, I was able to compare data systematically and repeatedly within and across all cases (Boeije, 2002; Glaser \& Strauss, 1967).

Interview transcripts and accompanying field notes were organized and coded according to emerging themes (Creswell, 2009). I transcribed all interviews myself. This process added value to my analysis and the ascription of meaning through a constructivist lens. During the process of listening and relistening to each interview multiple times in order to transcribe and ensure accuracy, I became deeply cognizant of the many facets and nuances of each participant's responses and developed insight into their perspectives (Chowdhury, n.d.; Yin, 2009). Even at the onset of data collection I began deconstructing data and sorting responses based on similarities and differencesdeveloping codes and reclassifying them as necessary during constant comparison and synthesis of data within and between interviews (Fram, 2013). 
I initially "fragmented" my data by "lifting" excerpts and organizing it using general, open coding (Saldana, 2016). This was a continual comparative process each time I added new data collected from individual participants (Boeije, 2002). As patterns emerged, I began to reclassify data using axial coding as connections between data became apparent (Saldana, 2016). Cross-case abstractions emerged from patterns in the data and are described in six themes: equal opportunities for all; correlation of achievement and effort; legitimization of race-based stereotypes; prodigious examples; oversensitivity to race; and race as a crutch. Further inspection of these themes led to alignment with three of Bonilla-Silva's four Colorblind Racial Ideology tenets: abstract liberalism, cultural racism, and minimization of racism. As each case offered insights into teacher viewpoints, the collection of stories created a more comprehensive picture (Bogda \& Biklen, 1992) of the onsite presence of CBRI.

\section{Researcher Positionality}

Reflectivity is critical in qualitative research and should always address the researcher's personal influence on the study. The aforementioned research journal served as a purposeful tool for eliciting and setting aside my own perspectives and biases as a White female teacher of diverse students. Even so, I share demographic characteristics with the study participants and have been through a process of reflection concerning colorblindness in my personal and professional lives. My own story is "interwoven" here, which Huber and Whelan (1999) deem permissible. To some degree, my teaching experience positioned me as a professional peer to the study participants-I am a part of the world I study—and so there exists an undeniable "teacher lens" within the researcher (Hatch, 2002). Hammersley and Atkinson (1983) state, "There is no way to escape the 
social world in order to study it; nor, fortunately, is that necessary" (p. 15). My

positionality as a White female elementary school teacher of diverse students added to, rather than detracted from, the study as shared contexts increased understanding and allowed me to gain confidence in my interpretations (Hatch, 2002). A personal interest in American history, coupled with race-based professional experiences, elucidates the focus on the Black/White binary in this study.

\section{Trustworthiness}

Trustworthiness is imperative in research involving practitioners who impact people's lives (Merriam, 2015). During the research process, knowledge that passes from participant to writer is at risk of losing authenticity. Trustworthiness, then, refers to the "ways of safeguarding the trip" (Stake, 2005, p. 455). This section details what Lincoln and Guba (1985) refer to as credibility, dependability, transferability, and confirmability in this multiple case study.

\section{Credibility}

Credibility speaks to the internal validity of a qualitative study. In this multiple case study, which rests on constructivist beliefs that knowledge is based on individuals' perceptions and experiences in the world, data does not stand alone but is coconstructed through an interpreter - the researcher (Ratcliffe, 1983). Participant perspectives gathered through interviews are more "real" or credible than if a "data collection instrument had been interjected between us and the participants" (Merriam, 2015, p. 244). To ensure credibility during the research process and when communicating the findings, I ensured accuracy of the interview transcripts through member checks, a process also known as respondent validation (Merriam, 2015), which lent credibility to the study. I 
also maintained ongoing dialog with participants during the data collection and restorying processes to ensure the descriptions match the reality of the data. Rich, thick descriptions in the form of case narratives "transport[ed] readers to the setting and g[ave] the discussion an element of shared experiences" (Creswell, 2009, pp. 191-192). Further, triangulation involves using multiple data sources "to build coherent justification for themes" and added to the validity of the data (Creswell, 2009, p. 191).

\section{Dependability}

Reliability is problematic in qualitative research because human behavior is variable and study results cannot be reproduced in absolute form (Merriam, 2015). Lincoln and Guba (1985) underscore that the inability to replicate findings does not invalidate the results of the study. Instead, dependability focuses on "consistency" and showing that data matches the interpretations by providing clear explanations at how the researcher arrived at the results (Dey, 1993). By studying multiple cases, I strengthened the validity of the findings - not because the data can be replicated, but because the procedures for data collection and analysis for each case were static (Merriam, 2015; Yin, 2009).

\section{Transferability}

Reflecting on the purpose of this study, it was important to me that the results have applicability for future use. Recognizing that each case represents the unique experiences and perceptions of an individual participant, transferability suggests ways in which findings can inform (Eisner, 1997) professional practice not only for the participants, but with implications for the teaching practices of others as well. Using maximal sampling - teachers in grades 2 through 5 at the research site with three or more 
years of teaching experience - expanded the range of data and increases the possibility of applicability in new contexts (Lincoln \& Guba, 1985; Patton, 2002).

\section{Confirmability}

I maintained confidentiality at all stages of the research process. All materials pertinent to my research - interview protocols, recordings, and transcripts, as well as my researcher journal, notes, and log — are securely stored in a locked location. Digital materials are password protected. These measures provide an audit trail and the secured materials can be used to corroborate the study at any time.

\section{Limitations}

The roots of racial discord, intolerance, and misunderstanding run deep in America. We have a unique history of race-based slavery - a long trail of explicit segregation and implicit separation between Black and White in this country. For these reasons, the subject of race and achievement provides seemingly endless avenues for study. This study was limited in following ways:

First and foremost, this study was constrained by the understandings and abilities of the researcher. It was not until my doctoral coursework that I developed a curiosity about this subject - about the ways in which teachers "see" or "don't see" race, and the impact their vision might have on teacher-student relationships and learning outcomes. Gary Howard (2006) said, "Honesty begins for Whites when we learn to question our own assumptions and acknowledge the limitations of our culturally conditioned perceptions of truth" (p. 73). For me, what has followed is a journey of personal discovery and professional growth. The path continues to stretch far ahead of me. Even so, I have tried to give due diligence to this project as a researcher and as a learner. 
Study participants had no more than ten years of individual teaching experience from which to offer their perspectives. While participants had limited years of professional experience, they were also less removed from teacher preparation programs as compared to more experienced teachers within Agency School District. Thus, these participants provided insight into recent teacher preparatory practices under the umbrella of diversity training and coursework. Additionally, all participant backgrounds were selfreported as from small, rural communities. The study is therefore framed by that demographic. All participants, however, attended either a mid to large-sized State university, an Historically Black College or University (HBCU), or both. These college campuses provided exposure to and experiences with diversity for all eight participants.

Data was collected at a single site and did not include perspectives from Kindergarten teachers, Special Education teachers, or Art, Music, or P.E. teachers. A detailed explanation for participant selection is found in the methodology section of this study. Should equity training or other diversity-related professional development be provided at Branch Elementary or within the broader school district, it will be critical to consider the needs of all staff members regardless of teaching position or other assignments.

This study was conducted over the course of a semester and each participant provided data during a single interview setting, barring any follow-up questions for clarity. Time constraints created boundaries around the discussions with participants. Given the expressions of CBRI, as well as the professional development needs and wants identified at Branch Elementary, it is essential for candid and courageous conversations to be prioritized and ongoing if universal growth among staff is to occur. 
Finally, this study proceeded with constructivist paradigm assumptions that "subjective meanings are negotiated socially and historically. They are not simply imprinted on individuals but are formed through interaction with others... and through historical and cultural norms that operate in individuals' lives”' (Creswell, 2009, p. 8). I collected and analyzed participant perceptions about race and performance, and to those findings I ascribed meaning. In that regard, this study achieved its goal. It did not, however, result in action steps for change - indicative of the critical paradigm - as the urgency here was to identify perceptions and construct meaning from them. Heightened awareness and understandings of a problem of practice that impacts student achievement should result from this study, thereby informing the instructional practices of the teachers within this project. It is my hope and recommendation that the findings will facilitate much-needed conversation at Branch Elementary and beyond, and that intentional action steps developed by the district will follow.

\section{Summary}

Academic performance of African American students is consistently lower than White students in the United States. Despite federal mandates to improve student achievement, gaps persist. Professional development of teachers frequently offers surface level fixes relating to instructional strategies or programs, but does not address the underlying and longstanding pangs associated with racial segregation and discrimination in this country which continues to impact minority students today. By exploring the perspectives and experiences of White female teachers with regard to race, the study sought to understand how pedagogy and instructional practices might impact teacher-student interactions and, ultimately, student academic success. 


\section{Chapter 4: Findings}

The purpose of this qualitative, multi case study was to explore a problem of practice through the lens of the White female teacher-to understand perceptions about the impact of race on achievement. The goal was to facilitate candid conversations about race and question how colorblindness impacts the learning environment — to identify perceptions and then construct meaning using Bonilla-Silva's four tenets of Colorblind Racial Ideology as a framework. One research question guided this study: What are White teachers' perceptions about race and the achievement gap between Black students and White students in a post-Civil Rights Era? Eight teachers participated in this study. They represent 49 years of combined teaching experience-all but twelve of those years at Branch Elementary - ranging from three to ten years of experience individually. Participant stories were constructed from individual interview transcripts and accompanying field notes. To remove potential biases from the following participant narratives, I bracketed my personal responses in a research journal both during and after data collection.

In this chapter I first present the stories of each participant through her own voice. The iteration of these stories provides insight into the unique individual perceptions and allows for single case analysis (Creswell, 2009; Yin, 2009). I then discuss overarching and emerging themes found across the stories en masse. These themes provide strong and reliable abstractions across cases (Baxter \& Jack, 2008; Yin, 2009), unambiguously articulating the onsite presence of Colorblind Racial Ideology at Branch Elementary. 


\section{Participant Stories}

\section{Susie}

Susie grew up in a small town with no stoplights and no city government. The area was largely rural and it was necessary for her to drive many miles between home and school. The population in her hometown was almost exclusively White, with the exception of a small number of low income Latinx factory workers. Socioeconomics in the area ranged from low to high. Many of the more expensive homes there were actually second homes whose owners lived elsewhere. These were vacation homes, as the area was in close proximity to a prime tourist spot.

Susie has had little interaction with African Americans. Her hometown lacked racial diversity save for the few Latinx laborers. She was limited to a singular and notable exception of exposure to Black kids growing up. There was a local Boys' Home that took in wayward youth. Susie described two Black boys from the Home who "were there for being in trouble" and so were at the Home "to be fixed." They attended school with her for a year and then left, returning to the larger cities from which they had come. Susie attended a large, diverse State college but had few African American friends because there "weren't a lot of them there." As an adult, Susie's social group consists solely of White people, a fact she attributes to her chosen profession and current place of employment—-both of which are predominantly White.

Susie believes the extent of equitable opportunities for Black people and White people is dependent upon where they live. She grew up poor and has encountered Black families that were much wealthier than hers; Black children whose parents provided things for them that hers could not. When it was time for her to apply for college 
scholarships, she believes she was denied access to certain monies because she is White. This still troubles Susie and she feels as though she has experienced "reverse" racism: "I remember getting frustrated to hear about the scholarships that were available in college and I was like, 'Gosh, because of the color of my skin I don't get them?,' and it was like reversed." She questions why racial classification is important and suspects the purpose is to fill minority quotas at the collegiate level. Even as a public school professional, she ponders the necessity of racially classifying students and wonders if Black families use their race to get a "leg up." Similarly, Susie laments that employers are sometimes "forced" to hire Black candidates and notes "that's the part that is hard for a White person to swallow, because really, it's supposed to be about 'Don't judge me by the color of my skin. Judge me by the content of my character."

As an adult living in a different town from that in which she was raised, Susie's socioeconomic status has greatly improved. She now has greater exposure to African Americans as well. In her town she sees noticeable housing differences along color lines, indicating some of the variation is a result of cyclical learned helplessness; values and principles that are lacking in hard work and motivation. She has researched this subject and discovered that learned helplessness is a "real thing," even though some people argue otherwise. Many local African American families are experiencing low rates of success and achievement because generations ago, family members "failed out" of collegespecifically an HBCU in the area - and got "stuck" in that part of town. She indicates this failure has thwarted the families' future progress and the data supporting this is very strong. Given the implied strength of the data, she feels many White people with racist ideations are not going to change their minds about Black stereotypes because "it's really 
hard to get around that mindset, and honestly, it's hard to get around the data because that data is so strong that in some areas you can't change it, you know, the way that people feel about it, and so it's hard."

Susie points out that while it can happen to any ethnicity, "statistics show that African Americans have a higher rate of unemployment. They have a higher rate of violence"- in any city, not just the one in which she currently lives. She laments these truths because although 'it's not all of them, [but] it's a huge chunk, which [is] a misrepresentation for a lot of families that are trying their best and working really hard to change that"- to overcome the stigma associated with race. Additionally, as a teacher she makes specific assumptions about incoming students from a different part of town. I will say that there is a specific school in this town that if a kid comes from that school I'm going to guess that they're going to be African American, and I'm going to guess that the income is low and I'm going to guess that their achievement is low. And that's just a preconceived notion and it's data. And I think that's almost causing me to have feelings toward... because of what I've experienced so far from that one school. All three things line up. African American. Low income. Troubled. Whatever it may be, there's going to be some issues there.

In the classroom, Susie sometimes feels she must "bite her tongue" during curricular objectives like the study of Martin Luther King, Jr. She is concerned about teaching racially sensitive topics such as civil rights issues or slavery. Her unease is that African American kids who do not know about Black history might have hurt feelings. 
While she believes it is important to discuss our shared American history, even if the truths are ugly, she does not want to upset Black kids who may not know about the past: You know, when Martin Luther King, Jr. comes around and I just want to, there are things that I want to say but I don't want to upset the African American kids in there that don't know about that. Or that could really hurt, you know, if they don't know anything about it. I don't want to go so far as to say, "Yes, people hated you," because that's hard to take. And I can't imagine being that, in that situation. And I feel like I have to bite my tongue somewhat even though I really shouldn't.

It is also uncomfortable for her when, during these lessons, students suddenly realize that in a different era, certain classmates could have been slaves. She describes those instances as a "weird back and forth" of kids' noticing everyone's skin colors and not necessarily being sensitive. Susie worries that her students will go home and tell their parents about the racial discussions in the classroom and it then "turning into this big deal that it didn't need to be." She believes that would be unfortunate for those African American families who have worked really hard to overcome the stigma attached to their race. Another reason for her discomfort relates to a time when she witnessed what she described as oversensitivity to race by a Black father in the school. The man felt his daughter had not received an award at an assembly simply because she was Black. The child was new to the school and so the father was not aware that other African American children in the class had received awards at previous assemblies. Susie described a "horrifying" scene in which the angry father yelled and "backed a teacher into the corner." Because the teachers at the school are all White, she said they could not yell 
back. She expressed confusion about why the father would "go that route with it," meaning to blame race for the incident. Even so, Susie believes as a society we have come far even in the last ten years when it comes to racial issues.

Susie has not participated in professional development (PD) addressing race during her seven years of teaching. The school district has not offered any. She appears conflicted about whether or not such PD is something that would benefit her teaching practice and thinks perhaps parents would be upset if race became a PD focus. The idea of it makes her very nervous. Professional development centered around race and student success is not "super important" to her because she "just hasn't experienced issues" with it. She did have a cultural "tolerance" class in college that focused on "tolerating people that are not like you," and her practicum placements were in racially diverse settings. Susie says she wants to build community in her classroom and acknowledging or addressing race in the classroom might diminish that goal.

\section{Emily}

Emily grew up in a very rural farming community of predominantly White, middle-class Catholics. She had virtually no exposure to other races growing up, with the exception of one mixed-race family that lived in the area for only a brief time. It was not until college that she had opportunities to socialize with people of other races, a fact she considers unfortunate. As an adult she developed some friendships with African Americans, although these friends have since moved away. One of those friends was a bridesmaid in her wedding. Because some family and community members held racist views, Emily was greatly concerned about how her friend would be treated at the time of the wedding festivities. 
Emily acknowledges her own privilege concerning education and employment and recognizes that non-Whites have struggles that she has not had to endure because of her skin color. While her parents taught her that all people are equal, she admittedly held some preconceived notions in the past that were developed from the hearsay of others. These ideations prompted her to take extra personal safety precautions when first arriving to the HBCU where she attended college.

I remember going into it and thinking I was, I was nervous. I was kind of scared because when you don't, when you're not around other races and stuff, you hear, I feel like sometimes you hear the bad and so you go in thinking, "Okay, well I need to make sure I lock my car because somebody might break into it," or, "I need to make sure that I'm walking with someone if it's dark outside," you know, and that kind of thing. And that's just a stigma that was just, I grew up and that's what I heard and that's all I knew, and so it took me awhile to get used to the fact that, you know... My parents always taught me that everybody's the same no matter what, but you know, you hear things at school and you hear things elsewhere and it was scary.

In a short time, Emily became comfortable with the racial diversity on campus and counts her experiences there with non-Whites as valuable.

Emily connects cyclical poverty and drug use to lessened success or achievement but does not think these factors are defined by race. Regardless of skin color, people impacted by poverty or drug use do not always have many opportunities to break the cycle. She acknowledges this can be especially difficult on African American families due to an existing opportunity gap between Black people and White people. She wonders 
if performance gaps are the result of being "born into a certain situation," since for a "vast majority of people, they're left there and that's just what they know and the cycle continues." She connects this "cycle" to bigger cities "where there's more of a population of African American families that probably experience poverty," but isn't sure how to otherwise explain achievement discrepancies between Black students and White students. Emily also notes the media is biased against the Black community, highlighting negative aspects more so than in the White community, and this can make "breaking the cycle" even more problematic for non-Whites.

Beyond the minimal required diversity coursework in college, Emily has had no district-provided or other professional development focused on race or diversity in the six years of her teaching career. She counts the time she spent studying at the HBCU as positive, believing it provided her with much-needed exposure to, and experiences with, people of color-both of which she acknowledges are important for teachers to have. Diversity is something she deems valuable in her classroom and yet she feels ill-prepared to address it. A great sense of anxiety overcomes her when she considers any focus on race in the classroom as she worries about responding inappropriately, or perhaps offending someone.

I would say that I...I try really hard to be very understanding and all that stuff but I do find myself kind of tiptoeing a little bit because I don't want to offend anybody and I don't want to say or do the wrong thing, because I know that it's wrong. I just don't know how to react to certain situations with families and things like that. 
Her apprehension could admittedly impede the progress of her students if she is reticent to push them to their full potential for fear of backlash. Emily strongly feels

if I knew how to deal with certain situations appropriately and feel confident, then I feel like I could better serve the students who may be a little different. And that may not necessarily mean race. That might mean other things too.

She has been called a racist before by a parent who was unhappy about a class assignment and that experience has further heightened her concern.

I was actually called a racist one year whenever I had asked a certain student to do something I had asked of any other student in my classroom and that wasn't well perceived at home and so [the mom] called me a racist... And so I feel like sometimes maybe people like me who might worry and who might not respond to certain things, I don't know, like maybe I don't push some of my students hard enough because I'm worried.

Greater than her nervousness about being called a racist is her fear of actually being one. Emily does not want to espouse racist views and would like to develop confidence in building relationships across racial lines to better partner with parents and effectively serve her students.

\section{Lucy}

Lucy's hometown is small and rural; a farming community. As a child she had virtually no exposure to non-Whites except for a Black student who attended her school during her senior year. She never really had opinions "either way" about Black people but also did not know anything about them. Growing up, she was "sheltered" in terms of racial interactions and so as a teacher, she strives to provide her students with more 
experiences than those of her own "White childhood," wanting to offer them a "more rounded background" than she had.

There were two significant periods in Lucy's life in which she was "awakened" regarding race. The first occurred when she attended an HBCU for her undergraduate studies. The diversity she found there was initially shocking to her but soon became a comfortable norm. She questions if Black children feel a similar shock when they are in classrooms that are majority White.

I went to a predominantly Black college, and so going from my [K12] school up to [the HBCU] was a huge difference coming in. So that impacted my life because I was then able to interact with not only African Americans but, like, Chinese and all the different backgrounds...Hispanics. I was never around them and so I got to learn a lot about their backgrounds and stuff.

Lucy's second "awakening" centers around a current friendship she has developed with an African American female, the girlfriend of one of her best friends. She has "opened her eyes" during this friendship and believes emphatically that race is not a barrier to greatness. Lucy describes this Black female as a best friend.

I think they [Black people] just face a different challenge up to a point because of their skin color, but I've definitely opened my eyes recently because one of my best friends started dating an African American girl and she is literally my best friend now... I feel like sometimes when we go out in public, though, people will be like, "Oh, Lucy's with an African American." But it doesn't affect me because I'm like, “She's a great person.” It doesn't affect your personality.

Lucy believes society has made much progress with regard to race relations since 
the Civil Rights Era. She has seen "both highs and lows education-wise" with the African American students in her classroom and doesn't really see "gaps" in this regard. Behavior issues are where she notes differences and she indicates they seem to arise more from her Black students. "Sometimes I see a lot of behaviors. Several of my troublemakers have been African American, but not all of them have been." Lucy indicated she does not know why this happens. "I've thought about it...maybe home life a little bit? How they're growing up?"

During her teacher preparation program, Lucy had one diversity course and has had no district-supported [or other] PD. She feels it is important for teachers to have professional development on the topic of race even if they had exposure to it in college. Although she did not feel comfortable with matters of race during her first two years of teaching, she does feel better about it now. Still, it remains an admittedly touchy subject. She feels somewhat better now about racial matters in part due to the relationships she has built with African American students_-she has heard "their side of things." Lucy is concerned that if we do not have PD on diversity issues, we will not be able to best meet the needs of our students.

\section{Joy}

Joy is from a small town with a population that is socioeconomically middle to upper class. The area is predominantly White, as was the high school she attended. Athletics gave her some exposure to other cultures and races but more so in connection to her siblings' basketball experiences. Her own sports affiliations — cheerleading and figure skating — had less racial diversity. Her next door neighbors were African 
American and while her exposure to diversity was extremely limited, it surpassed that of her peers.

Joy's current social group consists of White individuals, which she attributes to her background and familiarity with White people. The diversity she experienced at a large State university, though, she counts as a benefit. Early in her college career she was granted an internship with a major international company and lived with racially and ethnically diverse interns from around the world for two semesters. This experience fueled an interest in celebrating diversity in her classroom. "Unfortunately" mostly White women go into teaching and therefore schools lack diverse teacher candidates. Her own teacher preparation program was intentional in its coursework, believing in the importance of preparing teacher candidates for racially and culturally diverse educational settings. She stated

They definitely put an emphasis on it and they thought that was an important aspect of our education program...how to integrate that within teaching. And the other [educational experiences were] more like working with cultures and races that we're not familiar with and how their traditions and their spoken words and different things are different than ours and how to interact with that.

Joy admits college studies cannot replace actual experiences, however, and her workrelated professional development is lacking in this area-which she deems problematic. She thinks "it's important to have those conversations and to have PD on it so people feel more comfortable about it. Especially in our society today where race is very, it's an issue. That's evident in our society." She looks for opportunities to make curricular 
connections to diversity and invites discussion with her students. Even so, race is really an "uncomfortable" topic for her to navigate.

Joy insists that "as a White person, I have benefits" and sees opportunity gaps between Black people and White people_-gaps borne of American history and African Americans' denied access to education.

White people in general have, just forever, since we were here, we've kind of, "taken over" is probably not the right word, but we've kind of put ourselves first. And so, yes, I think that White people usually have a leg up in social or financial situations and things like that just because of the history, of everything.

She further notes "the ability is there for everyone to perform at the same level" but sees a connection between economics and performance, "because again, if you go back to the beginning of America, African Americans and people of color have not had as many opportunities to be educated." She feels the value that families place on education to "break the cycle" is critical, yet acknowledges some Black families have adults who are working multiple jobs out of necessity. In such circumstances, a family's effort to meet basic needs is paramount and so, understandably, greater value is placed on employment obligations over education. As a result, Joy does see connections between race and success, but underscores that this connection is in no way indicative of ability. She believes everyone has the same abilities even if they do not have equal opportunities.

Race has not significantly impacted Joy's life and she counts this among her privileges as a White woman. She sees stigma attached to race in society and has witnessed the impact this has had on non-Whites. The idea that we are "not to see race" is a misconception in her opinion. Difference is obvious and she does not shy away from 
race-related issues in the classroom. Aside from her college experiences, she has not been provided any race-related PD or training and has only participated in limited collaborative conversations related to subgroup achievement on standardized tests. She does not feel she has been adequately trained to navigate race-related matters in her teaching practice and welcomes opportunities for further professional development.

\section{Marie}

Marie is from a small farm town and had limited exposure to non-Whites in her formative years. Socioeconomically, the population in her hometown ranged from homeless to wealthy business owners. She interacted with other races during sports events at which diverse members of other teams were present. In high school she moved to a larger town and had more contact with other races there. The transition was a seamless one for her, and non-Whites were included as part of her social group. She later attended college at a State university on a diverse campus and describes her interactions with those of other races as positive. It was not uncommon for her to reach across racial and gender lines to form study partnerships. One such relationship involved a "large Black football player," who might have proved intimidating to other "small White girls" like herself. She described this memory with sarcasm, in a tone of voice that mocked stereotypes to which she does not subscribe. Marie considered this classmate and study partner to be her friend.

Marie is very blunt about her privilege and the opportunities and experiences she has been privy to as a White person. She sees many similarities between her background and those of her White students. Even though some Americans would assert that we [Black/White] are all on a level playing field, she strongly disagrees. Despite making 
some progress since the Civil Right era, this is still very much "White America" and "White male everything." Marie says she was raised with an open mind and heart and is dismayed that Black people have not benefited from the opportunities, experiences, and education that White people have enjoyed.

Marie regards lack of opportunities and centuries of denied access to education as contributing factors to a cycle of poverty and low achievement for some African Americans. Through no fault of their own, life has been harder on them because they have been denied the privileges inherent in White America.

I feel that White people such as myself are very privileged and we are, we have access to more experiences than a lot of other backgrounds. Being a teacher and seeing White students with backgrounds that are very similar to mine versus Hispanic and my Black students, most of which have come from very poor backgrounds; not a lot of family support, not a lot of education. They don't get as much experience and exposure to things that I did growing up... It seems that families that are Black, they don't have as, a lot of times as good of an education as White people were given; may not have had, like I said, the same opportunities or experiences to grow from.

Certainly, this cycle can be broken and unquestionably there are successful Black people, but Marie sees race as a barrier to success and opportunities. It infuriates her that many employers would likely not interview Black candidates for certain jobs if they were not legally mandated to do so. 
Marie is reflective about the persistent achievement gap between Black students and White students given that teachers instruct all students—Black and White—using the same materials within the same curricular framework.

It depends so much on each individual family and situation. One of the things I question....is do we see or do we feel that the opportunities are equal? I mean, we like to say it's all equal because here it is-we're all in school together. We're doing the same curriculum. But do we really feel like it's equal? And maybe that's not a question of what we're doing in the classroom. Maybe it's a question of, do we feel like opportunities just as a whole, are they equal? Because all of it seems to have some sort of impact on education, employment, [and] socioeconomics. I'm kind of questioning things.

Because some students come to school with "a lot of baggage," it is important to build relationships and have an open mind and heart, and to meet all students with acceptance. She relayed a story of one particular African American student and as she did, she became emotional. This child was enduring adult-like stress-long hours involving school, work (even though he was far too young to be legally employed), extra responsibilities at home, and extreme exhaustion. Marie forged a relationship with the child and his mother and sought assistance on their behalf. The mother was grateful and appreciated that Marie wants the best for her child. Conversely, Marie notes that many White families and students display a sense of entitlement and act as though they are beyond reproach.

Marie describes her feelings about acknowledging or addressing race in the classroom as "wishy washy." Even though she insists she has an open heart and mind, 
she does not feel she has been properly trained on matters of race. Like other interviewees, she has had minimal coursework related to diversity and no work-related PD on the topic. She is interested in participating in such PD but has not sought it out, largely because the district mandates so many other types of PD that she forgets to think about it. Beyond professional development, she wishes the district would incorporate more culturally relevant curricular activities and not continue to perpetuate "superhero myths" about White people like Christopher Columbus. She would like to see "more awareness, more understanding, [and] more acknowledgement" in her district in an effort to let Black children know, "You are seen. You are heard."

\section{Tina}

Tina was raised in a very small farming community and only one Black family lived in the town. She attended a Catholic school where middle class White kids were enrolled. The public school kids with whom she rode the bus were of a lower socioeconomic status than her Catholic school peers. As a child, Tina's parents fostered children in their home. Two were African American. Tina felt close to those Black children and considered them her siblings. Her parents were interested in adopting a young African American child who had been in their care since birth. The Black family in town advised against the adoption, suggesting it would be unfair to the child to raise her as the sole minority in an all-White town. Currently Tina's social group is all White although she has a few African American friends. She does not socialize with her Black friends, however.

Tina sees prejudice and disadvantages experienced by non-Whites, but also believes that in today's society, opportunities are the same for everyone, regardless of 
race. Prejudice can be aimed at White people too, however-“you know, someone that's not White feeling like they are entitled to things and therefore putting the prejudice against White people, or whether it's White people who put the prejudice against other people." She feels that those who do not agree that reverse racism exists stand as "barriers to progress." According to Tina, there is no real connection to race and achievement because success is equal to the effort you put forth. Race was a big factor historically and some people "didn't stand a chance because of their ancestors." Now there are "super high achieving" Black students, though, and America has even elected its first Black President. Concerning school achievement and Black students, she believes a lot of it comes down to the family the kids come from. Like, do they help? Do they step in and help their child with learning? Because we can't do it all. We can try, and we can try, but we can't do it all. So, you know, is their family actually supporting them and helping them?

She states that in her experience, the Indian families are typically overachievers and White families go "both ways," which is also true of African American families—-some are "willing to go the extra mile and others, not." Typically she has "a higher percentage of African American families [in her classroom] that don't."

More so than race, Tina feels socioeconomic status is significant to achievement and success. She believes that despite any disadvantages facing African Americans, some families choose to "push past it" regardless of how difficult it may be and "won't let race hold them back." Others "are holding on to, "Well, there was segregation and we didn't have any opportunity'... and that's why [we] work at a gas station because [we] didn't get a scholarship." 
Tina attended an HBCU and felt like she got "looks" as the "White chick" on campus. She indicated that Black students attend the HBCU simply because it is a Black college and they receive scholarships to go there; "because they're Black and they got a full ride to school because [it] is a Black college." She is proud that she, too, was given a full-ride scholarship to the school. Like other participants, Tina's cultural diversity coursework in college was limited and her work-related professional development on the subject is nil. When discussing PD, Tina feels that learning about other cultural backgrounds would be helpful. The skills she has developed regarding race-related matters in the classroom have all been of her own accord.

Tina is bothered when students bring up race in the classroom and she "shuts this talk down immediately," telling students they "don't get to bring that forward in the classroom." Tina doesn't like to address things based on race in the classroom because she "doesn't see race." If the adults in the classroom address race, then the students will think it is okay to do so as well. Race "comes up" when she teaches certain Social Studies history objectives and it always makes her nervous because of comments the students make. The African American students say things like, "Those are my people and that's what I suffered through." They "step into the role of their ancestors" and she prefers that the classroom climate remain neutral.

\section{Annie}

Annie was raised in a small, middle-class town of about 4,000 people and there was little poverty. The racial makeup was mostly White or Latinx. Her family was affluent and she acknowledges the privileges that accompany her status—she had many opportunities and experiences growing up that others did not. Her only exposure to 
African Americans involved a few girls on her basketball team. She had more exposure to diversity in college but it was not until she became a teacher that she saw opportunity gaps between Black students and White students. These gaps she attributes to socioeconomic standing and not race, however. Her current social group is all White, although she has dated Black men.

Annie feels race plays a huge role in today's society, although it has not personally affected her and she has not "taken a stand" on racial issues. She does believe that some people "play the race card" and tend to attribute things to race "when race isn't really the issue." Although she knows it happens, she has not personally witnessed anyone being treated differently because of race. Sometimes Black people have less opportunities, but there are Black people who have great opportunities as well.

Annie had some cultural diversity coursework in college and in her Master's program, both occurring at the same large State university. Her work-related professional development on the subject has been non-existent for the duration of her seven-year teaching career. She has completed some race-related reading on her own because of her interests (e.g. the Civil Rights Movement and MLK, Jr.) but has not been provided any training in the two school districts in which she has taught. During one particular class in college, a Black female professor repeatedly stereotyped her all-White class of female students.

It was a Black teacher, and she, I mean, she had all White students and, definitely I wasn't the only one because a lot of my classmates thought this, but it felt like, she did treat us like, "You guys are all just affluent White women who have had everything handed to you. Your parents are probably paying for your schooling." 
And so she did treat us like that. [We were] stereotyped as White women who were being teachers, like, "You guys just come into this because it's easy." Those kind of comments, and so, I don't know, that felt...like obvious difference. This made Annie very uncomfortable, and yet now she wonders if perhaps the professor wanted the students to experience what their own minority students might someday feel in the classroom setting — classrooms in which the White teacher is racially and culturally different than them.

Annie is a reflective practitioner who often ponders the difference she encounters in her classroom. She is adamant that she does not want to be ignorant or oblivious. She does not shy away from conversations about culture or race and lets her genuine interest in traditions, behaviors, and observed practices act as a tool for building relationships with students. Annie underscores her belief that building relationships is critical to helping children succeed. She believes all students have the same opportunities in public school since they are "all being taught the same thing." Problems related to student achievement might stem from "what's going on at home." During the pre-Civil Rights era, education "was not a focus" in Black families but she does not see race as a limitation, believing that all students have the same abilities regardless of skin color. Still, she says she doesn't "know why that [achievement disparities] happens. I mean, I don't know if I've ever thought about that."

Annie lets her natural curiosity about her students guide conversation and aid in building connections. She is open to classroom discussion about sensitive race-related topics - although she does not know the best way to handle the "N word" if it comes up in class. She acknowledges she can never share some of the same experiences with 
certain students because of her own privilege as a middle class White woman. For this reason, she feels she may not be the best person to speak about certain subjects since she "sees things through [her] lens," which is different than those of her students.

\section{Ruth}

Ruth grew up in a small town with a population of less than 1,000 . The area is middle to upper class and largely Catholic. She attended an all-White parochial elementary school and a high school with only one or two Black students. As a child she would see Black children playing at the public school near her Catholic school and assumed "all the Black kids" went to public school. In high school she witnessed White students making racist remarks about the few Black kids who attended there. The Black students "handled it very well" though. They were talented athletes and so Ruth believes that helped their social standing in the school. Unlike Ruth, her father attended school in a more racially diverse setting. She feels his experiences benefited the family. Her hometown was "racist" but because of her father's early exposure to diversity, her family is not.

In college Ruth had "zero problems" interacting with other races. A lot of her friends in her dorm were Black and she keeps in touch with many of them. She attended college at a mid-sized, racially diverse State university for two years before transferring to an HBCU. Ruth's current social group is White and her boyfriend's family is very racist. She hears racist commentary in the boyfriend's "friend group" and it makes her very sad.

Ruth believes non-Whites do not have as many opportunities as Whites but also feels socioeconomic status represents the biggest struggle. She is also passionate about 
the idea that you "shouldn't let your color hold you back." Ruth sees opportunities provided for all races within the Agency School District, and counts having had a Black President as indicative of improved opportunities for African Americans. She believes Obama's election is proof that "you can attain a higher status even if you're Black." Moreover, she feels that regardless of where you come from, even if you have nothing, you should be able to achieve success - you may just have to go out and find it. Ruth notes that non-Whites typically need more government assistance and admits to wondering if African Americans use their color to receive or abuse such assistance.

Classroom experiences have made Ruth "very comfortable" dealing with racerelated matters in her teaching practice. She counts her openness to diversity as a personal and professional strength. During her third year of teaching she encountered an ongoing classroom situation in which students were making "racial comments." This made her more aware of race in the classroom as she worked to deescalate the problems; mediating between students and interacting with parents for additional support. Regarding the achievement gap, Ruth sees a connection to socioeconomics more so than race, although acknowledges that Black people tend to have more struggles with poverty than White people. She is adamant that she has no idea why Black Americans struggle more than Whites.

Ruth thinks it is important to have ongoing professional development on diversity for teachers and staff because it is important to have a better understanding of kids' lives and how to address their needs. Aside from required diversity coursework in college and a state-mandated session for teacher certification, she has had no PD on the subject. She believes the administration in Agency School District does not really know how to 
properly address racial topics and suggests that is the reason why training is not provided to staff either. The district has been "bashed on Facebook" by the community and some of the outcry centers around racial issues. Until we are "properly prepared to address the issues," Ruth believes the district will continue to see problems. Her own "proficiency" at addressing race in the classroom has come from experience and is saddened that teachers are not given the proper tools and resources to deal with such matters. Even so, Ruth is concerned that highlighting race at the district level might encourage non-Whites to claim race as a crutch. She feels

if you highlight it and bring more awareness to the problem or to the issue, that you might...quite possibly could see it becoming more of a, "Well, if they got this, oh now, I didn't realize this was a thing so I'm going to start using this again."

Ruth is thankful to work in a school district with racial diversity and it makes her mad with she hears people speaking negatively about Black people. She insists she is not a racist - that "there isn't an ounce of blood in [her] that is."

\section{Overarching Themes and Alignment to Colorblind Racial Ideology}

During data analysis I coded each transcript, field note, and reflection to isolate emerging themes. I first completed within-case analyses, as previously presented, to develop a picture of each individual case. I then conducted an across-case analysis to capture the essence of onsite Colorblind Racial Ideology presence. Bonilla-Silva's second CBRI tenet is the naturalization of race-related matters. This viewpoint justifies a racial hierarchy grounded in biology and the natural order of social processes (BonillaSilva, 2013). I found no evidence of this tenet during data collection and analysis and so 
it is not further referenced here. The first, third, and fourth tenets of CBRI were represented in the data and so are discussed here in conjunction with applicable themes. Respectively, those tenets are abstract liberalism, cultural racism, and minimization of racism.

\section{Tenet One: Abstract Liberalism}

The first and foundational precept of CBRI is abstract liberalism. This viewpoint presents as rational and explains variations in achievement or outcomes in meritocratic ways. Success or failure is not inherently race-based but is the result of equal opportunities and individual effort (Bonilla-Silva, 2013; Hartmann et al., 2017). Two major themes emerged within this tenet: existence of equal opportunities for all Americans regardless of race, and correlation of achievement to effort. Of the eight participants, four espoused abstract liberal thought: Susie, Tina, Annie, and Ruth.

Equal opportunities for all. Abstract liberal thought adheres to rudimentary notions of equal opportunity. Although Civil Rights progress has not been swift, abstract liberalists believe in the existence of a "level playing field." For some, this steadfast belief in extant equal opportunity (and its value) allows them to comfortably oppose programs and practices designed to abate de facto racial inequality (Hughey et al., 2015) and perpetuate a "race-neutral" society (Lewis, 2001).

Participant responses ranged from simple statements regarding equal opportunities for Black people, to emphatic declarations that equal opportunity exists as an absolute in today's society. Susie, Annie, and Ruth referenced these analogous opportunities without extensive elaboration. Susie acknowledged that while generally equal, the degree to which opportunities are available is "depend[ent up] on where they 
[Black people] come from." As a public school teacher, Annie feels "they [students] are all getting the same opportunities. They're all getting the exact same thing. I'm not taking this one over here and doing more with him or anything." She recognizes, however, that she sees this "through [her] lens" and so "doesn't know that if they [Black people] think that they do [have equal educational opportunities]." Ruth feels as though "Black and Whites have the same opportunities upfront" but seemingly contradicts this statement by saying "there is some type of hold on [opportunity]." Tina's belief in extant equal opportunities was explicitly stated. She asservated intensely and repeatedly that "at this point in America, we all have the same opportunity," with all of the same possibilities to "become what we can become." She further stated that Black people "are the ones making the decisions in their life [sic]; that they are the ones holding themselves back." Tina describes varying achievement levels of Black people as "the difference between ones who are still holding on to, 'Well, there was segregation and we didn't have equal opportunity,' or the ones that [recognize] that they are the ones making the decisions in their life [sic]' and are responsible for their own successes and failures."

Correlation of achievement and effort. Resting on the foundation of equal opportunities for all, abstract liberalism endorses meritocratic ideals (Burke, 2017; Hughey et al., 2015). Certainly, individual effort promotes academic success. What abstract liberalism misses is that "merit and effort are quite differently rewarded, supported, encouraged, funded, and framed" (Lewis, 2001, p. 800).

Annie, Tina, and Ruth cited decreased effort or a lack of focus on education as a factor in lessened achievement within the Black community. Annie seemed empathic for their plight and acknowledged that many African Americans face cyclical poverty or 
opportunity gaps. She expressed concern that many families are unable to provide the necessary academic support to their Black children because they may be working multiple jobs in order to maintain economic stability within the household. She stated, Maybe they don't know how to do things at home. Now we're in a post-Civil Rights era and maybe it [is] just continuing down the line where their education wasn't a focus. Education has to be a focus if we're going to change it. It has to be a focus somewhere down the line. It's a lot to think about.

Despite an oppressive history and inequities in education and opportunities for Black people in America, Tina noted that "others stepped up and said, 'I don't care that this is how it is,' and pushed past that and set up achievement for themselves and their kids."

Ruth indicated that all people "have the possibility" for success regardless of skin color, but people "might have to go out and find it. Now days it seems there are more resources out there than when I was a kid. Things have evolved and developed to assist." Her beliefs about motivation and effort here coincide with her views on government assistance, which will be referenced later in this chapter.

Rather than inequitable access to opportunities, Susie cites learned helplessness, poor upbringing, lower values and principles, and a lack of hard work and motivation as reasons for disproportionate performance and achievement outcomes within the Black community. When asked about the persistence of a performance gap between Black students and White students in a post-segregation setting, she responded,

That's a really, really good and deep question. I've often thought about that. Like, "Why is it this way?" Especially this being fairly recent, moving to a city 
where you can see the notable differences. You can see the neighborhoods... Again, I kind of go back to learned helplessness. The way that they were raised. Values. Principles. Hardworking. Motivation. A lot of the time that's what gets you through college, and if you are in college, then you can make a little more money. Then you can be more successful—define that however you want to. In [the city which is home to the HBCU], especially, it seems like [there] should [be] less of a gap because that university, you know, [is] tailored for those kids. But it doesn't seem like it's making as big of a difference as I expected it to.

The first tenet of Colorblind Racial Ideology, abstract liberalism, echoes the very essence of the American Dream — that when coupled with opportunity, hard work improves social mobility. Abstract liberalism, however, assumes equal opportunity for all and turns a "blind eye" to the social and economic history of the African American since his arrival on this continent in 1619.

\section{Tenet Three: Cultural Racism}

The third tenet of CBRI, cultural racism, refers to the legitimization of stereotypes of a marginalized group based on the holder's "genuine ignorance" or flawed assumptions about the nature of the group's social or economic realities. This viewpoint holds that racism has been all but eliminated through the application of Civil Rights law (Bonilla-Silva et al., 2004). Those who embrace this mindset often cite examples of high achieving Black people — outliers — who have excelled despite an American history of discrimination against African Americans (Howard, 2006).

Cultural racism was the most prominent CBRI tenet evidenced in this study, with two overarching themes: legitimization of race-based stereotypes and notable 
exceptional Black performers - accentuating the belief that low achievement is the fault of individuals and not attributable to racism. All eight participants exhibited some degree of stereotype legitimization. Four participants—Susie, Tina, Annie, and Ruthreferenced high achieving Black people or the election of a Black President as evidence of progress in the post-Civil Rights era.

Legitimization of race-based stereotypes. Race-based stereotypes were socially acceptable to White people in the days of slavery and segregation. In today's society, however, overt stereotyping is associated with political incorrectness. Today this behavior is increasingly embedded in the colorblind precept that attempts to codify cultural stereotypes (Taguieff, 2001). Further, "race talk avoids racist terminology and preserves its myth" (Bonilla-Silva, 2002, p. 61) and assigns "blame" to the target of the culturally racist ideations. Data from all eight participants showed evidence of legitimization.

Emily, Marie, and Annie connected poverty, crime, and home life to cultural stereotypes. Emily questioned whether "things are as bad as some people say they are" and cited racial conflicts with law enforcement as an example. She wondered, "Is it a race issue or a matter of crime?" She also described concerns early in her tenure at an HBCU. She had "heard about non-Whites" and so locked her doors and did not travel alone on campus because she was "nervous; scared."

Marie appeared almost enthusiastic when she discussed cross-racial relationships. She did express that "African American kids sometimes come with a lot of baggage: academics, homelife, whatever. They have a lot on their plates." She mentioned diminished educational opportunities as a cause of these stereotypes. "It goes down the 
line. Achievement does come back to family and what kind of education parents and grandparents have. It trickles down and affects children.”

Annie noted "race and socioeconomics go hand-in-hand. There is a level of poverty if you are a minority and with continuing poverty, [minorities] have less opportunities or experiences than those around them." As a teacher, she stated socioeconomics is at the forefront of her mind. Deficits in that regard are readily apparent, and more so with Black and Latinx students, especially when they are "coming to school for the third day in a row in the same clothes, or eating two breakfasts because they are so hungry."

Lucy's responses associated behavior issues to cultural stereotypes. This past year she had "four behavior issues and they were all African American." During the previous year there were no behavior issues, but "the year before, [she had] one behavior problem and the student was African American."

Susie, Joy, Tina, and Ruth exhibited strong ties to legitimization. For Susie, cultural stereotypes dominated her descriptions about housing and achievement. When speaking about the town in which she currently lives, she referred to a section which is heavily populated by African Americans as "over there"-an area, she said, where people who failed out of an HBCU established families many years ago. For her, the connection between race and achievement transcends the opportunity-plus-effort scenario of Tenet One's abstract liberalism. She stated, "Statistics show that African Americans have a higher rate of unemployment. They have a higher rate of violence." She talked of former classmates from the Boys' Home and indicated they were "in trouble" and were there "to get fixed." The comment was not made in isolation and she admitted, "I have some 
preconceived notions." Cultural stereotypes were further underscored when she referenced experiences with incoming students from a certain elementary school in the district, saying she "assumes[s] the child is African American, low income, and low achieving."

Joy spoke with understanding of African American subordination and the dominance of White culture throughout the history of America; yet also believes "the way your parents grew up kind of determines how you're going to live," indicative of a deficit mindset. She noted "if you grew up in a family where education was valued, you are more likely to care about education." She qualified her beliefs about the importance of valuing education by acknowledging opportunity gaps that have robbed African American families of educational privilege since the early days of America.

Tina frequently referenced lack of family support and effort (indicative of CBRI Tenet One), noting this is a continuing cycle within the African American community (which is associated with the cultural stereotyping of Tenet Three). She notes "Indian families are typically overachievers" and questions whether or not Black families "step in and help their child with learning. Are they supporting and helping them?" White families "go both ways" and it is obvious "if there's a lot of care and support." Tina stated there is "typically a higher percentage of African American families that don't. They either can't or aren't willing [to support their student]."

Ruth discussed elevated financial struggles of African Americans and talked often about Black families' dependence on government assistance. She has observed "more financial struggles with Black families than White families" and so feels "race has a big effect" on success and achievement. She noted that while there "are many White families 
that have problems, Black people seem to need more governmental assistance." In fact, she stated that "because of their color, she always wonders if they receive assistance." She "wonders if some of them abuse it and use their color as a way to receive assistance." She has "always wondered."

Prodigious examples. Although minutely represented in the data, a second theme present within Tenet Three is one that I believe resonates with many White people. I observe this theme in my own social groups and extended family — the recognition of exceptional Black people who have overcome the odds against them due to historical discrimination (Howard, 2006). In the context of socioeconomics and referencing Black people who were wealthier that her own family—which was poor—Susie stated these outliers are "not typical." This "atypicality" further legitimizes race-based stereotypes and represents a deficit mindset. Annie mentioned high achieving African Americans but indicated there is a balance of high and low achievers, as in any given subgroup. Tina cited the election of a Black President as an exceptional example — but rather than as an exceptional example of achievement, she indicated there "was always a push for something... We've had our first Black President so now it's like, 'Can we get a president of another race? Can we get a female?'” Ruth highlighted President Obama numerous times as someone of high rank who represents opportunity for Black people: "It has helped that we've had our first Black President. It goes to show that people are becoming more aware of opportunity. Maybe if we see [Black] people holding such a high title it will start changing things." 


\section{Tenet Four: Minimization of Racism}

Minimization of racism, the fourth tenet of CBRI, diminishes the existence of racism by suggesting African Americans are hypersensitive and contribute to racial strife by "playing the race card" (Bonilla-Silva, 2013). Minimizers believe opportunities exist for everyone regardless of skin color, and Black people should not use American history as a "crutch" to justify lower socioeconomic standing (Ioanide, 2015). These two themes were echoed in the data collected during this study. Five participants displayed minimization. Oversensitivity was evidenced in the responses of Susie, Emily, Tina, and Annie. Race as an excuse or "crutch" was present in responses as given by Emily, Tina, Annie, and Ruth

Oversensitivity to race. Minimization regards racism as virtually non-existent in today's society. Race should not, and does not, matter. (Bonilla-Silva, 2013). Further, racial disconnect is bolstered when African Americans play the "race card." Annie mentioned oversensitivity and attached it to "playing the race card." She believes "race plays a huge part in our world today, but sometimes a lot of people will just play the race card whereas it's not really a thing about race." As described in her participant story, Annie felt her Black professor was overly sensitive to race and she believes the White students in the class were targets of stereotyping as a result.

Susie and Tina held strong opinions about the oversensitivity of Black people. In particular, in Susie's description of the incident involving a Black father at school who became irate about an award his daughter did not receive — an incident he believed was pointedly racist — she found it "interesting that he went that route with it" and did not 
consider any background experiences the man might have had to explain his lens. His accusatory behavior, she said, was "horrifying."

Tina believes Black people "feel like they are entitled to things" and therefore put prejudice against White people. Sometimes she observes Black students - who are for some reason unhappy in the classroom — call out, "Oh, that's just because of my race," or "It's because I'm Black," blaming skin color on teacher or student actions toward them. She also notes Black students will become petulant during instruction of race-related historical events. They dramatically identify with the suffering of their ancestors even though the classroom, in her opinion, should be race-neutral.

Race as a "crutch." Those who maintain a minimization perspective affirm equal opportunities and meritocratic ideals (Ioanide, 2015). They believe African Americans should not use race as a "crutch"—-blaming past segregation and discrimination for their current social and economic standing — but should instead avail themselves to opportunities for advancement (Bonilla-Silva et al., 2004).

Evidence of this theme in Emily's data was subtle and perhaps questionable. She indicated African Americans should be able to achieve success regardless of where they come from or the color of their skin. She stated this as fact and did not overtly indicate whether or not she believed race was somehow used as an excuse for lessened success. Tina's beliefs are less subtle. She spoke openly and often of Black people holding on to deficits and blaming the past for their lack of success and achievement. She said—as though she were a Black person_- "Well, there was segregation and we didn't have equal opportunity..." and "Well, I didn't have as much opportunity as the White people did." 
The strongest confirmation of this theme came from Ruth's data. She believes skin color should not be a limitation and Black people should not let it inhibit their success. She indicated there are now resources available to everyone, so African Americans can achieve great things, even if they have to "go out and find it." Conflict is evident here given that "available resources" might be in the form of state or federal monies...yet Ruth does not know why African Americans are so bound to government assistance in today's society. She also espouses the view that if race-related professional development becomes a focus in Agency School District, it might highlight an "issue" and motivate some Black families to "use it as a crutch," excusing them from realizing their full potential. She feels "if you highlight or bring more awareness to a problem or issue, it might become more of a thing" and she doesn't want it to become a crutch.

\section{Professional Development Needs: An Emerging Theme}

A goal of this study was to facilitate conversations about race in the learning environment and to consider ways in which race might impact student success. This goal was achieved in part and will be further addressed in the limitations section of this study. I am confident that participants were not duplicitous during our conversations and their responses have provided insight into the presence of colorblind ideations at Branch Elementary School—a school within a district that continues to pull many teacher candidates from the small towns described in this study. Although the data collection process was not intended to serve as a Needs Assessment, responses indicated strong participant beliefs about the importance of professional development on race-related matters. 
Of the eight participants, all described themselves as having come from small towns with minimal racial diversity. Some participants still live in towns that are similar to those in which they were raised. Others now live in the small city where Branch Elementary School is located. One participant lives in a larger, neighboring city which is home to several institutions of higher education. The participants' colleges experiences occurred on campuses ranging from small to large State universities and an historically Black college. The diversity coursework they experienced was similar across institutions, with slightly more emphasis on diversity at the larger institutions. Despite a few years of teaching experience outside of Agency School District, none of the participants indicated they had received any district-provided professional development in the area of race, culture, or equity at any time during their teaching careers. One participant, Annie, has pursued diversity-based reading on her own because it is an area of interest for her.

Vision and mission statements of Agency School District do not explicitly detail any focus on diversity. Similarly, the mission statement of the district's Professional Development Committee is vague-improving student achievement by providing professional development opportunities to teachers for that purpose - and does not provide an in-depth philosophy or insight into a professional development plan that benefits teachers and their students.

Several years ago I conversed with a district-level administrator within Agency School District at a question-and-answer session I happened to attend. I asked about the district's professional development trajectory, as the subject was of personal interest. (I was actively involved in the professional development committee within my own school 
district.) I was specifically interested to learn of any diversity-related or equity training that might eventually be offered for teachers and staff. The administrator, who was Superintendent at that time, replied, “That's a great idea, but it would be just one more thing on teachers' plates."

Based on participant responses during my interviews, it is apparent this type of professional development remains of little subsequence within Agency School District. Susie said, "We never talk about how race impacts student education, the culture in our building, or our students." Emily noted teachers in the district are

told all the time [to] be mindful of diversity issues and yet are never given training. There is no discussion on how to address demographic changes. Those who are unprepared to handle situations might shy away or be mean... Professional development in this area would help teachers know how to deal with situations confidently.

She further stated, "There should be more opportunities for growth." Because "it is evident that race is very much an issue in our society," Joy questions why Agency School District doesn't provide necessary professional development to its staff. Ruth wishes the district would provide more training for staff that encompasses the socioeconomic aspect of diversity.

We need training addressing race and the achievement gap because the ones experiencing the greater need or who fall under the poverty line are not having their basic needs met [and are] not meeting achievement expectations either. Socioeconomic needs are most important. Then we can address achievement. Adults needs a better understanding of these kids' lives before they throw all 
these expectations at them that are maybe unrealistic. That might be the reason for the achievement results. I wish we could know what the kids go through. It's something I'm extremely passionate about. We want academics to be number one and for kids to be successful, but we need to ensure that basic needs are being met. The district is struggling with that. Teachers are not given the proper amount of resources or training to better meet those needs, and that's a huge problem. Teachers are not fully prepared for diversity. Until the district prepares, we are going to continue to see problems.

Despite the district's ongoing failure to provide equity training, diversity-related professional development is both valued and desired by teachers. Emily believes such PD "would allow teachers to better serve their students" and "prepare [them] for situations that might arise; to help students learn regardless of where they come from or what color they are." She is interested to know whether or not the district would offer some training, as "more exposure or knowledge of difference is beneficial; [helping teachers] to be inclusive so no one feels inferior." She appeared excited as she contemplated the possibilities and expressed her willingness to participate in additional "classes" if they were offered. Similarly, Lucy believes continuing PD on race and achievement is valuable, even if these topics were previously addressed in teacher preparation programs.

Teachers should know and be reminded. Maybe their college did talk about it, but they need to be reminded now that they are teaching. We should talk about it more when we meet with our weekly data teams and look at the whys. Why are some groups achieving and others aren't? We should talk about it more. We 
should definitely talk about it more. You've given me a lot to think about. Being here and talking with you about this-this has been my PD!

Joy, Marie, and Tina also highlighted the importance of race-related professional development and expressed interest in participation. Joy underscored that it is "important to have conversations and PD so people feel more comfortable about it," and feels it would be good to be able to talk about it and learn more; to gain knowledge so we'd be better about dealing with race issues." Marie would "love to have more PD on this topic if the district provides it," and Annie feels ongoing PD centered around racial issues would help in relationships with parents, especially those "who play the race card." Tina feels confident in her ability to address and acknowledge race in the classroom but thinks it is

important to engage in ongoing PD centered around race issues if for no other reason than to learn about the cultures students come from, and [to help] us with handling parents or different situations connected to different cultures or races. When kids aren't open and willing to share, maybe having some PD would give teachers something to work with.

For Ruth, diversity-minded professional development is "something we should be hitting on every year" and she repeated this sentiment more than once during her interview.

[We should be] refreshing ourselves—giving us different scenarios to see how we would react; not only handling the student but also the families. If we did this at the building level, I think we would see a wave of change throughout the district. This would benefit students' experiences at school. 


\section{Summary}

This study found the presence of Colorblind Racial Ideology at Branch Elementary School as evidenced by the perspectives of White, female teachers there. The degree to which participants espouse CBRI varied. Tenet Two-naturalization of race-related matters, was not evident during data collection. Tenet One, abstract liberalism, was revealed through two major themes - the belief that equal opportunity exists for all Americans regardless of race, and the meritocratic ideal that success is the fruit of one's effort and motivation. Participants also displayed Tenet Four's minimization of racism through two major themes. They relayed stories in which Black families and students demonstrated oversensitivity to race or "played the race card." Some shared concerns or beliefs that Black people use race as a "crutch." They supported these assertations with descriptions of African Americans using or abusing government assistance, or using a history of oppression as an "excuse" for their current social and economic standing.

The strongest manifestation of Colorblind Racial Ideology was demonstrated through the presence of Tenet Three-cultural racism. Several participants described “exceptional examples” of Black people, specifically referencing Barack Obama and the election of a Black President as an indicator of opportunity, possibility, and achievement. The principal theme of cultural racism in this study, however, was legitimization of racebased stereotypes. These were both subtly noted and boldly championed, but stereotypes were present in the data collected from all participants and included the following: associations with poor housing as a result of learned helplessness and failure; increased 
unemployment and violence within the Black community; and low academic achievement resulting from low family support and a lack of value placed on education.

This study additionally found that teachers at Branch Elementary and within the greater Agency School District have not been provided professional development necessary to equip them with tools for race-related competency in the classroom. Of note is the overt desire to participate in such professional development as expressed by these teachers - stating their recognition that it is critical for the betterment of school culture, facilitating deeper understanding of our students, and promoting the success of all. 


\section{Chapter 5: Conclusion}

The purpose of this qualitative, multi case study was to examine perceptions about race and achievement and to consider ways in which those views might influence classroom instruction and academic outcomes. To mirror the teaching monoculture in American schools, White female teachers were invited to share their stories-their backgrounds and beliefs about race in a post-Civil Rights era.

Using Bonilla-Silva's Colorblind Racial Ideology framework, I conducted withincase data analyses and isolated across-case abstractions. The findings indicate the onsite presence of CBRI. In this chapter I discuss the major findings in the context of significant literature and offer implications for further research and practice.

\section{Discussion}

There are many factors affecting American education today. The predominance of a White, monocultural teaching force in classrooms of increasing diversity is but one of them. White educators - the dominant group here- have the power to influence standards and practices in our schools (Howard, 2006; Johnson, 2006). Given the increase in tumult surrounding race in today's society, it is critical that White teachers challenge the notion of dominance (Abrams \& Gibson, 2007; Ortiz \& Jani, 2010) so that we might improve the experiences and learning outcomes of all students.

In their book about transpersonal research methods, Rosemarie Anderson and William Braud (1998) suggest three requisite characteristics for making progress toward the common good:

(a) a full recognition of our actions - and complicity in actions - that harm others and an expression of appropriate remorse; (b) an amendment of harmful actions 
and their consequences, including reparation of broken relationships and commitments; and (c) a change in future actions, including working for the common good. (p. 248)

I empathize with participant denials of racist ideations and have often separated myself from the longstanding history of "hierarchical social arrangements" (Howard, 2006, p. 34). There is a sting that accompanies the vocabulary of dominance and marginality, especially when you are not deliberately or knowingly part of "the problem." Of benefit to the novice, though, is a realization that "the key difference between systems and the people who participate in them [is] we don't have to be ruthless people in order to support or follow paths of least resistance that lead to behavior with ruthless consequences" (Johnson, 2006, p. 86). Good people can still do better.

\section{Abstract Liberalism}

The foundational tenet of Colorblind Racism focuses on "the denial of the centrality of discrimination" (Bonilla-Silva et al., 2004, p. 560) and is evidenced by two themes within this study_Equal Opportunities for All, and a Correlation of Achievement and Effort. These abstract liberal perspectives are not new. Scholars long ago highlighted the comfort of a colorblind stance for many White Americans (Gaertner \& Dovidio, 1986).

Opportunities in America are not only not equal for all (as indicated in the literature review), but in the educational setting, gaps between Black students and White students are perpetuated through colorblind lenses that act as barriers to meaningful discourse, culturally-responsive practices, and heightened performance of marginalized students (Irvine, 2003; Milner, 2012; Nieto, 1994). Susie and Tina both indicated equal 
opportunity is a fact, and Annie stated her belief that equal opportunities for all exist in the public school setting. While the other participants referenced disproportionate opportunities between Black people and White people, they did not speak to any belief regarding unequal educational opportunities in the contemporary classroom. Assumptions of the proverbial "level playing field" and expectations of sameness, then, can be dangerous to realizing the overall purpose of public education - to wholly educate the American citizenry (Ladson-Billings, 2000; Milner \& Williams, 2008; Tate, 2008)— if teachers are not fully aware of the intersections at play in the marginalization of certain groups.

Further, the meritocratic notion which correlates effort and achievement outcomes acts as a conduit of legitimized inequity. While connections between socioeconomics and educational success were drawn by participants in this study, the associations were often attributed to the effort attached to the "cycle" of poverty or underperformance within the Black community. Conversely and despite intimations, there was no real discussion of the "cycle" of generational unearned privilege within the White community (Milner, 2012) although Joy, Marie, and Annie did acknowledge their personal privilege as White women. Participants referenced intersections of race and class, but those perspectives may be rooted in misinformation or racial stereotypes. Susie, Tina, and Ruth described connections between hard work and success, which encompassed consideration of whether or not families fully support the academic needs of their students. 


\section{Cultural Racism}

The third tenet of Colorblind Racial Ideology was prolific in the findings as evidenced primarily through Legitimization of Race-Based Stereotypes, and to a lesser degree, in recognition of Prodigious Examples of Black people. Unlike naturalization, cultural racism is not rooted in biology. Instead, cultural practices and stereotypes align with deficit ideations in this frame and are prominent in the United States. Findings here connect a "culture of poverty" mindset, citing lower socioeconomic standing as an inhibitor to both a stout social standing and a more robust sense of general success across the Black population. Even participants who expressed a sympathetic or benevolent tone concerning the "plight" of African Americans - those who acknowledged poverty and generational education gaps as inhibiting factors - did not address systemic discrimination regarding housing, employment, or accessible and equitable education (Bonilla-Silva, 2014).

Cultural stereotypes evidenced in this study include specific references to housing and the negative impact of a nearby historically Black college (note Susie's story); learned helplessness in support of meritocratic ideals and abstract liberalism; perceived increased rates of unemployment and violence of Black people; and low academic achievement based on a supposed lack of family effort and negligible valuation of education. These race-based stereotypes serve to justify the social and economic standing of African Americans (Hoschchild, 1995; Wetherell and Potter, 1992).

To emphasize the "truth" behind cultural stereotypes - ultimately nurturing the marginalization of African Americans - is the elevation of "exceptional" examples of Black high achievers. In this study, general references were made to high achieving 
Black students. The references were made in both conciliatory ways (uplifting the abilities and performance of Black students to that of other subgroups) and as atypical observations. Specific to the findings here were the recurrent references of both Tina and Susie to the election of a Black President. Obama's status as a high achieving Black man, one who rose to the highest office in the nation, lessens the focus on historical discrimination of Black Americans. While Obama serves as an outlier for many, this mindset further endorses the abstract liberal view of equal opportunities and meritocracy (Neville, Poteat, Lewis, \& Spanierman, 2014). It also reinforces cultural stereotypes by setting apart the high achiever as uncharacteristic.

\section{Minimization of Racism}

Oversensitivity to Race-Related Matters and using Race as a "Crutch" emerged as the overarching themes within Bonilla-Silva's fourth tenet of Colorblind Racial Ideology, or minimization. Both Susie and Emily detailed concern about oversensitivity to race by Black parents at Branch Elementary. Susie expressed shock that a Black father would "go that route" and accuse a teacher of withholding recognition from his child because she was not White. For Emily, there is fear associated with "pushing" her Black students to perform to the best of their ability because she has been called a racist before by a Black parent; one who was sensitive to the treatment of her child and questioned the equity of the academic workload. Tina's experiences are that Black children become emotionally charged during lessons on slavery or Civil Rights and they personally connect to the suffering of their ancestors. Labeling such reactions of Black people as "oversensitive," devoid of any experiential context, is problematic. Minimizing the effects of years of oppression and continuing discrimination acts to strengthen colorblind 
ideations (Hartmann et al., 2017). As White teachers, we must not discount the years of oppression experienced not only in times of slavery and segregation, but also that which has emerged contemporarily (Bonilla-Silva et al., 2004).

A second minimization theme emerged with strong ties to the cultural stereotypes of Tenet Two-cultural racism. Participants spoke of Black people using race as a "crutch," a mindset which also ties to the meritocratic principle of abstract liberalism. Susie indicated Black college students benefited from scholarships (which were denied to her) based on the color of their skin. Emily, Tina, and Ruth all used "crutch" as terminology to describe beliefs about practices or potential for misuse by Black people. This included a concern about race-related professional development, as the participants believed the subject might expedite the desire of Black people to use race as an excuse for lessened success. Similarly, when Ruth encounters Black people, she instinctively questions whether or not they receive government assistance, and if so, wonders if they abuse it.

White teachers with disparate backgrounds and experiences from their students need to understand that lower socioeconomic standing or other oppressive circumstances can have a somber influence on a child's opportunities and educational performance (Ladson-Billings, 2006a). Teacher perceptions of using "race as a crutch" reject the legacy of discriminatory practices and its detrimental effects on generations of African American families (Milner, 2010, 2012).

\section{Professional Development}

A significant barrier to heightened understanding and progress is one which was evidenced within the participants of this study—silence; fear. Mazzei (2008) elaborates 
on this idea: [It is the] "fear of offending, fear of being wrong, fear of appearing stupid, and fear of being marginalized by peers" (p. 1130.) This fear acts as a paralysis as evidenced by in the findings of this study—-fear of maintaining high expectations for Black students; fear of interacting and partnering with Black parents; and fear of being labeled a racist. As indicated in the study, participants were concerned about the impact this fear might have on the achievement of their students.

Teacher preparation programs can assist by developing candidate dispositions; spaces in which "empathy might be of greatest support for enabling their teaching effectiveness with Black, Latinx, and Indigenous students," (Warren, 2018, p. 176). These spaces allow students to examine personal beliefs and competencies, and to develop skills to create learning environments that provide maximum and equitable opportunity for all (Schussler, Stooksberry \& Bercaw, 2010; Sheets, 2007; Warren, 2018).

Professional development of educators must not end with the culmination of undergraduate preparation studies, however. Just as increased exposure to collegiate diversity studies is critical to an increased awareness of racism (Neville, et al., 2014), it is equally important for teaching professionals if they are to challenge colorblind ideologies. The participants in this study have all encountered a deficit in diversityrelated and equity-minded professional development. Educators cannot be silent regarding race-related matters in the classrooms if we are to maximize opportunities for all students and increase engagement and effective communication between themselves and their students of color. Teachers need support in terms of resources and effective training for that purpose and to assist them in understanding their own racialized 
emotions (Matias, Henry, \& Darland, 2017). Otherwise we are in danger of slighting our students by falsely empathizing in their plight (Warren, 2018; Warren \& Hotchkins, 2015). and by failing to recognize and acknowledge our "preconceived biases based on [how we are] racially positioned" (Grosland \& Matias, 2017, p. 78).

Racism is deeply woven into the fabric of American culture. As educators we can and should engage in meaningful dialogue of race and opportunity and the success of our students and their families. We must collaborate in an equity-minded focus to narrow the existing gaps (Singleton \& Linton, 2006) - gaps in opportunity, of understanding, and in achievement. It is my recommendation that candid discourse be embedded in districtsponsored professional development to allow inspection of the historical contexts which address meritocracy and opportunity gaps experienced by the African American community.

\section{Implications}

As I was concluding this study, Ahmaud Arbery—a Black man jogging along a neighborhood street—was gunned down by two White men while a third man filmed the killing. An unrelenting public outcry acted as the only real impetus for action, for an investigation — months after Ahmaud was left dead in a Georgia suburban street. And then there was Christian Cooper-bird watcher; Black man—accused by a White woman of threatening her life simply because she was asked to follow the law and put a leash on her dog in Central Park. It did not matter that Mr. Cooper is a Harvard-educated professional and a "prodigious example" of his race. His accuser used his Blackness against him. As weaponry. And then...then there was George Floyd. Black. Perhaps a forger; a passer of bad checks. Perhaps not. Undeniably handcuffed and conversing with 
police officers as he sat on a Minneapolis curb. Enter another police officer on the scene. White. Mr. Floyd is now on the ground as the officer places his knee on George's neck-George who asks for water; George who says he cannot breathe; George who is now dead of a "medical incident." Still handcuffed and beneath an officer's knee. Dead.

Those who say they don't see race? They lie. Maybe unintentionally or without malice, but they lie nevertheless. I see color, and you do too. Colorblindness is a code word. In its best form it encompasses unease; unrest; an unenlightened lens. In its worst form? It wears the white hood of political correctness while perpetuating the stillunrealized emancipation of Black Americans.

I do not claim to know all of the pertinent details concerning the stories of Ahmaud, of Christian, or of George. I want to believe in a justice system that closely looks at truths. What I absolutely believe is this - If it is true that we cannot teach what we do not know, and considering the words of W.E.B. Du Bois (1903), And herein lies the tragedy of the age: not that men are poor, -all men know something of poverty; not that men are wicked, -who is good? not that men are ignorant, -what is Truth? Nay, but that men know so little of men (p. 152), then it is imperative that our understanding of one another does not stop at the color line. Colorblind Racial Ideology is present at Branch Elementary School and within Agency School District, a hub among small towns from which teacher candidates are drawn. Colorblind Racial Ideology is present in middle America - the Bible Belt, where folks wave to passersby and many believe we should love our neighbors as ourselves ${ }^{10}$.

\footnotetext{
${ }^{10}$ Note the biblical reference, "Love your neighbor as yourself" (Mark 12:31 New International Version).
} 137 
The problem is that we don't really even know our neighbors, at least not the ones who don't look just like us.

The teachers at Branch Elementary are passionate about their profession. By all accounts they are hardworking individuals who express a desire to see all students succeed. When we become teachers, we study best practices and engage in training for years during our undergraduate careers. Professional development must not stop with an undergraduate degree and become stagnant. Maya Angelou said, "When you know better, you do better" (Winfrey, 2011). When gaps in understanding and training are made apparent, they become gifts - opportunities to grow and make our classrooms engaging and colorful places in which to learn. In fact, when teachers fail to engage in "an ongoing process of growth, both as a person and as a professional, [they are] a threat to the well-being and success of all students" (Howard, 2006, p.129). And so, the stakes are extremely high.

\section{Positionality - a Final Note}

Many years ago as I was beginning the dissertation process and searching for the words I did not yet know - the adjectives that would lead me to a theoretical framework in which to situate the questions in my mind-I had a discussion with my then-advisor, Dr. Juanita Simmons. I remember well the day we first conversed about my study interests. I did not want her to think my interest in writing about White teachers and race was merely some passing bandwagon on which I hoped to jump. What I learned that day is that ignorance, once you are aware of it, can be an auspicious field on which to stand... if you are willing to learn and grow and keep putting one foot in front of the other in the name of progress. I remember Dr. Simmons telling me that as a Black woman, she 
can write all day about this subject, but "sometimes it takes a White girl to stand up and say it before people listen." And then she asked, "How brave do you want to be?" I ask myself that question often and know this much is true: the subject of race in America and in her schools is not always a comfortable one to navigate. It is not, however, uncomfortable enough for me not to speak while I am privileged enough to have a voice that might be heard.

I am a White female teacher. Had I not been the researcher, I could easily have been a participant in this study. The demographics to my story match many of those found in the previous chapter. With every page that I read and every page that I write, I discover how little I really know and understand. At the onslaught of my data collection I was naïve about my participants. I carried assumptions that intentionality — or at least the desire for better understanding — was perhaps solely mine as a doctoral student. I was wrong. What I have learned from the collective stories is that these teachers, regardless of the strength in their convictions about race and achievement, are open to learning more.

Public school teaching is a collaborative act and professional development should not be solely driven by the whims or interests of individual professionals. Agency School District has a responsibility to its teachers and staff. It has a greater duty to its students and the community in which they grow and learn. The participants in this study have answered a question, at least in part, that I could not: What does it mean, per the district's professional development mission statement, to improve student achievement by providing professional development opportunities to teachers for that purpose? For these 
teachers, it means that professional development with an equity focus has value to them and for their students. It means that now is a good time to travel along that path.

I am now faced with questions of next steps. I have a responsibility to act- to think critically about how to encourage growth in the professional practices of these teachers, as well as to nurture growth in my own practice. I must consider ways in which to use my voice to facilitate optimal learning spaces for the children and adults within my sphere of influence. I envision taking immediate (perhaps initially small) steps, looking for opportunities and readiness, and then building momentum. I will be reaching out to participants and colleagues to invite them to join me in courageous conversations, both informal and otherwise, and ask that we study together so that we might develop equitable learning environments which are ultimately facilitated by "colour brave" (Ojike, 2018), rather than colorblind, teachers.

Building-level initiatives directed at equity and inclusion cannot be sufficient, however, if the efforts are in isolation... and so I have begun outreach at the district and community levels to offer my energy and research as a catalyst for systemic change. I recently listened to a powerful presentation by Ugo Ojike concerning courageous conversations about race, and I carry her thoughts forward with me as I attempt to partner with the district at large, a process that will begin with my position as a member of the district-level professional development committee: First, as school districts we must acknowledge and own the problems of racism in our communities and schools so that we might actualize change for the better. Second, it is imperative that we "put the customer first." In the world of education, these customers are our students and their families. Prioritizing them involves actively trying to understand rather than minimizing the effects 
of discriminatory thoughts and behaviors. Ojike (2018) said, "The time to act disruptively is now... When you listen, you learn...[and] you can't be what you can't see." It is high time we open our eyes. 
APPENDIX A

Informed Consent Form

\section{CONSENT FORM TO PARTICIPATE IN A RESEARCH STUDY}

\section{NAME OF RESEARCHER: STEPHANIE SANDERS GREEN \\ PROJECT IRB \#: 2019262 MU}

\section{STUDY TITLE: PIGMENTATION AND PRACTICE: UNDERSTANDING PERCEPTIONS OF WHITE FEMALE TEACHERS WITHIN A COLORBLIND RACIAL IDEOLOGY FRAMEWORK}

This research study is about teachers' perceptions of student achievement. I am doing this study to understand teachers' thoughts about the academic success of Black students and White students and how race might be perceived as a factor in that performance.

I invite you to take part in this research study because you are a White female teacher in grades $1-5$ with at least three years of professional teaching experience, and you teach in classrooms with a diverse group of students. This consent form tells you why I am doing the study, and what will happen if you join the study.

Please take as much time as you need to read this consent form. If there is anything you do not understand, please ask me to explain. Then you can decide if you want to take part in the study or not.

Research studies help us to answer questions that may improve our understanding of human behavior, attitudes, beliefs, and interactions. Taking part in a research study is voluntary. You are free to say yes or no. I will only include you in this study if you give me your permission first by signing this consent form.

\section{WHY IS THIS STUDY BEING DONE?}

The study will seek to understand the role that a teacher's experiences and perspectives about race might have on instructional practices and/or the teacher-student relationships. HOW MANY PEOPLE WILL BE IN THIS STUDY? Approximately ten participants will take part in this study. 


\section{WHAT WILL HAPPEN IF I TAKE PART IN THIS STUDY?}

If you agree, you will come to the interview site and respond to interview questions that I ask of you. An audio recording of the interview will be made and a transcript of the session will be prepared. You will be provided a copy of the interview transcript for review.

\section{HOW LONG WILL I BE IN THE STUDY?}

You will be in the interview portion of the study for a total of approximately 40 60 minutes. Any follow-up interview(s) and transcript review may take approximately an additional hour at a later time.

\section{CAN I STOP BEING IN THE STUDY?}

Yes, you can stop being in the study at any time without giving a reason. Just tell me right away if you wish to stop taking part.

\section{ARE THERE ANY BENEFITS TO TAKING PART IN THIS STUDY?}

There might be no direct benefit to you from taking part in this study. However, the information learned from you during this study might inform your professional practice. It might also help inform professional development within the district and help us learn more about equitable learning environments for students of all racial backgrounds.

\section{ARE THERE ANY RISKS FROM BEING IN THIS STUDY?}

There are no specific risks related to participation in this study. Discomfort may occur as you express ideas regarding race in America and its connections to student achievement. You may skip any questions you do not want to answer, and you may stop the interview at any time.

\section{WHAT OTHER CHOICES DO I HAVE IF I DON'T TAKE PART?}

You are under no obligation to participate in this study. Your decision on whether or not to participate will have no impact on your professional duties. 


\section{WILL INFORMATION ABOUT ME BE KEPT PRIVATE?}

The information collected about you will be stored in the researcher's electronic/computer or paper files. Computer files are protected with a password and the computer is stored in the researcher's home office. Paper files are kept in a locked file cabinet that is only accessible to the researcher.

Your records will be labeled with your chosen pseudonym and will not contain your name or other information that could identify you. The pseudonym that connects your name to your information will be kept in a separate, secure location. Information that may identify you may not be given to anyone who is not working on this study without your written consent, or if required by law.

I will do my best to make sure that your personal information from this study is kept private, but I cannot guarantee total privacy. I may give out your personal information if the law requires it. If I publish the results of this study or present them at scientific meetings, I will not use your name or other personal information.

The information I collect from you for this study will not be used or shared with other investigators for future research studies. This applies even if I remove all information that could identify you from your information.

You must give me permission to use the information gathered from audio recordings I take of you during the study. You will be able to review a transcript of the audio recording(s) before you give your permission for me to use them.

\section{WILL I BE PAID FOR TAKING PART IN THIS STUDY?}

You will receive a $\$ 25.00$ gift card to either Target, Amazon, or Starbucks in appreciation of your time and contribution to this study.

\section{WHAT ARE MY RIGHTS AS A STUDY PARTICIPANT?}

Taking part in this study is voluntary. If you do decide to take part, you have the right to change your mind and drop out of the study at any time. Whatever your decision, there will be no penalty to you in any way.

I will tell you about any new information discovered during this study that might affect your health or welfare, or might cause you to change your mind about taking part. 


\section{WHOM CAN I CALL IF I HAVE QUESTIONS, CONCERNS, OR COMPLAINTS?}

If you have more questions about this study at any time, you can call me at , or contact my advisor, Dr. Sarah Diem, at

You may contact the University of Missouri Institutional Review Board (IRB if

you: • Have any questions about your rights as a study participant; - Want to report any problems or complaints; or • Feel under any pressure to take part or stay in this study. • The IRB is a group of people who review research studies to make sure the rights of participants are protected. Their phone number is 573- 882-3181.

If you want to talk privately about your rights or any issues related to your participation in this study, you can contact University of Missouri Research Participant Advocacy by calling 888-280-5002 (a free call), or emailing MUResearchRPA@missouri.edu.

I will give you a copy of this consent form. Please keep it where you can find it easily. It will help you to remember what we discussed today.

\section{SIGNATURE OF PARTICIPANT}

Consent to Participate in Research

By signing my name below, I confirm the following:

- I have read/had read to me this entire consent form.

- All of my questions were answered to my satisfaction.

- The study's purpose, procedures/activities, potential risks, and possible benefits were explained to me. $\bullet$ I voluntarily agree to take part in this research study. I have been told that I can stop at any time.

Subject's Signature Date

IRB Approved Date 1/23/2020 


\section{APPENDIX B}

\section{Interview Protocol}

\section{Personal Background}

1. Please tell me about the area in which you grew up.

- Would you consider it rural, suburban, or inner city? A big or small town?

- How would you describe the racial and socioeconomic makeup of your town?

2. Growing up, did you socialize with different races? Why or why not?

- If yes: probe for setting - friend groups, school activities...

- What is the racial makeup of your social group now?

\section{General Views}

1. How do you think the experiences and opportunities of people of various other racial backgrounds compare to yours as a White person in America?

2. We largely live in a post-Civil Rights era with regard to race. What significance or role do you feel race has in today's society?

3. Please tell me your thoughts about race in connection to lessened success or achievement.

- Probe for socioeconomic standing, employment, education, etc.

4. Has race ever impacted your life in a significant way? Please describe.

\section{$\underline{\text { Educational and Professional Background }}$}

1. Tell me about your K-12 and college experiences.

- What was the racial makeup of your schools?

- Describe your experiences there with peers who were racially different than you.

2. The teaching force in America is predominantly White and female and so I am curious about your teacher preparation program.

- Describe the effort of your program to help you embrace an increased focus on diversity.

- How prepared do you feel to comfortably acknowledge or address race in a classroom of diverse students? Please explain. 
3. Tell me about your teaching history. How long have you taught, and where?

- Probe for racial makeup in schools.

4. What are your experiences, past and present, with professional development centered around race and cultural competency?

- To what extent do you feel that your work-related training or professional development has been sufficient in developing proficiency with race-related interactions in the classroom?

- How important is it to you that teachers engage in ongoing professional development centered around racial issues, including the achievement gap? Please explain.

5. In your professional experience, how have issues of race and/or changing demographics been addressed at meetings or during other formal discussions?

- Tell me about any collaborative dialogue in which you have participated to address the needs of African American students in our schools.

\section{$\underline{\text { Academic Achievement }}$}

1. There is a significant achievement gap between Black students and White students in this country. Black students and White students attend school together, so why do you think the gap persists years after legally-sanctioned segregation has ended?

- Probe for thoughts on opportunity gaps.

2. How might the teacher's beliefs about race impact her teaching possibly impact her relationships with students?

3. How do you believe race should be acknowledged in the educational setting?

- At the district level? School level? Should race be a focus at any time in your classroom? Please explain your thoughts.

- How might an acknowledgement of race benefit or detract from a student's experiences in the school and classroom settings?

\section{Closing}

Thank you for taking time to participate in this interview.

- Is there anything else you'd like to share about your background or experiences that we have not covered today? 
- Are there any views you would like to share with me regarding the achievement of Black students and White students that might benefit this study?

- Do you have any questions for me? 


\section{APPENDIX C}

\section{Dream Deferred ${ }^{11}$}

by Langston Hughes

What happens to a dream deferred?

Does it dry up

Like a raisin in the sun?

Or fester like a sore--

And then run?

Does it stink like rotten meat?

Or crust and sugar over--

like a syrupy sweet?

Maybe it just sags

like a heavy load.

Or does it explode?

${ }^{11}$ Also known by the title "Harlem"

Hughes, L. (1951). Harlem. Montage of a dream deferred. New York: Holt. 


\section{REFERENCES}

Abrams, L., \& Gibson, P. (2007). Reframing multicultural education: Teaching White privilege in the social work curriculum. Journal of Social Work Education, 43, 147-160.

Aguirre, F. P. (2005). Mendez v. Westminster School District: How it affected Brown v. Board of Education. Journal of Hispanic Higher Education, 4(4), 321-332. http://dx.doi.org/10.1177/1538192705279406

Airstrup, J. A. (1996). The southern strategy revisited: Republican top-down advancement in the south. Lexington, KY: University Press of Kentucky.

Alexander v. Holmes County Board of Education, 396 U.S. 19 (1969).

Allen, J., \& Daugherity, B. (2006). Recovering a "lost" story using oral history: The United States Supreme Court's historic “Green v. New Kent County, Virginia” decision. The Oral History Review, 33(2), 25-44.

Amsterdam, D. (2017). Toward the resegregation of southern schools: African American suburbanization and the historical erasure in Freeman v. Pitts. History of Education Quarterly, 57(4), 451-479. http://dx.doi.org/10.1017/heq.2017.28

Anderson, J. D. (2005). Can public schools save America? Culture, race, academic achievement, and the American dream. Du Bois Review: Social Science Research, 2(1), 127-136. http://dx.doi.org/10.1017/S1742058X05050095

Anderson, J. D. (1988). The education of blacks in the south: 1860-1935. Chapel Hill: University of North Carolina Press. 
Anderson, N. \& Balingit, M. (2018, July 3). Trump administration moves to rescind Obama-era guidance on race in admissions. The Washington Post.

Anderson, R. \& Braud, W. (1998). Transpersonal Research Methods for the Social Sciences: Honoring Human Experience. Thousand Oaks, CA: Sage, 1998.

Anderson, S. (2008). The past on trial: Birmingham, the bombing, and restorative justice. California Law Review, 96(2), 471-504.

Asher, N. (2007). Made in the (multicultural) U.S.A.: Unpacking tensions of race, culture, gender, and sexuality in education. Educational Researcher, 36(2), 65-73.

Austin, E. H. (1965). Cultural deprivation: A few questions. Phi Delta Kappan, 47(2).

Baker, L. D. (1994). Savage inequality: Anthropology in the erosion of the fifteenth amendment. Transforming Anthropology, 5(1-2), 28-33. https://doi-org.proxy.mul.missouri.edu/10.1525/tran.1994.5.1-2.28

Banks, J. A. (2001). Citizenship education and diversity: Implications for teacher education. Journal of Teacher Education, 52(1), 5-16.

Baptiste, I. E. (2008). Wages of niceness: The folly and futility of educators who strive to not impose. New Horizons in Adult Education and Human Resource Development, 22(2), 6-28.

Baxter, P., \& Jack, S. (2008). Qualitative Case Study Methodology: Study Design and Implementation for Novice Researchers. The Qualitative Report, 13(4), 544-556.

Becker, H. S. (1998). Tricks of the trade: How to think about your research while you're doing it. Chicago: The University of Chicago Press.

Berlin, I., Favreau, M., \& Miller, S. F. (Eds.) (1996). Remembering slavery. New York: The New Press. 
Ben-Hur, M., \& Feuerstein, R. (2011). Feuerstein's new program for the facilitation of cognitive development in young children. Journal of cognitive education and psychology, 10(3), 224-237.

Billings, S. B., Deming, D. J., \& Rockoff, J. (2014). School segregation, educational attainment, and crime: Evidence from the end of busing in CharlotteMecklenberg. Quarterly Journal of Economics, 129(1), 435-476. https://doil.org/10.1093/qje/qjt026

Bissionette, J. (2016). The trouble with niceness: How a preference for pleasantry sabotages culturally responsive teacher preparation. Journal of Literacy and Language Developmen, 12(2), 9-32.

Blackmon, D. A. (2008). Slavery by another name: The re-enslavement of black Americans from the Civil War to World War II. New York: Doubleday. Board of Education of Oklahoma City Public Schools v. Dowell, 498 U.S. 237 (1991). Boeije, H. (2002). A purposeful approach to the constant comparative method in the analysis of qualitative interviews. Quality \& Quantity, 36, 391-409.

Bogdan, R., \& Biklen, S. K. (1992). Qualitative research for education. Boston. MA: Allyn and Bacon.

Bolling v. Sharpe, 347 U.S. 497 (1954).

Bonastia, C. (2015). Low-Hanging Fruit: The Impoverished History of Housing and School Desegregation. Sociological Forum, 30(S1), 549-570. https://doiorg.proxy.mul.missouri.edu/10.1111/socf.12177 
Bonilla-Silva, E. (2002). The Linguistics of Color Blind Racism: How to Talk Nasty about Blacks without Sounding "Racist.” Critical Sociology (Brill Academic Publishers), 28(1/2), 41.

Bonilla-Silva, E. (2013). Racism without racists: color-blind racism and the persistence of racial inequality in America. Lanham: Rowman \& Littlefield.

Bonilla-Silva, E. (1997). Rethinking Racism: Toward a Structural Interpretation. American Sociological Review, 62(3), 465-480.

Bonilla-Silva, E., Lewis, A., \& Embrick, E. (2004). "I did not get that job because of a black man...": The story lines and testimony of color-blind racism. Sociological Form, 19(4), 555-581. https://doi.org/10.1007/s11206-004-0696-3

Boorstin, D. J. (1982). The image: A guide to pseudo-events in America. New York: Knopf Doubleday Publishing Group.

Boser, U. (2014). Teacher diversity revisited: A new state-by-state analysis. Retrieved from https://www.americanprogress.org/issues/race/report/2014/05/04/88962/ teacher-diversity-revisited

Branch, T. (1988). Parting the waters: America in the King years, 1954-1963. New York: Simon and Schuster.

Brandon, W.W. (2003). Toward a white teachers' guide to playing fair: Exploring the cultural politics of multicultural teaching. Qualitative Studies in Education, 16(1), $31-50$.

Brantlinger, E. (2003). Dividing classes: How the middle class negotiates and rationalizes school advantage. New York: Routledge Falmer. 
Bridenbaugh, C., \& Bridenbaugh, J. (1962). Rebels and gentlemen: Philadelphia in the age of Franklin. New York: Oxford University Press.

Briggs v. Elliott, 342 U.S. 350 (1952).

Brown, E. (2017, March 30). Trump's Education Department nixes Obama-era grant program for school diversity. The Washington Post.

Brown, F. (2004, Summer). Nixon's “southern strategy" and forces against Brown. The Journal of Negro Education, 73(3), 191-208.

Brown v. Board of Education of Topeka, 347 U.S. 483 (1954).

Brown v. Board of Education of Topeka, 349 U.S. 294 (1955).

Bullock, H. A. (1967). A history of Negro education in the United States: from 1619 to present. Cambridge: Harvard University Press.

Burke, M. (2017). Colorblind racism: Identities, ideologies, and shifting subjectivities. Sociological Perspectives, 60(5), 857-865. https://doi.org/10.1177/0731121417723827

Cable, G. W. (1889). The silent South: together with the freedman's case in equity and, The convict lease system. New York: Scribner.

Caro, R. (2002). Master of the senate: The years of Lyndon Johnson. New York: Alfred A. Knopf.

Carson, C. (2005). Between contending forces: Martin Luther King, Jr., and the African American freedom struggle. OAH Magazine of History, 19(1), 17-21.

Carter, P. L., Welner, K. G., \& Ladson-Billings, G. (2013). Closing the opportunity gap: what America must do to give every child an even chance. New York: Oxford University Press. 
Cascio, E. U., \& Washington, E. (2014). Valuing the vote: The redistribution of voting rights and state funds following the Voting Rights Act of 1965. Quarterly Journal of Economics, 129(1), 379-433.

Causey, V. E., Thomas, C. D., \& Armento, B. J. (2000). “Cultural diversity is basically a foreign term to me": The challenges of diversity for preservice teacher education. Teaching and Teacher Education, 16(1), 33-45.

Charmaz, K. (2006). Constructing grounded theory: A practical guide through qualitative analysis. Thousand Oaks, CA: Sage.

Chay, K. Y., Guryan, J., \&Mazumder, B. (2009). Birth cohort and the black-white achievement gap: The roles of access and health soon after birth. Cambridge, MA: National Bureau of Economic Research.

Chowdhury, M. F. (n.d.) Coding, sorting and sifting of qualitative data analysis: debates and discussion. Quality \& Quantity, 49(3), 1135-1143. https://doiorg.proxy.mul.missouri.edu/10.1007/s11135-014-0039-2

Civil Rights Act, 18 Stat. $§ 335-337$ (1875).

Civil Rights Act of 1866, 14 Stat. $§ 27-30$ (1866).

Civil Rights Act of 1957, 71 Stat. $§ 634$ (1957).

Civil Rights Act of 1960, 74 Stat. $§ 86$ (1960).

Civil Rights Act of 1964, 78 Stat. $§ 241$ (1964).

Civil Rights Act of 1968, 82 Stat. $§ 73$ (1968).

Civil rights cases. (n.d.). In West's encyclopedia of American law (2). Retrieved from https://legal-dictionary.thefreedictionary.com/Civil+Rights+Cases 
Cochran-Smith, M. (2003). Learning and unlearning: The education of teacher educators. Teaching and Teacher Education, 19(1), 5-28. https://doi.org/10.1016/S0742-051X(02)00091-4

Cochran-Smith, M. (1995). Uncertain allies: Understanding the boundaries of race and teaching. Harvard Educational Review, 65(4), 541-571. https://doi.org/10.17763/haer.65.4.m77263886583326v

Coffey, A., Holbrook, B., \& Atkinson, P. (1996). Qualitative data analysis: Technologies and representations. Sociological Research Online, 1(1).

Cohen, S. S. (1974). A history of colonial education, 1607-1776. New York: Wiley.

Cohodas, N. (1993). Strom Thurmond and the politics of southern change. New York: Simon \& Schuster.

Cole, N. L. (2018). The definition of whiteness. Retrieved from https://www.thoughtco.com/whiteness-definition-3026743

Cole, N. L. (2020, February 11). The History of White Supremacy. Retrieved from https://www.thoughtco.com/white-supremacy-definition-3026742

Comer, D. R. (1993). An experiential capstone for students of organizational behavior. The International Journal of Organizational Analysis, 1(1), 97-114.

Cook, M. D., \& Evans, W. N. (2000). Families or schools? Explaining the convergence in white and black academic performance. Journal of Labor Economics, 18, 729 754.

Cooper v. Aaron, 358 U.S. 1 (1958).

Corson, D. (2001) Ontario students as a means to a government's ends. Our Schools/Our Selves, 10(4), 55-77. 
Creswell, J. W. (2009). Research design: Qualitative, quantitative, and mixed methods approaches $\left(3^{\text {rd }}\right.$ ed.). Thousand Oaks, CA: Sage.

Creswell, J. W. (2013). Qualitative inquiry and research design: Choosing among five approaches (3rd ed.). Thousand Oaks, CA: Sage.

Crocker, J. Major, B., \& Steele, C. (1998). Social stigma. In D. Gilbert, S.T. Fiske, \& G. Lindzey (Eds.), Handbook of Social Psychology (Vol. 2, pp. 504-553). Boston: McGraw Hill.

Daniel, P. T. (2005). The not so strange path of desegregation in America's public schools. Negro Educational Review, 56(1), 57-66.

Davies, J. (2010). Neoliberalism, governance and the integral state. Paper presented at Critical Governance Conference, University of Warwick, 13-14 December. Retrieved from http://www2.warwick.ac.uk/fac/soc/wbs/ projects/orthodoxies/papers/

Davis v. County School Board of Prince Edward County, 346 U.S. 483 (1954).

DeCuir, J. T., \& Dixson, A. D. (2004, June-July). "So when it comes out they aren't surprised that it is there": Using Critical Race Theory as a tool of analysis of race and racism in education. Educational Researcher, 33(5), 26-31.

Delpit, L. (2006). Other people's children: Cultural conflict in the classroom. New York: The New Press.

deMarrais, K. B., \& Lapan, S. D. (Eds.). (2003). Foundations for research: Methods of inquiry in education and the social sciences. London: Routledge.

Denzin, N., and Lincoln, Y. (1994). Handbook of Qualitative Research. Thousand Oaks, CA: Sage Publications. 
Dey, I. (2003). Qualitative data analysis: A user friendly guide for social scientists. Routledge.

Deprivation (2018). Lexico.com. Retrieved from https://www.lexico.com/en/definition/deprivation

Diem, S., \& Frankenberg, E. (2013). The politics of diversity: Integration in an era of political and legal uncertainty. Teachers College Record, 115(11).

Doherty, P. J. (1970, March 1). Integration now: A study of Alexander v. Holmes County Board of Education. Notre Dame Law Review, 45(3). Retrieved from http://scholarship.law.nd.edu/ndlr/vol45/iss3/6

Donald, D. H. (1995). Lincoln. New York: Simon \& Schuster.

Donoghue, J. (2010, October). Out of the land of bondage: the English revolution and the Atlantic origins of abolition. American Historical Review, 115(4), 942.

Dorris, R. (2009). Race as a social construct: The impact on education. Forum on Public Policy Online, 2009(1).

Douglass, F. (2016). The essential Douglass: Selected writings and speeches. Indianapolis: Hackett.

Dovidio, J. (2001). On the nature of contemporary prejudice: The third wave. Journal of Social Issues, 57(4), 829-849.

Dred Scott v. Sandford, 60 U.S. 393 (1857).

Du Bois, W. E. (1949/1970). The Freedom to Learn. In P. S. Foner (Ed.), W.E.B. Du Bois Speaks (pp. 230-231). New York: Pathfinder.

Du Bois, W. E. B. (1903). The Souls of Black Folk. New York: Bantam Classic. 
Du Bois, W. E., \& Aptheker, H. (1985). Against racism: Unpublished, papers, addresses, 1887-1961. Amherst: University of Massachusetts Press.

Dudley-Marling, C. (2007). Return of the deficit. Journal of Education Controversy, 2(1). Retrieved from http://cedar.wwu.edu/jec/vol2/iss1/5

Eisner, E. (1997). The enlightened eye: Qualitative inquiry and the enhancement of educational practice. Columbus: Merrill.

Elliott, M. (2001). Race, colorblindness, and the democratic public: Albion W. Tourgee's radical principles in Plessy v. Ferguson. The Journal of Southern History, 67(2), 287-330.

Ellis, Kate; Smith, Stephen (2011). State of siege: Mississippi whites and the civil rights movement. American Public Media. Retrieved May 15, 2018.

Elo, S., \& Kyngas, H. (2008). The qualitative content analysis process. Journal of Advanced Nursing, 62, 107-115.

Emerson, R., Fretz, R., \& Shaw, L. (2011). Writing ethnographic field notes (2nd ed.). Chicago: University of Chicago Press.

Enforcement Act of 1869, 16 Stat. $\S 140-146$ (1869).

Every Student Succeeds Act. (2015). Washington, D.C.: U.S. Government Publishing Office] Retrieved from http://search.ebscohost.com/login.aspx?direct=true \&db=cat04885a\&AN=merlin.b $11441660 \&$ site $=$ eds-live $\&$ scope $=$ site 
Farkas, S., \& Johnson, J. (1999). Looking at the schools: public agenda asks AfricanAmerican and white parents about their aspirations and their fears. Arts Education Policy Review, 100(4), 24. https://doiorg.proxy.mul.missouri.edu/10/1080/10632919909599466

Fiel, J. E. (2013). Decomposing school resegregation: Social closure, racial imbalance, and racial isolation. American Sociological Review, 78(5), 828.

Fine, M. (2004). The power of the Brown v. Board of Education decision: Theorizing threats to sustainability. American Psychologist, 59(6), 502-510. http://dx.doi.org/10.1037/0003-066X.59.6.502

Finkelman, P. (2012). Slavery in the United States: Persons or property? In J. Allain (Ed.), The legal understanding of slavery: From the historical to the contemporary (pp. 105-134). Retrieved from http://scholarship.law.duke.edu/cgi/viewcontent.cgi?article=5386\&content=facult y_scholarship

Fiss, O. M. (1971, Summer). The Charlotte-Mecklenberg case: Its significance for northern school desegregation. The University of Chicago Law Review, 38(4), 697-709.

Fram, S. M. (2013). The Constant Comparative Analysis Method Outside of Grounded Theory. Qualitative Report, 18.

Frankenberg, E., \& Orfield, G. (2012). The resegregation of suburban schools: A hidden crisis in American education. Cambridge: Harvard Education Press.

Frankenberg, R. (1993). White women, race matters: The social construction of whiteness. Minneapolis, MN: University of Minnesota Press. 
Freeman v. Pitts, 503 U.S. 467 (1992).

Freire, P., \& Freire, A. M. A. (2004). EPZ pedagogy of hope: Reliving pedagogy of the oppressed. A\&C Black.

Frey, W. (2011). Melting pot cities and suburbs: Racial and ethnic change in metro America in the 2000s. Washington, DC: The Brookings Institution.

Freyer, T. A. (2006). Cooper v. Aaron: Incident and consequence. The Arkansas Historical Quarterly, 65(1), 1-6.

Fylkesnes, S. (2018). Whiteness in teacher education discourses: A review of the use and meaning making of the term cultural diversity. Teaching and Teacher Education, 71, 24-33. https://doi.org/10.1016/j.tate.2017.12.005

Gaertner, Samuel L. and John F. Dovidio. (1986). The Aversive Form of Racism. In John F. Dovidio and Samuel L. Gaertner (Eds.) in Prejudice, Discrimination, and Racism (pp. 61-89). Orlando, FL: Academic Press.

Gartner, A., \& Ferreira, C. (2014). A state of action. New York Law School Law Review, 59(1), 95-109.

Gay, G. (2010). Culturally responsive teaching: Theory, research, and practice (2nd ed.). New York: Teachers College Press.

Gebhart v. Belton, 33 Del. Ch. 144, 87 A.2d 862 (Del. Ch. 1952), aff'd, 91 A.2d 137 (Del. 1952).

Gerber, R., \& Friedlander, A. (2008). The civil rights act of 1875: A reexamination. Connecticut Academy of Arts.

Gillborn, D. (1995). Racism and antiracism in real schools. Buckingham: Open University Press. 
Giroux, S. S. (2010). From the (new) gilded age to the (new) new deal: DuBois on race, education, and the possibilities of a reconstructed America. Cultural Studies Cultural Methodologies, 10(5), 397-403. http://dx.doi.org/10.1177/1532708610374814

Glaser, B. G., \& Strauss, A. L. (1967). The discovery of grounded theory: Strategies for qualitative research. New York, NY: Aldine De Gruyter.

Glazier, J. (2003). Moving closer to speaking the unspeakable: White teachers talking about race. Teacher Education Quarterly, 30(2), 73-94.

Godwin, R. K., Leland, S. M., Baxter, A. D., \& Southworth, S. (2006). Sinking Swann: Public school choice and the resegregation of Charlotte's public schools. Review of Policy Research, 23(5), 983-997. http://dx.doi.org/10.1111/j.15411328.2006.00246.x

Goldstein, S., Gee, E. G., \& Daniel, P. T. (1995). Law and Public Education. Charlottesville: Michie Law Publishers.

Gorski, P. C. (2011). Unlearning deficit ideology and the scornful gaze: Thoughts on authenticating the class discourse in education. In R. Ahlquist, P. C. Gorski, \& T. Montano (Eds.), Assault on kids: How hyper-accountability, corporatization, deficit ideologies, and Ruby Payne are destroying our schools (pp. 152-176). New York: Peter Lang.

Grosland, T. J., \& Matias, C. E. (2017). Fervent Fortitudes: Curriculum at the Intersection of Emotions and Race. JCT: Journal of Curriculum Theorizing 32(2), 72-83. 
Graglia, L. A. (2014, Winter). The Supreme Court's perversion of the 1964 Civil Rights Act. Harvard Journal of Law and Public Policy, 37(1), 103.

Green v. County School Board of New Kent County, 391 U.S. 430 (1968).

Griffin v. County School Board of Prince Edward County, 377 U.S. 218 (1964).

Grissmer, D. W., Flanagan, A., \& Williamson, S. (1998). Why did the black-white score gap narrow in the 1970s and 1980s? In C. Jencks \& M. Phillips (Eds.), The blackwhite test score gap (pp. 182-228). Washington, DC: Brookings Institution Press.

Grudridge, P. O. (1989). Privileges and permissions: The Civil Rights Act of 1875. Law and Philosophy, 8(1), 83-130. http://www.jstor.org/stable/3504632

Hale, F. W. (2004). What makes racial diversity work in higher education: Academic leaders present successful policies and strategies. Stylus Publishing.

Hammersley, M., and P. Atkinson (1983) Ethnography: Principles in Practice. London: Routledge.

Hartmann, D., Croll, P., Larson, R., Gerteis, J., \& Manning, A. (2017). Colorblindness as identity: Key determinants, relations to ideology, and implications for attitudes about race and policy. Sociological Perspectives, 60(5), 866 -888. https://doi.org/10.1177/0731121417719694

Hatch, J. A. (2002). Doing qualitative research in education settings. Albany: State University of New York Press.

Haviland, V. (2008). Things get glossed over: Rearticulating the silencing power of Whiteness in education. Journal of Teacher Education, 59(1), 40-54. 
Hayes, C., \& Juarez, B. (2012). There is no culturally responsive teaching spoken here: A critical race perspective. Democracy \& Education, 20(1), 1-14. Retrieved from https://democracyeducationjournal.org/home/vol20/iss 1/1

Hillard, A. G. (1995). The maroon within us: Selected essays on African American community socialization. Baltimore: Black Classic Press.

Holme, J. J., Diem, S., \& Welton, A. (2014). Suburban school districts and demographic change: The technical, normative, and political dimensions of response. Educational Administration Quarterly, 50(1), 34-66.

Hochschild, J. L. (1995) Facing Up to the American Dream. Princeton, NJ: Princeton University Press.

Howard, G. R. (2006). We can't teach what we don't know: White teachers, multiracial schools (2nd ed.). New York: Teachers College Press.

Huber, J., \& Whelan, K. (1999). A marginal story as a place of possibility: negotiating self on the professional knowledge landscape. Teaching and Teacher Education, 15(4), 381-396. https://doi-org.proxy.mul.missouri.edu/10.1016/S0742-

051X(98)00048-1

Hughes, L. (1951). Harlem. Montage of a dream deferred. New York: Holt.

Hughey, M., Embrick, D., \& Doane, A. (2015). Paving the way for future race research: Exploring the racial mechanisms within a color-blind, racialized social system. American Behavioral Scientist, 59(11), 1347-1357.

https://doi.org/10.1177/0002764215591033 
Hussar, W. J., \& Bailey, T. M. (2013). Projections of Education Statistics to 2022 (NCES 2014-051). U.S. Department of Education, National Center for Education Statistics. Washington, DC: U.S. Government Printing Office.

Hutchison, P. (2015). The Harlan renaissance: Colorblindness and white domination in justice John Marshall Harlan's dissent in Plessy v. Ferguson. Journal of African American Studies, 19(4), 426-447. http://dx.doi.org/10.1007/S12111-015-9316-y

Ioanide, P. (2015). The emotional politics of racism : how feelings trump facts in an era of colorblindness. Stanford University Press.

Irvine, J. J. (2003). Educating teachers for diversity: Seeing with a cultural eye. New York, NY: Teachers College Press.

Irvine, J. J. (2010). Foreword. In H. R. Milner's (Ed.), Culture, curriculum, and identity in education (pp. xi-xvi). New York: Palgrave Macmillan.

Jackson, Y. (2011). The pedagogy of confidence: Inspiring high intellectual performance in urban schools. New York: Teachers College Press.

Jefferson, T. (n.d.). Notes on the state of Virginia.

Jonassen, D. H., \& Hernandez-Serrano, J. (2002). Case-based reasoning and instructional design: Using stories to support problem solving. Educational Technology Research and Development, 50(2), 65.

Johnson, A. G. (2006). Privilege, power, and difference. New York, NY: McGraw-Hill. Johnson, L. (2002). "My eyes have been opened": White teachers and racial awareness. Journal of Teacher Education, 53(2), 153-67. https://doi.org/10.1177/0022487102053002007 
Kennedy, J.F. (1963). Report to the American people on civil rights. John F. Kennedy Library. Retrieved from https://www.jfklibrary.org/learn/about-jfk/historicspeeches/televised-address-to-the-nation-on-civil-rights

Kerl, S. B. (2002). Using narrative approaches to teach multicultural counseling, journal of Multicultural Counseling and Development, 30, 135-143.

Keyes v. School District No. 1, 413 U.S. 189 (1973).

Klarman, M. J. (2004). From Jim Crow to civil rights: The supreme court and the struggle for racial equality. New York: Oxford University Press.

Kluger, R. (1975). Simple justice. New York: Vintage Books.

Kozol, J. (2005). Still separate, still unequal. Harper's Magazine, 311(1864), 41.

Kozulin, A., Feuerstein, R., \& Feuerstein, R. (2006). Mediated learning experience paradigm in teacher training.

Kye, S. (2018). The persistence of white flight in middle-class suburbia. Social Science Research, 72, 38-52. https://doi.org/10.1016/j.ssresearch.2018.02.005

Ladson-Billings, G. (2000). Fighting for our lives: Preparing teachers to teach African American students. Journal of Teacher Education, 51(3), 206-214.

Ladson-Billings, G. (2006a). From the Achievement Gap to the Education Debt: Understanding Achievement in U.S. Schools. Educational Researcher, 35(7), 312.

Ladson-Billings, G. J. (1999). Preparing teachers for diverse student populations: A critical race theory perspective. Review of Research in Education, 24, 211-247. 
Ladson-Billings, G. (2006b). "Yes, but how do we do it?” practicing culturally relevant pedagogy. In J. Landsman and C. W. Lewis (Eds), White teachers/diverse classrooms: A guide to building inclusive schools, promoting high expectations, and eliminating racism (pp. 29-42). Sterling, VA: Stylus.

Lamb, C. M. (2005). Housing segregation in suburban America since 1960: Presidential and judicial politics. New York: Cambridge University Press.

Lave, J. W., \& Wenger, E. (1990). Situated learning: legitimate peripheral participation. New York: Cambridge University Press

LeCompte, M. D., \& Schensul, J. J. (2010). Designing and conducting ethnographic research: An introduction (Vol. 1). Rowman Altamira.

Levine, D. U., Cooper, E. J., \& Hilliard III, A. (2000). National urban alliance professional development model for improving achievement in the context of effective schools research. Journal of Negro Education, 305-322.

Lewis, A. E. (2001). There is no "race" in the schoolyard: Color-blind ideology in an (almost) all-white school. American Educational Research Journal, 38(4), 781811.

Lilley III, W. (1971). Housing report/Courts lead revolutionary trend toward desegregation of residential areas. National Journal, 27, 2346-47.

Lincoln, A. (1862). Address on colonization to a deputation of negroes. In The collected works of Abraham Lincoln, (pp. 370-375). New Brunswick, NJ: Rutgers University Press.

Lincoln, Y. S., \& Guba, E. G. (1985). Naturalistic inquiry. Newberry Park. 
Lipman, P. (2015) Urban education policy under Obama. Journal of Urban Affairs, 37(1), 57-61. https://doi-org.proxy.mul.missouri.edu/10.1111/juaf.12163

Lipton, A. (1962). Cultural deprivation. The Journal of Education Sociology, 36(1).

Logan, J., Zhang, W., \& Oakley, D. (2017) Court orders, white flight, and school district segregation, 1970-2010. Social Forces, 95(3), 1049-1075. https://doi.org/10.1093/sf/sow104

Lopez, G. R., \& Burciaga, R. (2014). The troublesome legacy of "Brown v. Board of Education”. Educational Administration Quarterly, 50(5), 796-811.

Lowery, C. D., Marszalek, J. F., \& Upchurch, T. A. (2003). Birmingham conflict. In The Greenwood encyclopedia of African American civil rights: From emancipation to the twenty-first century. Westport, CN: Greenwood Press.

Lum v. Rice, 275 U.S. 78 (1927).

Maglo, K. N. (2010). Genomics and the conundrum of race: some epistemological and ethical consideration. Perspectives in Biology and Medicine, 53(3), 357-372. http://dx.doi.org/10.1353/pbm.0.0171

Maidment, R. A. (1973). Plessy v. Ferguson re-examined. Journal of American Studies, $7(2), 125-132$.

Malik, K. (2013). Human development report 2013. The rise of the South: Human progress in a diverse world. The Rise of the South: Human Progress in a Diverse World (March 15, 2013). UNDP-HDRO Human Development Reports.

Massey, D. (2015). The Legacy of the 1968 Fair Housing Act. Sociological Forum, 30(S1), 571. 
Matias, C. E., Henry, A., \& Darland, C. (2017). The Twin Tales of Whiteness: Exploring the Emotional Roller Coaster of Teaching and Learning about Whiteness. Taboo: The Journal of Culture \& Education, 16(1), 7-29. https://doiorg.proxy.mul.missouri.edu/10.31390;taboo.16.1.04

May, D., \& Vinovskis, M. A. (1977). A ray of millennial light: Early education and social reform in the infant school movement in Massachusetts, 1826-1840. In T. K. Hareven (Ed.), Family and kin in American urban communities, 1800-1940 (pp. 62-99). New York: Watts.

Mazzei, L. (2011). Desiring silence: Gender, race and pedagogy in education. British Educational Research Journal, 37(4), 657.

Mazzei, L. (2008). Silence speaks: Whiteness revealed in the absence of voice. Teaching and Teacher Education, 24(5), 1125-1136. https://doiorg.proxy.mul.missouri.edu/10.1016/j.tate.2007.02.009

McDermott, K. A., Frankenberg, E. \& DeBray, E. (2016). How the Administration's "Stronger Together" school integration proposal built on the lessons learned from the flawed TASAP program. Retrieved from https://schooldiversity.org/pdf/DiversityIssueBriefNo7.pdf

McLeod, J. (2015). Narrative case studies and practice-based learning: Reflections on the case of "Mr. R." Pragmatic Case Studies in Psychotherapy, 11(4). Retrieved from http://pcsp.libraries.rutgers.edu

Mendez v. Westminster, 161 F. 2d 774 (9th Cir. 1947).

Mendez v. Westminster, 64 F. Supp. 544 (S.D. Cal. 1946). 
Merriam, S. B. (1998). Qualitative research and case study applications in education. San Francisco, CA: Jossey-Bass.

Merriam, S. B. (2015). Case study research in education: A qualitative approach. JosseyBass.

Meyer, C. B. (2001). A case in case study methodology. Field Methods, 13(4), 329-352. http://dx.doi.org/10.1177/1525822X0101300402

Meyer, J. (1994). The evolution of modern stratification systems. In D. B. Grusky (Ed.), Social stratification: Class, race, and gender in sociological perspective (pp. 730737). Boulder, CO: Westview Press.

Mickelson, R. A. (2001). Subverting Swann: First- and second-generation segregation in the Charlotte-Mecklenberg schools. American Education Research Journal, $38(2), 215-252$.

Mickelson, R., \& Nkomo, N. (2012). Integrated schooling, life course outcomes, and social cohesion in multiethnic democratic societies. Review of Research in Education, 36, 197-238. http://dx.doi.org/10.3102/0091732X1142266

Miles, M. B., \& Huberman, A. M. (1994). Qualitative data analysis: an expanded sourcebook. Thousand Oaks, CA: Sage.

Milliken v. Bradley, 418 U.S. 717 (1974).

Milliken v. Bradley, 433 U.S. 267 (1977).

Milner, H. R. (2012). Beyond a test score: Explaining opportunity gaps in educational practice. Journal of Black Studies, 43(6), 693-718.

https://doi.org/10.1177/0021934712442539 
Milner, H. R. (2015). Start where you are, but don't stay there: Understanding diversity, opportunity gaps, and teaching in today's classrooms. Cambridge, MA: Harvard Education Press.

Milner, H. R. (2010). What does teacher education have to do with teaching? Implications for diversity studies. Journal of Teacher Education, 61(1-2), 118131.

Milner, H. R., Delale-O’Connor, L. A., Murray, I. E., \& Farinde, A. A. (2016). Reflections on "Brown" to understand "Milliken v. Bradley": What if we are focusing on the wrong policy questions? Teachers College Record, 118(3).

Milner, H. R., \& Williams, S. M. (2008). Analyzing education policy and reform with attention to race and socio-economic status. Journal of Public Management and Social Policy, 14(2), 33-50.

Mishler, E.G. (1995). Models of narrative analysis: A typology. Journal of Narrative and Life History 5(2), 87-123.

Missouri v. Jenkins, 515 U.S. 70 (1995).

Moll, L. C., \& González, N. (2004). Engaging life: A funds of knowledge approach to multicultural education. In J. Banks \& C. McGee Banks (Eds.), Handbook of research on multicultural education (pp. 699-715). New York: Jossey-Bass.

Monroe, P. (Ed.). (1911). A cyclopedia of education. New York: Macmillan.

Morgan, E. S. (1975). American slavery, American freedom: the ordeal of colonial Virginia. Norton.

Motley, C. B. (1998). Equal justice under the law. New York: Farrar, Straus, \& Giroux. 
National Commission on Teaching and America's Future (NCTAF). What Matters Most: Teaching for America's Future, 1996.

Neville, H. A., Awad, G. H., Brooks, J. E., Flores, M. P., \& Bluemel, J. (2013). Colorblind racial ideology: theory, training, and measurement implications in psychology. American Psychologist, 68(6), 455-466.

http://dx.doi.org/10.1037/a0033282

Neville, H. A., Lilly, R. L., Duran, G., Lee, R. M., \& Browne, L. (2000). Construction and initial validation of the color-blind racial attitudes scale (CoBRAS). Journal of Counseling Psychology, 47(1), 59-70. https://doiorg.proxy.mul.missouri.edu/10.1037/0022-0167.47.1.59

Neville, H. A., Poteat, V. P., Lewis, J. A., \& Spanierman, L. B. (2014). Changes in White college students' color-blind racial ideology over 4 years: Do diversity experiences make a difference? Journall of Counseling Psychology, 61(2), 179190. https://doi-org.proxy.mul.missouri.edu/10.1037/a0035168

Neville, H., Spanierman, L., \& Doan, B.-T. (2006). Exploring the association between color-blind racial ideology and multicultural counseling competencies. Cultural Diversity and Ethnic Minority Psychology, 12(2), 275-290. https://doiorg.proxy.mul.missouri.edu/10.1037/1099-9809.12.2.275

Nieto, S. (1994). Lessons from students on creating a chance to dream. Harvard Educational Review 64(4), 392-427. https://doi.org/10.17763/haer.64.4.4846361m306pl670 
Nixon, Richard. 1971. Statement by the President on Federal Policies Relative to Equal Housing Opportunity.” White House Central Files: Staff Member and Office Files, Leonard Garment, Box 94, Folder: Alpha-Subject Files, June 11, 1971. Nixon Presidential Materials (NPM), National Archives and Records Administration, College Park, MD.

No Child Left Behind Act of 2001, P.L. 107-110, 20 U.S.C. § 6319 (2002).

Noguera, P. A. (2003). Schools, prisons, and social implications of punishment: Rethinking disciplinary practices. Theory Into Practice, 42, 341-350.

Ogbu, J. U. (1978). Minority and caste: the American system in cross-cultural perspective. New York: Academic Press.

Ogbu, J. U. (1994). Racial stratification and education in the United States: Why inequality persists. Teachers College Record, 96(2), 264.

Ogden, N., Perkins, C., \& Donahue, D. M. (2008, August). Not a peculiar institution: Challenging students' assumptions about slavery in U.S. history. The History Teacher, 41(4), 469. http://dx.doi.org/10.3102/00028312038002215

Ojike, U. (2018). Colour brave: How to start courageous conversations about race. Retrieved from https://www.gingerpublicspeaking.com/wow/ugo-ojike

Ollenrenshaw, J. A., \& Creswell, J. W. (2002). Narrative research: A comparison of two restorying data analysis approaches. Qualitative Inquiry, 8(3), 329-347.

Orfield, G., \& Eaton, S. (1996). Dismantling desegregation: The quiet reversal of Brown v. Board of Education. New York: The New Press. 
Orfield, G., Lee, C., \& Harvard Civil Rights Project, C. M. (2004). “Brown” at 50: King's Dream or "Plessy's" Nightmare? The Civil Rights Project at Harvard University.

Ortiz, L., \& Jani, J. (2010). Critical race theory: A transformational model for teaching diversity. Journal of Social Work Education, 46(2).

Parents Involved in Community Schools v. Seattle School District No. 1, 551 U.S. 701 (2007).

Parker, L., Deyhle, D., \& Villenas, S. (Eds.). (1999). Race is ...race isn't: Critical race theory and qualitative studies in education. Boulder, CO: Westview Press.

Parker, L., \& Villalpando, O. (2007). A race(ialized) perspective on education leadership: Critical race theory in educational administration. Educational Administration Quarterly, 43(5), 519-524. http://dx.doi.org/10.1177/0013161X07307795

Patterson, J. T. (2005). Brown v. Board of Education and the civil right movement. Stetson Law Review, 34(2), 413-422.

Patton, M. Q. (2002). Qualitative evaluation and research methods (3rd ed.). Thousand Oaks, CA: Sage.

Pauley, G. E. (1997) Presidential rhetoric and interest group politics: Lyndon B. Johnson and the civil rights act of 1964. Southern Journal of Communication, 63(1), 1-19. http://dx.doi.org/10.1080/10417949709373074

Peck, J., Thoedore, N., \& Brenner, N. (2012). Neoliberalism Resurgent? Market Rule after the Great Recession. The South Atlantic Quarterly, 111(2), 265-288. 
Phillippi, J., \& Lauderdale, J. (2018). A guide to field notes for qualitative research:

Context and conversation. Qualitative Health Research, 28(3), 381-388. https://doi.org/10.1177/1049732317697102

Plessy v. Ferguson, 163 U.S. 537 (1896).

Quintana, R. A. (2018, Spring). Slavery and the conceptual history of the early U.S. state. Journal of the New Republic, 38(1), 77-86. http://dx.doi.org/10.1353/jer.2018.0004

Randolph-McCree, I., \& Pristoop, E. (2005). The funding gap 2005: Low-income and minority students shortchanged by most states. A special report by the Education Trust. Washington, DC: Education Trust.

Reardon, S. F., Grewal, E. T., Kalogrides, D. \& Greenberg, E. (2012). Brown fades: The end of court-ordered school desegregation and the resegregation of American public schools. Journal of Policy Analysis and Management, 31(4), 876. https://doi-org.proxy.mul.missouri.edu/10.1002/pam.21649

Ratcliffe, J. W. (1983). Notions of validity in qualitative research methodology. Knowledge, 5(2), 147-167.

Reber, (2005). Court-Ordered Desegregation: Successes and Failures Integrating American Schools since Brown versus Board of Education. Journal of Human Resources, 40(3), 559-590.

Riddick v. School Board of the City of Norfolk, 784 F. 2d 521 (4th Cir. 1986).

Roberts v. Boston, 59 Mass. (5 Cush.) 198 (1850). 
Robinson, S. (2017). African American citizenship, the 1883 Civil Rights Cases and the creation of the Jim Crow South. History, 102(350), 225-241. http://dx.doi.org/10.1111/1468-229.12375

Rodriguez, J. P. (Ed.). (2007). Slavery in the United States: A social, political, and historical encyclopedia. Santa Barbara, CA: ABC-CLIO.

Romney, George. 1970. Letter to Richard Nixon, November 16. George Romney Papers, Box 4, Folder: HUD’s CR Policy. Bentley Historical Library, Ann Arbor, MI.

Rossiter, M. (1999). Understanding adult development as narrative. New directions for adult and continuing education, 1999(84), 77-85.

Ruef, M., \& Fletcher, B. (2003, December). Legacies of American slavery: Status attainment among southern blacks after emancipation. Social Forces, 82(2), 445480. http://dx.doi.org/10.1353/sof.2004.0024

Ryan, J. E. (2010). Five miles away, a world apart: one city, two schools, and the story of educational opportunity in modern America. Oxford; New York : Oxford University Press, 2010.

Saldaña, J. (2016). The coding manual for qualitative researchers $\left(3^{\text {rd }}\right.$ Ed.) Thousand Oaks, CA: Sage.

Sanders, R. (2002, Winter). Rassling a governor: Defiance, desegregation, Claude Kirk, and the politics of Richard Nixon's southern strategy. The Florida Historical Quarterly, 80(3), 332-359.

Santiago, M. (2013, March 1). Mendez v. Westminster, 1947: Teaching a new chapter of history. Phi Delta Kappan, 94(6), 35.

Schussler, D. L., Stooksberry, L. M., \& Bercaw, L. A. (2010). Understanding teacher 
candidate dispositions: Reflecting to build self-awareness. Journal of Teacher Education, 61(4), 350-363.

Schwartz, B. (2015). The Emancipation Proclamation: Lincoln's many second thoughts. Society, 52(6), 590-603.

Scott, R. W. (2014). Institutions and Organizations (4th ed.). Los Angeles, CA: Sage.

Secada, W. (1989) Educational equity versus equality of education: an alternative conception, in: W. Secada (Ed.) Equity and education (pp. 68-88). New York: Falmer.

Second Enforcement Act, 16 Stat. $\S ~ 433-440$ (1871).

Sedler, R. A. (1987). The profound impact of Milliken v. Bradley. Wayne Law Review, 33(5), 1693-1722.

Seshadri-Crooks, K. (2000) Desiring whiteness: a Lacanian analysis of race. London: Routledge.

Sheets, R. H. (2007). Competency vs. good intentions: Diversity ideologies and teacher potential. International Journal of Qualitative Studies in Education, 16(1), 111120.

Singleton, G. E., \& Linton, C. (2006). Courageous conversations: A field guide for achieving equity in schools. Thousand Oaks, CA: Corwin Press.

Smith, G. W. (2015). Blood cries out from the ground: Reflections on Ferguson. Anglican Theological Review, 97(2), 255-263.

Solorzano, D. G. \& Yosso, T. J. (n.d.) Critical race methodology: Counter-storytelling as an analytical framework for education research. Qualitative Inquiry, 8(1), 23-44. https://doi-org.proxy.mul.missouri.edu/10.1177.107780040200800103 
Spero, S. D., \& Harris, A. L. (1968). The black worker: The negro and the labor movement. New York: Atheneum.

Stake, R. E. (1995). The art of case study research. Thousand Oaks, CA: Sage.

Strum, P. (2014, November). "We always tell our children they are Americans": Mendez v. Westminster and the beginning of the end of school segregation. Journal of Supreme Court History, 39(3), 307-328. http://dx.doi.org/10.1111/j.1540$5818.2014 .12051 x$

Suburb. (2012). Dictionary.com. Retrieved from https://www.dictionary.com/browse/suburb.

Swann v. Charlotte-Mecklenberg Board of Education, 402 U.S. 1 (1971).

Swaroop, S. \& Krysan, M. (2011) The determinants of neighborhood satisfaction: Racial proxy revisited. Demography, 48(3), 1203.

Taguieff, P.-A. (2001). The force of prejudice: on racism and its doubles. University of Minnesota Press.

Tate, W. F. (2008). Geography of opportunity: Poverty, place, and educational outcomes. Educational Researcher, 37(7), 397-411.

Texas Dept. of Housing and Community Affairs v. Inclusive Communities Project, Inc., 576 U.S. $(2015)$

The 50th anniversary of the Civil Rights Act of 1957 and its continuing importance [electronic resource]: Hearing before the Committee on the Judiciary, United States Congress, One Hundred Tenth Congress, first session, Sept. 5, 2007. (2008). Retrieved from http://laurel.1so.missouri.edu:80/record=b6752414 s1

Third Enforcement Act, 17 Stat. $§ 13$ (1871). 
Tilly, C. (1998). Durable inequality. Berkley, CA: University of California Press.

Toldson, I. (2018). No bs (bad stats): Deconstructing the black-white achievement gap using a DuBoisian framework (editor commentary). The Journal of Negro Education, 87(3), 191-199.

Tracy, S. J. (2013). Qualitative research methods: collecting evidence, crafting analysis, communicating impact. Wiley-Blackwell.

Trawalter, S., \& Richeson, J. (2008). Let's talk about race, baby! When Whites' and Blacks' interracial contact experiences diverge. Journal of Experimental Social Psychology, 44(4), 1214-1217.

Turner E. (2015). Districts' responses to demographic change: making sense of race, class, and immigration in political and organizational context. American Educational Research Journal, 52(1), 4-39. https://doiorg.proxy.mul.missouri.edu/10.3102/0002831214561469

Tyack, D. B. (2003). Seeking common ground: public schools in a diverse society. Cambridge, MA: Harvard University Press.

Tyack, D. (1974). The one best system: A history of American urban education. Cambridge: Harvard University Press.

U.S. Census Bureau. (2011, March). Population Distribution and Change: 2000-2010 (Report No. C2010BR-01). Retrieved from https://www.census.gov/prod/cen2010/briefs/c2010br-01.pdf

U.S. Const. amend. XIII.

U.S. Const. amend. XIV.

U.S. Const. amend. XV. 
U.S. Const. art. $1, \S 2$, cl. 1.

U.S. Department of Education, National Center for Education Statistics. (2016). The Condition of Education 2016. Retrieved from nces.ed.gov/pubs2016/2016144.pdf

U.S. Department of Education, National Center for Education Statistics. (2018). Status and trends in the education of racial and ethnic groups, 2018. Retrieved from https://nces.ed.gov/pubs2019/2019038.pdf

U.S. Department of Education, National Center for Education Statistics. (2019). The Condition of Education 2019. Retrieved from https://nces.ed.gov/pubs2019/2019144.pdf

United States Department of Justice. (2017). History of Federal Voting Rights Laws. Retrieved from https://www.justice.gov/crt/history-federal-voting-rights-laws United States Congress. (1866, June 16). The House Joint Resolution proposing the 14th amendment to the Constitution. Enrolled Acts and Resolution of Congress, 17891999, General Records of the United States Government, (Record Group 11). National Archives.

Valelly, R. M. (1993). The puzzle of disfranchisement: Party struggle and AfricanAmerican suffrage in the south, 1867-1894. Harvard University: Center for American Political Studies.

Valencia, R.R. (1997a). Introduction. In R.R. Valencia (Ed.), The evolution of deficit thinking (pp. ix-xvii). London: Falmer Press.

van Dijk, T. A. (1992). Discourse and the Denial of Racism. Discourse \& Society, 3(1), 87. 
Van Horn, J. (2017). The dark “iconoclast": African Americans' artistic resistance in the Civil War south. Art Bulletin, 99(4), 133-167.

Vinovskis, M. A. (1987, January). Family and schooling in nineteenth-century America. Journal of Family History, 12(1-3), 19-37.

Vorauer, J. D., Hunter, A. J., Main, K. J., \& Roy, S. A. (2000). Meta-stereotype activation: Evidence from indirect measures for specific evaluative concerns experienced by members of dominant groups in intergroup interaction. Journal of Personality and Social Psychology, 78(4), 690-707. https://doiorg.proxy.mul.missouri.edu/10.1037/0022-3514.78.4.690

Voting Rights Act of 1965, 79 Stat. $§ 437$ (1965).

Warren, C. A. (2018). Empathy, teacher dispositions, and preparation for culturally responsive pedagogy. Journal of Teacher Education, 69(2), 169-183.

Warren, C. A., \& Hotchkins, B. K. (2015). Teacher education and the enduring significance of "false empathy." The Urban Review, 47(2), 266-292. Responsive Pedagogy. Journal of Teacher Education, 69(2), 169-183.

Watkins, W. H. (2001). The white architects of black education: ideology and power in America, 1865-1954. New York: Teachers College Press.

Waugh, D. (2012). The issue is the control of schools. Southern Cultures, 18(3), 76. http://dx.doi.org/Retrieved from

Wells, A. S., Holme, J. J., Revilla, A. T. \& Atanda, A. K. (2004, January). How society failed school desegregation policy: Looking past the schools to understand them. Review of Research in Education, 28(1), 47-99.

West, C. (2001). Race matters. Beacon Press. 
Wetherell, M., \& Potter, J. (1992). Mapping the Language of Racism; Discourse and the Legitimation of Exploitation. New York; Columbia University Press.

Whinnery, J. C. (1952, December). Critical issues in education. Phi Delta Kappan, 34(3), 87-93.

White flight. (2019). Merriam-Webster. Retrieved from https://www.merriamwebster.com/dictionary/white\%20flight.

Wilson, T. B. (1965). The black codes of the south. University of Alabama Press.

Wilson, W. J. (1978). The declining significance of race. Society, 15(5), 11-11.

Winfrey, O. (Producer). (2011). When you know better. Retrieved from www.oprah.com/oprahs-lifeclass/the-powerful-lesson-maya-angelou-taughtoprah-video

Winter, M. (2014). The Civil Rights Movement. North Mankato, MN: ABDO Publisher. Woodward, C. V. (1974). The strange career of Jim Crow (3rd ed.). New York: Oxford University Press.

Wormser, R. (2003). The rise and fall of Jim Crow. New York: St. Martin's Griffith.

Yin, R. K. (1994). Designing single and multiple case studies. In Bennett, N., Glatter, R., \& Levacic, R. (Eds.), Improving Education Management through Research and Consultancy. London: Open University.

Yin, R. K. (2009). Case study research: design and methods. ( $3^{\text {rd }}$ Ed.) Thousand Oaks, CA: Sage.

Zeichner, K. (2006). Reflections of a university-based teacher educator on the future of college-and university-based teacher education. Journal of Teacher Education, 57(3), 326-340. https://doi.org/10.1177/0022487105285893 
Zelizer, J. E. (2012). Governing America: The revival of political history. Princeton, N.J.: Princeton University Press.

Zou, L. X. \& Dickter, C. L. (2013). Perceptions of racial confrontation: The role of color blindness and comment ambiguity. Cultural Diversity and Ethnic Minority Psychology, 19(1), 92-96. https://doiorg.proxy.mul.missouri.edu/10.1037/a0031115

Zuczek, R. (2015). Reconstruction: A historical encyclopedia of American mosaic. Santa Barbara: Greenwood, an imprint of ABC-CLIO, LLC. 
Stephanie Sanders Green received her Bachelor of Arts degree in Elementary Education from Columbia College with an emphasis in Psychology and Social Studies. She earned a Master's degree in Elementary School Administration from William Woods University, and a Doctor of Education degree in Educational Leadership and Policy Analysis from the University of Missouri-Columbia. She is a member of Alpha Chi and Kappa Delta Pi honor societies, Delta Kappa Gamma International Society for Key Women Educators, Phi Delta Kappa International Professional Education Association, and the Griffith's Leadership Society for Women at Mizzou.

Dr. Sanders Green has taught in the Jefferson City Public Schools for more than twenty years and is a three-time finalist for Teacher of the Year. She began her career as a reading teacher and currently serves as a first grade teacher in the district. She is a reading and writing enthusiast and enjoys spending time with family and friends. 